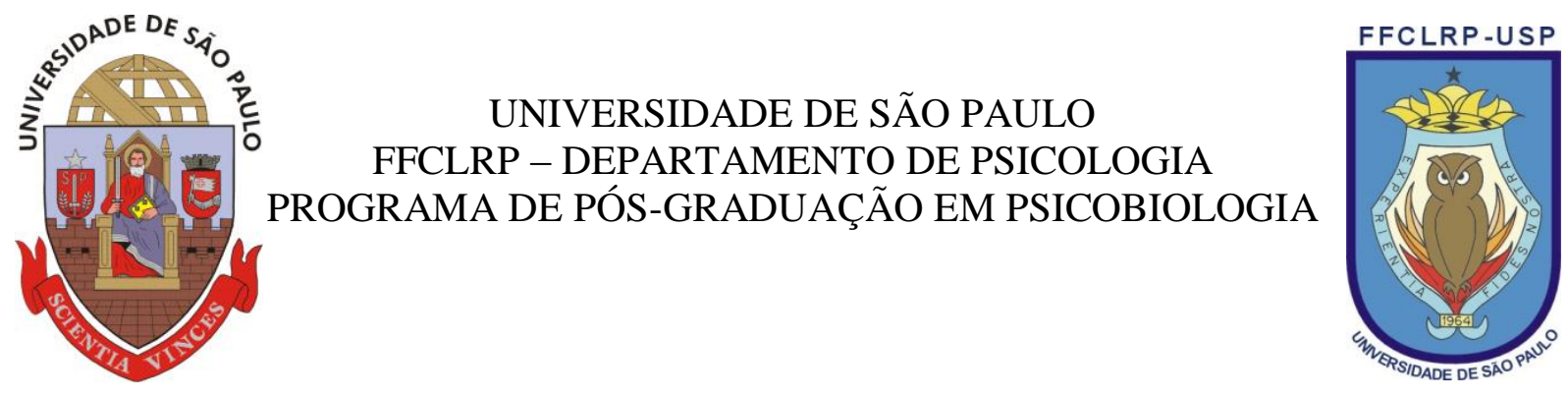

RUI DE MORAES JÚNIOR

RECONHECIMENTO DE FACES COM FILTRAGENS DE FREQUENCIAS ESPACIAIS ALTAS E BAIXAS NOS HEMICAMPOS VISUAIS DIREITO E ESQUERDO 
RUI DE MORAES JÚNIOR

\section{RECONHECIMENTO DE FACES COM FILTRAGENS DE FREQUÊNCIAS ESPACIAIS ALTAS E BAIXAS NOS HEMICAMPOS VISUAIS DIREITO E ESQUERDO}

Dissertação apresentada à Faculdade de Filosofia, Ciências e Letras de Ribeirão Preto - USP, como parte das exigências para obtenção do título de Mestre.

Área: Psicobiologia

Orientador: Sérgio Sheiji Fukusima 
Autorizo a reprodução e/ou divulgação total ou parcial da presente obra, por qualquer meio, convencional ou eletrônico, para fins de pesquisa e estudo, desde que citada a fonte.

\section{FICHA CATALOGRÁFICA}

Moraes Júnior, Rui de

Reconhecimento de faces com filtragens de frequências espaciais altas e baixas nos hemicampos visuais direito e esquerdo. Ribeirão Preto, 2012. 80 p. : il.; $30 \mathrm{~cm}$.

Dissertação apresentada à faculdade de Filosofia, Ciências e Letras de Ribeirão Preto/USP - Departamento de Psicologia. Área de concentração: Psicobiologia.

Orientador: Prof. Dr. Sérgio Sheiji Fukusima

1. Percepção de faces

2. Assimetria cerebral

3. Frequências espaciais

4. Diferenças de sexo 


\section{FOLHA DE APROVAÇÃO}

Rui de Moraes Júnior

Reconhecimento de faces com filtragens de frequências espaciais altas e baixas nos hemicampos visuais direito e esquerdo.

Dissertação apresentada à Faculdade de Filosofia, Ciências e Letras de Ribeirão Preto - USP, como parte das exigências para obtenção do título de Mestre. Área: Psicobiologia.

Aprovado em: 06/03/2012

Banca examinadora:

Prof. Doutor Sérgio Sheiji Fukusima (Orientador)

Instituição: FFCLRP - Universidade de São Paulo

Assinatura:

Prof. Dr. César Alexis Galera

Instituição: FFCLRP - Universidade de São Paulo

Assinatura:

Prof. ${ }^{\text {a }}$ Dr. ${ }^{a}$ Maria Lúcia Bustamante Simas

Instituição: CFCH - Universidade Federal da Paraíba

Assinatura: 
Para Ana e Rui. 


\section{AGRADECIMENTOS}

Ao professor Sérgio Sheiji Fukusima, por me aceitar em seu laboratório e me encaminhar na vida científica, pela presteza e entusiasmo com que me tratou nestes dois anos e, principalmente, por sempre me passar a sensação de que muito pouco sei.

Ao professor Marcelo Andrade da Costa Vieira, ao amigo Gustavo Nozela Rocha e à pesquisadora Valerie Goffaux, pelo apoio computacional.

A professora Maria Lúcia de Bustamante Simas, por gentilmente aceitar a compor a banca de defesa de mestrado.

Ao advogado Armando Parreira de Oliveira, por se dispor voluntariamente a revisar o Português da dissertação.

Ao Igor, técnico do laboratório, e à Renata, secretária do Programa, pela disposição em atender minhas solicitações na pós-graduação.

Aos colegas da USP: Claudinha, Diego, Dudu, Jeanny, Juliana, Kátia, Paulinho, Regiane, Ricardo, Roberto, Sérgio, Thiago, e as colegas de laboratório Lina, Cristina e Patrícia.

Em especial, aos colegas de laboratório, amigos e mestres Bruno e Léo, pela longa amizade desde os tempos da UFU, pelo apoio na vinda para Ribeirão Preto, pelos momentos de descontração na cantina do seu Zé ou na Terça do Bolinha e pela atenção e orientação às minhas questões acadêmicas. Aprendi e ri muito com vocês.

Ao Hugo, colega de faculdade, amigo e o irmão que escolhi, junto ao Fantin, obrigado pela companhia e convivência diária na república.

A minha namorada, Sarah, que faz os meus dias melhores.

Ao meu pai, Rui, e minha mãe, Ana, que proporcionaram com muito afeto as condições para a formação humana de seus filhos e sempre me incentivaram no caminho profissional que escolhi. Eu amo vocês. Aos meus irmãos Bruno e Lucas, minhas melhores companhias.

Aos meus avós, dona Guilherma, dona Judith e seu Luiz, que mesmo desconhecendo o propósito do meu trabalho, sempre me encorajaram a fazer o que gosto. Aos familiares, em especial os primos Ana Maria, Nelber e Rogério.

Aos amigos da Rua Tomaz Falbo: Aretusa, Guilherme, Gustavo, Helen, Huguinho, Maurírio, Pedrinho, Renato e Taísa. Obrigado pela infância prolongada quando estou ao lado de vocês. 
Aos amigos psicólogos Mário, Poeta, Tatiane e Tiago, pela parceria, mesmo à distância, e pelas boas lembranças.

Aos médicos, enfermeiros e funcionários do Hospital do Câncer de Uberlândia, pela ajuda nos dias difíceis.

A todos aqueles que se voluntariaram, seja por amizade, curiosidade ou boa vontade, a fazer os experimentos. Aos alunos de Psicologia Álvaro, Juliana, Karina e Milca, pela ajuda na coleta dos dados.

A CAPES e ao CNPq, pelas bolsas concedidas. 
La verdadera ciencia enseña, sobre todo, a dudar y a ser ignorante. A verdadeira ciência ensina, sobretudo, a duvidar e a ser ignorante. 


\title{
RESUMO
}

\author{
MORAES JÚNIOR, R. Reconhecimento de faces com filtragens de frequências espaciais \\ altas e baixas nos hemicampos visuais direito e esquerdo. 2012. 80 f. Dissertação \\ (Mestrado) - Faculdade de Filosofia, Ciências e Letras de Ribeirão Preto, Universidade de \\ São Paulo, Ribeirão Preto, 2012.
}

O presente estudo teve por objetivo investigar se o reconhecimento de faces ocorre prioritariamente por processamento analítico ou holístico nos hemisférios cerebrais em homens e mulheres por meio do estudo do espectro de frequência espacial. Para isso, no Experimento I, 40 voluntários (20 mulheres) realizaram duas sessões. Em cada uma delas foram memorizadas 14 faces para uma tarefa de reconhecimento. Nesta, cada face foi apresentada por $300 \mathrm{~ms}$, e em uma das sessões as imagens foram apresentadas somente no hemicampo visual direito, e noutra só no hemicampo visual esquerdo por meio de uma adaptação do método do campo visual dividido. A tarefa dos participantes foi assinalar o grau de confiabilidade de sua resposta (confidence rating method) ao discriminar as faces memorizadas de outras inéditas. Os estímulos da tarefa de reconhecimento foram apresentados em três condições: (1) em frequências espaciais altas, FEAs, (2) em frequências espaciais baixas, FEBs, e (3) sem filtragem, SFE. As frequências de respostas aos graus de confiabilidade permitiram calcular as curvas $R O C$ e os parâmetros $A z$ e da da Teoria de Deteção de Sinal. Por meio destes, foi comparado o desempenho do reconhecimento facial nas diferentes faixas do espectro espacial. De maneira complementar, foi realizado uma ANOVA para testar a diferença dos tempos de resposta no reconhecimento entre as filtragens. Não foi evidenciada especialização hemisférica no reconhecimento de faces com filtragem espacial. Mas homens, de modo tênue, perceberam melhor faces em FEBs e mulheres em FEAs. Para verificar se este resultado não se deu em função da apresentação lateralizada, foi realizado o Experimento II, nos moldes de uma sessão experimental do Experimento I, mas com apresentação central. Vinte voluntários (10 mulheres) participaram do experimento. Novamente, homens e mulheres foram mais sensíveis às faces em FEBs e FEAs, respectivamente. Deste modo, conclui-se que homens utilizam mais recursos holísticos e mulheres, por sua vez, operações analíticas. Os resultados dão bases para a não ocorrência de especialização hemisférica de frequencias espaciais no reconhecimento de faces em longos tempos de exposições. A diferença de sexo observada e nos atenta para a necessidade de controle amostral por sexo em pesquisas da área.

Palavras-chave: Reconhecimento facial. Assimetria cerebral. Frequências espaciais. Diferenças de sexo. 


\begin{abstract}
MORAES JÚNIOR, R. Facial recognition in high and low spatial frequency filtering in the right and in the left hemifields. 2012. $80 \mathrm{f}$. Dissertação (Mestrado) - Faculdade de Filosofia, Ciências e Letras de Ribeirão Preto, Universidade de São Paulo, Ribeirão Preto, 2012.

This study aimed to investigate whether face recognition occurs primarily by analytic or holistic processing in the cerebral hemispheres of men and women through the study of the spatial frequency spectrum. Therefore, in Experiment I, 40 volunteers ( 20 women) performed two sessions. In each of, 14 faces were memorized for a recognition task and each face was presented for $300 \mathrm{~ms}$. Images were presented only in the right visual hemifield in a session, and in another only in the left visual hemifield by means of an adaptation of the method of divided visual field. The participant's task was to assign the reliability of their response (confidence rating method) to discriminate the study faces from distractors. The recognition task stimuli were presented in three conditions: (1) at high spatial frequencies, FEAs, (2) at low spatial frequencies, FEBs, and (3) unfiltered, SFE. The frequencies of responses to the degree of reliability used to calculate ROC curves and parameters $\mathrm{A} z$ and $\mathrm{d} a$ of the Signal Detection Theory compared the performance of face recognition in different bands of the spectrum. In a complementary way, an ANOVA was conducted to test response times differences in the recognition between filtering. There was no evidence of hemispheric specialization in face recognition with spatial filtering. But men had better performance in recognizing faces in FEBs and women faces in FEAs. To verify that this result was not in function of lateralized presentation, Experiment II was conducted, along the lines of an experimental session of Experiment I, but with central presentation. Twenty volunteers (10 women) participated in the experiment. Again, men and women were more sensitive to faces in FEBs and FEAs, respectively. Thus it follows that men use holistic resources and women analytical operations. The results provide no basis for the occurrence of hemispheric specialization of spatial frequencies in face recognition over long exposure times. The sex difference observed brings us to the need for control sample by sex in spatial frequency research.
\end{abstract}

Keywords: Face recognition. Cerebral asymmetry. Spatial frequencies. Sex differences. 


\section{LISTA DE ILUSTRAÇÕES}

Figura 1: Equipamento utilizado para a apresentação dicótica dos estímulos

Figura 2: Esquema da apresentação dicótica dos estímulos. O estímulo à esquerda se reflete no espelho para a retina temporal do olho esquerdo e o estímulo à direita se projeta para a retina nasal do olho direito. O processo se inverte para testar o hemisfério oposto. Imagem inspirada no esquema de Triphaty et al. (1995). Legenda: F - fóvea; RN - hemiretina nasal; RT - hemiretina temporal; $D$ - direita; $E$ - esquerda

Figura 3: Estímulos utilizados no experimento. A, face com frequências espaciais que vão de 2-128 cpi; B, imagem em altas frequências espaciais (32-128 cpi); C, imagem em baixas frequências espaciais (2-8 cpi)

Figura 4: Exemplo de imagem apresentada na etapa de reconhecimento. As bordas internas e externas das faces possuíam aproximadamente 3 e 7 graus de ângulo visual, respectivamente.

Figura 5: Sequência de apresentação dos estímulos em cada tentativa

Figura 6: Curvas ROC e parâmetros $\mathrm{A} z$ e $\mathrm{d} a$ do desempenho dos grupos amostrais no reconhecimento de faces em frequências espaciais altas (FEA), frequências espaciais baixas (FEB) e sem filtragem espacial (SFE) nos hemisférios direito e esquerdo em homens, mulheres e na amostra total

Figura 7: Parâmetro da obtido na tarefa de reconhecimento de faces apresentadas em frequências espaciais altas (FEA), baixas (FEB) e sem filtragem espacial (SFE) para os hemisférios direito e esquerdo, em homens, mulheres e em toda a amostra

Figura 8: Logaritmo natural da média dos tempos de resposta (ms) de homens, mulheres e de toda a amostra para estímulos faciais apresentados em frequências espaciais altas (FEA), baixas (FEB) e sem filtragem espacial (SFE) em campo visual lateralizado

Figura 9: Curvas ROC e parâmetros $\mathrm{A} z$ e d $a$ para o reconhecimento de faces em altas (FEA) e baixas (FEB) frequências espaciais e sem filtragem espacial (SFE) em homens, mulheres e em toda a amostra 36

Figura 10: Parâmetro da obtido em tarefa de reconhecimento de faces em altas (FEA) e baixas (FEB) frequências espaciais e sem filtragem espacial (SFE) em homens, mulheres e em todo o grupo amostral

Figura 11: Logaritmo natural da média dos tempos de resposta (ms) de homens, mulheres e de toda a amostra para estímulos faciais apresentados em frequências espaciais altas (FEA), baixas (FEB) e sem filtragem espacial (SFE) no centro da tela 38 


\section{LISTA DE ABREVEATURAS E SIGLAS}

ANOVA: análise de variância

Az: índice de desempenho dos participantes, relativo à área abaixo da curva ROC; corresponde valores de 0 - 1

$\mathbf{c d} / \mathbf{m}^{2}$ : candela por metro quadrado

cpg: ciclos por grau de ângulo visual

cpi: ciclos por imagem

da: índice de desempenho dos participantes livre de viés de resposta; quanto mais alto o índice, melhor o desempenho

ERP: potencial relacionado ao evento

FEs: frequências espaciais

FEAs: frequências espaciais altas (imagens em)

FEBs: frequências espaciais baixas (imagens em)

fMRI: ressonância magnética funcional

HD: hemisfério direito

HE: hemisfério esquerdo

In: logaritmo natural

ms: milissegundo

PET: tomografia por emissão de pósitrons

$\mathbf{R}^{2}$ : coeficiente de determinação

ROC:receiver operating caracteristic

s: desvio padrão amostral (da idade dos participantes)

SFE: sem filtragem espacial (imagens)

TDS: Teoria de Detecção do Sinal

TR: tempo de resposta

VEP: potencial cortical visual evocado

$\overline{\boldsymbol{x}}$ : média amostral (da idade dos participantes) 


\section{SUMÁRIO}

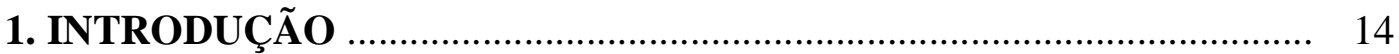

1.1 Reconhecimento de faces .................................................................. 14

1.2 Especialização hemisférica e substrato neural no processamento analítico e holístico de faces .................................................................... 15

1.3 Especialização hemisférica de frequências espaciais no reconhecimento de faces ..................................................................... 18

2. OBJETIVO E PREDIÇÕES ................................................................ 21

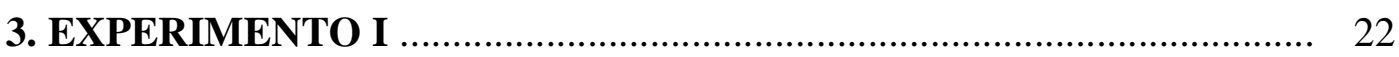

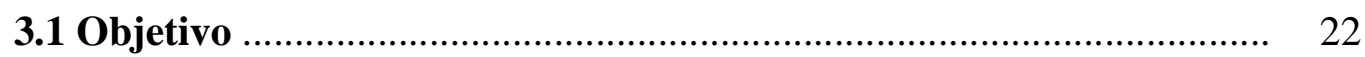

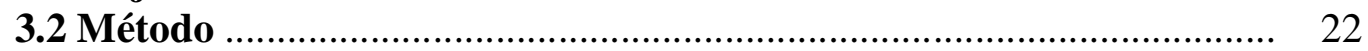

3.2.1 Participantes ................................................................................. 22

3.2.2 Materiais e equipamentos ………………………………………... 22

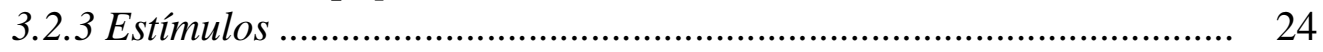

3.2.4 Apresentação dos estímulos e delineamento experimental ............... 25

3.2.5 Procedimento ......................................................................... 28

3.2.6 Análise dos dados .................................................................... 28

3.3 Resultados ................................................................................ 29

3.3.1 Análise das Curvas ROC e dos parâmetros $\mathrm{A} z$ e $\mathrm{d}$ a ......................... 29

3.3.2 Análise dos tempos de resposta ………………………………….... 32

4. EXPERIMENTO II ......................................................................

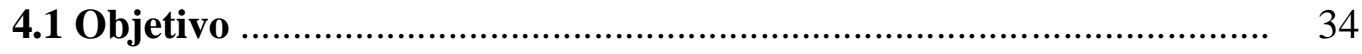

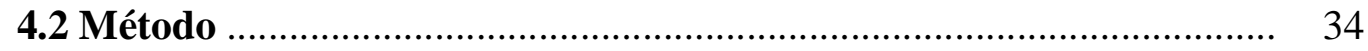

4.2.1 Participantes …………………………………………………. 34

4.2.2 Materiais e equipamentos .............................................................. 34

4.2.3 Estímulos, delineamento experimental e procedimento .................... 34

4.2.4 Análise dos dados ...................................................................... 35

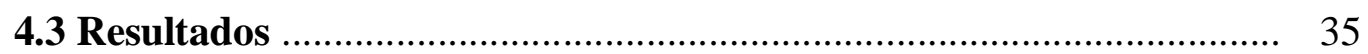

4.3.1 Análise das Curvas ROC e dos parâmetros $\mathrm{A} z$ e $\mathrm{d}$ a ........................ $\quad 35$

4.3.2 Análise dos tempos de resposta ………………………………….. 37

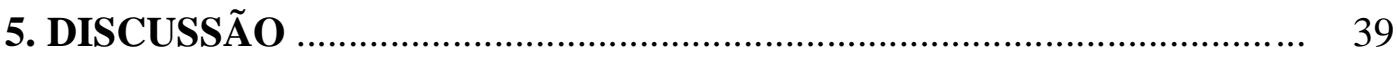

5.1 Especialização hemisférica ............................................................ $\quad 40$

5.2 Diferenças de sexo …………....................................................... 44

5.3 Limitações e sugestões para estudos posteriores …………………….... 45

5.4 Importância do estudo ……………………………......................... 47

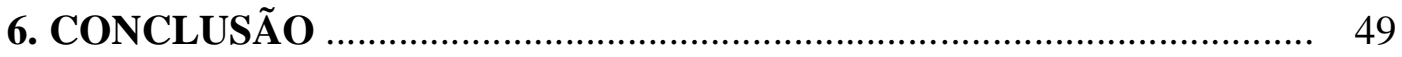

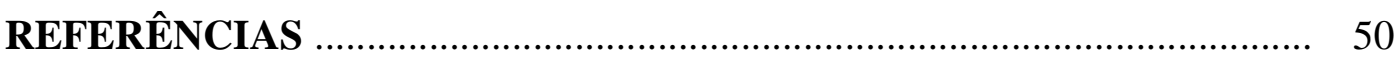

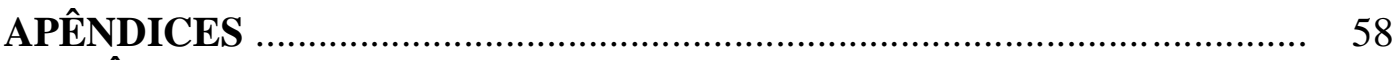

APÊNDICE A - Método do campo visual dividido ………………….......... 59

APÊNDICE B - Processamento computacional e biológico de 61 
frequências espaciais

APÊNDICE C - Confidence rating method

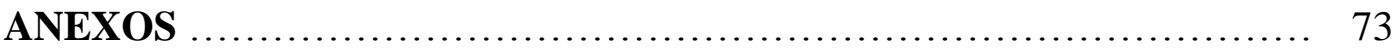

ANEXO A - Termo de Consentimento Livre e Esclarecido ................... 74

ANEXO B - Parecer do Comitê de Ética em Pesquisa da FFCLRP ....... 75

ANEXO C - Inventário de Dominância Manual de Edimburgo ............. 76

ANEXO D - Instruções dadas durante os experimentos ........................ 77

ANEXO E - Ata da defesa de Metrado .................................................. 80 


\section{INTRODUÇÃO}

\subsection{Reconhecimento de faces}

A face humana é um importante canal de informação e comunicação sobre vários aspectos: etnia, idade, sexo, atratividade, emoção, estado de saúde, etc. Deste modo, é a região mais expressiva do corpo (CHELLAPA; WILSON; SIROHEY, 1995). Por isso ela proporciona diversos sinais sociais que podem ser detectados e interpretados por outros indivíduos, sendo essencial às relações interpessoais. A interação social é facilitada, em grande parte, pelo hábil processo de reconhecimento facial, que está adaptado à nossa necessidade biológica de saber rapidamente quem está se aproximando, e que classe de saudação ou sinal emocional este indivíduo mostra (BRUCE; YOUNG, 1998).

Nós somos especialistas em reconhecer faces: podemos reconhecer minúsculas variações em cada uma, percebê-las mesmo à distância, com má iluminação, com um novo corte de cabelo e de um novo ponto de vista. E isto acontece de maneira automática, sem nenhum esforço cognitivo e em menos de um segundo (BRUCE; YOUNG, 1998; MAURER et al., 2007). Este processo, além de rápido, é muito preciso. Os adultos são hábeis para reconhecer rostos familiares com uma exatidão superior a $90 \%$, ainda que algumas faces não tenham sido vistas por 50 anos (CARBON, 2003).

Dada a importância deste processo, em nosso passado evolutivo, os primatas que possuíam uma área cortical e um tipo de processamento específico para a percepção de rostos foram mantidos pela seleção natural ao longo da especiação humana (CHELLAPA; WILSON; SIROHEY, 1995, CARMEL; BENTIN, 2002). Mas ainda não se sabe, ao certo, como se dá este processamento. Duas teorias da origem do reconhecimento facial se distinguem.

A hipótese da especificidade de domínio (domain-specificity hypothesis) afirma que o processamento diferencial utilizado em faces só ocorre nesta classe de estímulo. Não esclarece a origem deste processo, mas é possível que conte com fatores inatos e/ou que seja necessária experiência num período crítico do desenvolvimento, sendo que a infância se destaca (ROBBINS; MCKONE, 2007). Pesquisas chegaram a resultados que apoiam esta hipótese. Por exemplo, no estudo de Yovel e Kanwisher (2004) a resposta cerebral e comportamental mediante tarefas que forçam mecanismos face-específicos (distância entre as 
partes e efeito de inversão) não foram encontrados no estímulo teste: casas, somente em faces. Robbins e McKone (2007) testaram juízes, criadores e treinadores de cachorros em tarefa de reconhecimento de faces humanas e de cães invertidas, desalinhadas e em contraste reverso; o desempenho foi fraco e não significativo apenas para as faces de cães.

Já a hipótese da individuação especializada (expertise hypothesis) sustenta que a habilidade em reconhecer faces é potencialmente genérica a outras classes de estímulos e que alcança faces pela experiência substancial em discriminações a níveis individuais, o que indica que este processo pode alcançar qualquer tipo de objeto por este mesmo mecanismo (ROBBINS; MCKONE, 2007). A pesquisa de Meadows (1974) é um exemplo clássico que revela estudos de caso de pacientes com prosopagnosia ${ }^{1}$ que perderam a capacidade de discriminar estímulos particulares com os quais tinham experiência (pecuarista que tinha constante contato com vacas, por exemplo). E mais recentemente, Gauthier e Tarr (1997), ao utilizar formas orgânicas complexas (os greebles) em experimentos de memorização e reconhecimento, revelaram a importância da experiência sobre a percepção.

A face possui uma organização peculiar. Seus elementos (nariz, boca, olhos) estão organizados de forma que geram uma percepção global, generalizada. E as pequenas mudanças destes elementos proporcionam a distinção entre um indivíduo e outro (BRUCE; YOUNG, 1998). Há uma boa quantidade de evidências de que o padrão facial é processado mais holisticamente, como uma combinação gestáltica das características individuais, do que outros tipos de estímulos (BRUCE; YOUNG, 1998; CHEUNG et al., 2008), o que estaria relacionado a uma atividade melhor desempenhada pelo hemisfério direito (HD) (SPRINGER; DEUTSCH, 1993). Estas suposições deram bases a pesquisas que investigaram dominância e assimetria cerebral na percepção de faces, bem como as modalidades de processamento utilizadas por cada hemisfério.

\subsection{Especialização hemisférica e substrato neural no processamento analítico e holístico de faces}

Na década de 60, pesquisas com pacientes com danos neurológicos evidenciaram que a maioria dos indivíduos com prosopagnosia possuíam lesões no HD (LEVY;

\footnotetext{
${ }^{1}$ Também conhecida como agnosia facial ou cegueira facial. É uma inabilidade específica para reconhecer rostos familiares (MEADOWS, 1974).
} 
TREVARTHEN; SPERRY, 1972). Na década seguinte, Levy, Trevarthen e Sperry (1972) chegaram aos mesmos resultados ao estudarem pacientes comissurotomizados utilizando figuras quiméricas: uma forte assimetria em reconhecimento facial em favor do HD. $\mathrm{O}$ hemisfério esquerdo (HE) também percebe, reconhece e revela capacidades superiores quando elas são familiares; porém esta tarefa se mostra de maior dificuldade quando no processamento de faces não familiares como um todo.

Ademais, a vantagem que o HD apresenta sobre o HE se dá de diferentes formas. Ele se mostra superior em velocidade de processamento, exatidão da identidade facial, resposta da memória de longo prazo, recepção e armazenamento de informações faciais (CHELLAPA; WILSON; SIROHEY, 1995; CURYTO, 2000; GAZZANIGA, 2000).

O desempenho superior do HD com relação ao reconhecimento facial deriva de sua especialização na codificação e processamento sintético e holístico de estímulos visuoespaciais e de informações configuracionais ${ }^{2}$ (SPRINGER; DEUTSCH, 1993; RHODES, 1993). Ao passo que o HE processa informações de forma verbal, sequencial, temporal, digital, lógica, analítica e racional, o $\mathrm{HD}$ o faz de forma não-verbal ou visuoespacial, simultânea, espacial, analógica, gestáltica, sintética e intuitiva (SPRINGER; DEUTCH, 1993).

Regiões do cérebro humano respondentes especificamente a faces humanas têm sido consistentemente evidenciadas dentro da literatura por meio de estudos de eletroencefalograma, estudos de casos com pacientes com prosopagnosia e, mais recentemente, por estudos de neuroimagem (ROSSION et al., 2000; GOFFAUX et al., 2011). Em muitos estudos, nos quais foram contrapostos e controlados a discriminação de faces e de outros objetos, foi demonstrada uma ativação bilateral na região média do giro fusiforme para estímulos faciais, com uma atividade mais acentuada no HD. Tais resultados são coadunantes com casos de prosopagnosia provenientes de lesões bilaterais no córtex occipitotemporal. Também há muitos casos descritos deste tipo de agnosia provocado somente por lesão unilateral do lado direito desta mesma área cerebral, o que demonstra sua maior participação na capacidade de reconhecer faces (ROSSION et al., 2000).

\footnotetext{
${ }^{2} \mathrm{O}$ termo configuracional tem sido utilizado para se referir a fenômenos que envolvem a percepção das relações entre as características faciais. O processamento configuracional pode ser dividido em três tipos: (1) relações de primeira ordem: referente ao padrão facial com dois olhos, uma boca e nariz; (2) processamento holístico: percepção da forma facial em uma gestalt; (3) relações de segunda ordem: percepção das distâncias entre as partes. No entanto não existe consenso sobre o termo, sendo que alguns pesquisadores se restringem a apenas um dos processos e outros utilizam os três (MAURER; LE GRAND; MODLOCH, 2002). Aqui, configuracional, holístico e global são utilizados como sinônimos.
} 
A região localizada na superfície ventromedial dos lobos temporal e occipital no giro fusiforme médio lateral, associada ao reconhecimento de faces, é conhecida como Área Facial Fusiforme. A magnitude de sua atividade varia de acordo com a atenção dirigida ao estímulo, o que mostra que não depende exclusivamente da apresentação da face em si (ROSSION et al., 2000; ROSSION et al., 2003; MAURER et al., 2007).

O giro fusiforme médio é ativado em ambos os hemisférios, mas com uma vantagem do HD. Já o giro fusiforme posterior é ativado apenas no HD sob o foco de atenção em padrões faciais. Uma região do giro temporal inferior, nomeada de Área Facial Occipital, também responde mais a faces do que a objetos, novamente com vantagem do HD (ROSSION et al., 2003). Em adição, foi relatada atividade seletiva no sulco temporal superior e no giro occipital inferior, mas estas observações são menos consistentes (HAXBY et al., 1999; ROSSION et al., 2000; ROSSION et al., 2003).

A participação do HE no reconhecimento de faces ainda é motivo de debates entre estudiosos do assunto. Muitos pesquisadores defendem a ideia de que a área fusiforme do HD estaria relacionada ao reconhecimento de faces, ao passo que a área equivalente no hemisfério oposto faria parte de um sistema mais geral, de reconhecimento de objetos. Entretanto, há evidências consideráveis que sugerem que ambos os hemisférios estariam envolvidos no reconhecimento de padrões faciais, mas de maneira diferentes. A partir deste ponto de vista, o HD processaria faces de maneira integrativa e global. Já o HE se valeria de uma estratégia de processamento por características de elementos faciais (ROSSION et al., 2000; ROSSION et al., 2003).

A ideia de uma especialização hemisférica apresentada, na qual o HD faz uma análise holística e o HE faz uma análise por características, é corroborada por alguns experimentos. Faces apresentadas em sua orientação usual no campo visual esquerdo são percebidas com mais rapidez e acurácia do que quando apresentadas no campo visual direito (RHODES, 1993). Já quando as faces são apresentadas invertidas ou modificadas, e induzem um processamento elemento por elemento em campo visual dividido (APÊNDICE A), a vantagem do HD é eliminada ou reduzida dada a interrupção de sua codificação global (HILLGER; KOENIG, 1991). Recentemente, pesquisas com imageamento cerebral têm corroborado a participação dos dois hemisférios no processamento facial. No estudo de Rossion et al. (2000), por exemplo, em que foi utilizado tomografia por emissão de pósitrons (PET), foi evidenciado uma diminuição da atividade face-específica da área fusiforme facial direita quando a atenção está focada nos componentes faciais, mas que, em contrapartida, é aumentada na região homóloga do lado esquerdo. 
O modelo holístico/global, dentro da literatura sobre processamento facial, recebeu muita atenção nas últimas três décadas (GOFFAUX; ROSSION, 2006). O maior número de resultados em relação à ativação, tempo de reação e taxa de acerto em vantagem do processamento global e do HD, talvez seja devido ao seu modo de operação. Lux et al. (2004) sugerem que o processamento global é a configuração automática por default da atenção visual, ou seja, requer menos ativação que o processamento local, que necessita de controle atentivo. Dois conflitos na análise local dos estímulos fazem com que este processo não seja natural: o conflito com o processamento default da informação global e o conflito com a tendência para focalizar itens de interesse. Sendo assim, o sistema global, muitas vezes, é o mais utilizado e importante para a percepção e o reconhecimento de faces, mas ambos os tipos de processamento são fundamentais para esta tarefa (CASEY; NEWELL, 2007; STERNBERG, 2010).

Em suma, a percepção e o reconhecimento de faces contam com dois sistemas de processamento diferentes. O sistema global/holístico é um tipo de processamento em que os elementos interagem entre si de maneira integrada, sendo realizado prioritariamente pelo HD. Em contrapartida, o sistema local/analítico é especializado no reconhecimento de partes e promove um processamento separado de cada uma delas, sendo realizado preferencialmente pelo HE. Evidências comportamentais e neurofisiológicas sugerem que o processamento de faces humanas para reconhecimento e discriminação recai tanto sobre os elementos individuais, como na relação configuracional entre eles (GOFFAUX et al., 2005).

\subsection{Especialização hemisférica de frequências espaciais no reconhecimento de faces}

Percepção configuracional, global ou holística, em contraponto à percepção de características, locais ou analítica são operações cognitivas de alto nível que dependem de um processamento perceptual de baixo nível (HILLS; LEWIS, 2009). A análise das frequências espaciais (FEs), variações de luminância ao longo do espaço (ver APÊNDICE B), é um dos primeiros processos realizados na codificação da informação visual. Prestar atenção a elas pode ter um papel importante na assimetria hemisférica (YAMAGUCHI; YAMAGATA; KOBAYASHI, 2000) e na percepção de faces (GOFFAUX et al., 2005).

Há um acúmulo de evidências de que o sistema visual tem filtros de FEs sintonizados a diferentes bandas do seu espectro (CAMPBELL; ROBSON, 1968). Estes filtros 
decompõem a cena visual ainda na retina, e iniciam funções cognitivas e perceptuais de alto nível de complexidade, antes de serem processadas diferencialmente nos hemisférios. Células do sistema visual sensíveis a frequências espaciais altas (FEAs) processam bordas finas, ou seja, alta variação de luminância; deste modo, elementos faciais discretos e detalhados são percebidos, o que dá base a operações analíticas. Ao passo que células sensíveis a frequências espaciais baixas (FEBs) processam sinais "grosseiros", em regiões de baixa variação de luminância, o que dá base para operações holísticas (GOFFAUX et al., 2005).

Deste modo, diferentes FEs codificam diferentes aspectos dos objetos. Por isso, uma dada faixa do espectro pode afetar a percepção e o reconhecimento de faces (GOFFAUX et al., 2005). Além disso, dados comportamentais e de neuroimagem indicaram que o processamento de faces é mais dependente de FEs do que outros objetos (COLLIN, et al., 2004; YUE; TJAN; BIEDERMAN., 2006).

Em acordo com a ideia de que a segregação precoce de baixo nível pelos canais de FEs inicia processos cognitivos e perceptuais de alto nível visual, como a codificação holístico e analítico, e que estes processos são mais bem desempenhados pelos HD e HE, respectivamente, Sergent (1982) postulou a hipótese da especialização hemisférica no processamento de FEs. Esta prediz que o HE está predominantemente envolvido no processamento de FEAs, ao passo que o HD teria um processamento prioritário de FEBs.

Como a face é um estímulo complexo, não se sabe ao certo se a percepção do padrão facial segue a hipótese da especialização hemisférica no processamento de FEs. Keenan, Whitman e Pepe (1989) realizaram uma tarefa de reconhecimento facial com filtragem de FEs em campo visual dividido, e chegaram a resultados que corroboram a hipótese de Sergent (1982). Mas eles utilizaram apresentações taquistoscópicas de apenas 10 milissegundos (ms). Estudos apontam que o processamento diferencial de faces novas e memorizadas acontece entre 200-400 ms (MÜNTE et al., 1998), 300-600 ms (PALLER at el., 2000; PALLER et al., 2003), 400-600 ms (YOVEL et al., 2003) e 110-600 ms (BARBEAU et al., 2008).

Whitman e Keegan (1991) realizaram uma pesquisa em que pares de faces em FEBs ou FEAs eram apresentados taquistoscopicamente no hemicampo visual direito (HE) ou esquerdo (HD), em que o participante executava respostas same-different. Os resultados corroboram parcialmente a hipótese de especialização hemisférica de FEs. O HE produziu mais erros, e esta diferença foi maior para faces em FEBs. No HD, faces apresentadas em FEBs obtiveram menor tempo de resposta (TR) e menores taxas de erros. Apesar de ser utilizado um tempo de $200 \mathrm{~ms}$, dois estímulos eram apresentados simultaneamente, prejudicando, assim, a codificação facial. Ainda, a excentricidade da borda interna das faces 
era menor que 1,3 graus de ângulo visual. Esta distância do ponto de fixação permite que os estímulos apresentados incidam sobre a área de convergência binocular, o que inviabiliza a técnica do campo visual dividido. Por fim, foram utilizados somente homens (26) no estudo.

Perilla-Rodríguez (2008) realizou estudo de reconhecimento de faces em FEAs e FEBs previamente memorizadas sem filtragem. As faces tiveram apresentação lateralizadas por meio de uma adaptação do método do campo visual dividido para que fossem apresentadas por $300 \mathrm{~ms}$. Apenas a amostra feminina apresentou especialização hemisférica de FEs. Os homens reconheceram melhor as faces apresentadas em FEBs tanto no HD quanto no HE. Este trabalho evidenciou que o reconhecimento facial, além de levar em consideração a especialização hemisférica e o espectro de FE, pode ser influenciado pelo sexo. A literatura mostra que homens e mulheres têm desempenhos diferentes em muitas tarefas visuais. 


\section{OBJETIVO E PREDIÇÕES}

Como foi exposto até aqui, é de extenso conhecimento e corroboração científica o efeito de especialização hemisférica bem como a importância do padrão facial para a espécie humana. Ao pensar nestes dois aspectos, esbarramo-nos em questões para as quais a comunidade científica busca respostas mais contundentes, como, por exemplo: qual o papel dos hemisférios cerebrais na habilidade de reconhecer faces? Algum hemisfério é mais hábil? Este processo se dá de maneira holística ou analítica nos hemisférios? Há diferenças de sexo no processamento e reconhecimento de faces?

Para tentar responder a estas perguntas, esta pesquisa se valeu do estudo do espectro de FE da imagem facial e as perguntas passaram a ser as seguintes: qual a importância das diferentes bandas de FEs no reconhecimento de faces? Os hemisférios cerebrais processam preferencialmente alguma faixa de FE? Homens e mulheres são mais eficazes para alguma faixa do espectro? Se sim, em qual hemisfério isto acontece?

Sendo assim, este estudo foi motivado por indagações provenientes da dissertação de mestrado de Perilla-Rodríguez (2008), único trabalho encontrado na literatura acerca de especialização hemisférica de frequências espaciais no reconhecimento de faces apresentadas com baixa restrição temporal em homens e mulheres. Para isso, este estudo utilizou uma variação inédita do método do campo visual dividido (ver APÊNDICE A e a sessão Materiais e equipamentos, no Experimento I) que impedia que movimentos sacádicos percorressem todo o campo visual mesmo em tempos longos de exposição (acima de $180 \mathrm{~ms}$ ). Outra contribuição à literatura foi a utilização do método Confidence Rating (APÊNDICE C), em substituição a ferramentas estatísticas tradicionais ou aos métodos psicofísicos clássicos ou sim-não da Teoria de Detecção do Sinal (TDS). Em adicional à pesquisa de Perilla-Rodríguez (2008), no presente trabalho foram controlados luminância e contraste dos estímulos, aumentou-se o número de participantes e optou-se por um delineamento de medidas repetidas.

De maneira geral, esta pesquisa visava o estudo do desempenho dos hemisférios cerebrais de homens e mulheres no reconhecimento de faces em bandas de FEs altas e baixas em campo visual dividido. Era esperado que o HE tivesse maior sensibilidade a faces em FEAs e que o HD, por sua vez, a faces em FEBs. Além disso, era esperado que homens processassem melhor as FEBs do espectro visual em relação às FEAs. E o contrário era esperado para as mulheres. 


\section{EXPERIMENTO I}

\subsection{Objetivo}

Investigar diferenças dos hemisférios cerebrais no reconhecimento de faces em bandas de FEAs e FEBs em campo visual lateralizado em homens e mulheres. A tarefa dos participantes consistia em assinalar o grau de certeza de sua resposta ao discriminar faces memorizadas e inéditas, sendo que as faces da etapa de reconhecimento foram apresentadas em FEBs, em FEAs e SFE (sem filtragem espacial).

\subsection{Método}

\subsubsection{Participantes}

Quarenta voluntários [idade média $(\bar{x})=24,60$ e desvio padrão da idade $(\mathrm{s})=3,81)$ ], alunos da Universidade de São Paulo (USP), campus de Ribeirão Preto, maiores de 18 anos, sendo 20 homens ( $\bar{x}=24,95$ e $s=3,17)$ e 20 mulheres $(\bar{x}=24,25$ e $s=4,42)$ participaram deste estudo. Foram escolhidos apenas participantes com acuidade visual normal ou corrigida $\left(6 / 6^{3}\right)$, sem histórico de doença neurológica, livres de doenças oculares identificáveis e destros ${ }^{4}$. Todos os participantes assinaram o Termo de Consentimento Livre e Esclarecido (ANEXO A), aprovado pelo Comitê de Ética em Pesquisa da FFCLRP-USP (ANEXO B), conforme as normas vigentes no Brasil referente a experimentos com humanos.

\subsubsection{Materiais e equipamentos}

A acuidade visual dos participantes foi avaliada pelo aparelho Ortho-Rather (Bausch \& Lomb Optical Co.), e a dominância manual por uma versão adaptada e traduzida do Inventário de Dominância Manual de Edimburgo (OLDFIELD, 1971) (ANEXO C).

\footnotetext{
${ }^{3}$ Este é o valor de visão normal da forma fracionária de medida de acuidade visual, em que o numerador representa a distância em que o teste foi feito e o denominador a distância em que o menor optótipo deve ser percebido (BICAS, 2003).

${ }^{4}$ Segundo a literatura existente, pessoas canhotas são menos lateralizadas em tarefas de processamento visual (CURYTO, 2000).
} 
Os programas utilizados foram instalados em um computador Intel Pentium 4, CPU 2.80 GHz, 512 MB de RAM, placa de vídeo GeForce FX 5500 (NVidia) e sistema operacional Windows XP. Os estímulos foram apresentados num monitor CRT de 19 polegadas, LG, modelo Flatron ez T930B, com frequência de atualização de $85 \mathrm{~Hz}$. Um fotômetro J17 LumaColor (Tektronix) foi utilizado para medir a luminância dos estímulos refletidos através do monitor.

Para permitir a apresentação dicótica das imagens em um campo visual dividido, foi utilizado um suporte metálico constituído de duas hastes laterais apoiadas na mesa, e uma barra horizontalmente suspensa e presa às extremidades superiores das duas hastes. Ao meio e perpendicular à barra horizontal, uma lâmina metálica com encaixe para espelho foi afixada verticalmente. Ainda, o suporte metálico contava com um oclusor para que um hemicampo fosse visto somente pelo reflexo do espelho. Este suporte metálico foi projetado no próprio Laboratório de Percepção e Psicofísica da USP-RP. Foi utilizado um espelho optimirror de 28 $\mathrm{cm}$ de altura $\times 40 \mathrm{~cm}$ de largura x $0,4 \mathrm{~cm}$ de espessura (Figura 1).
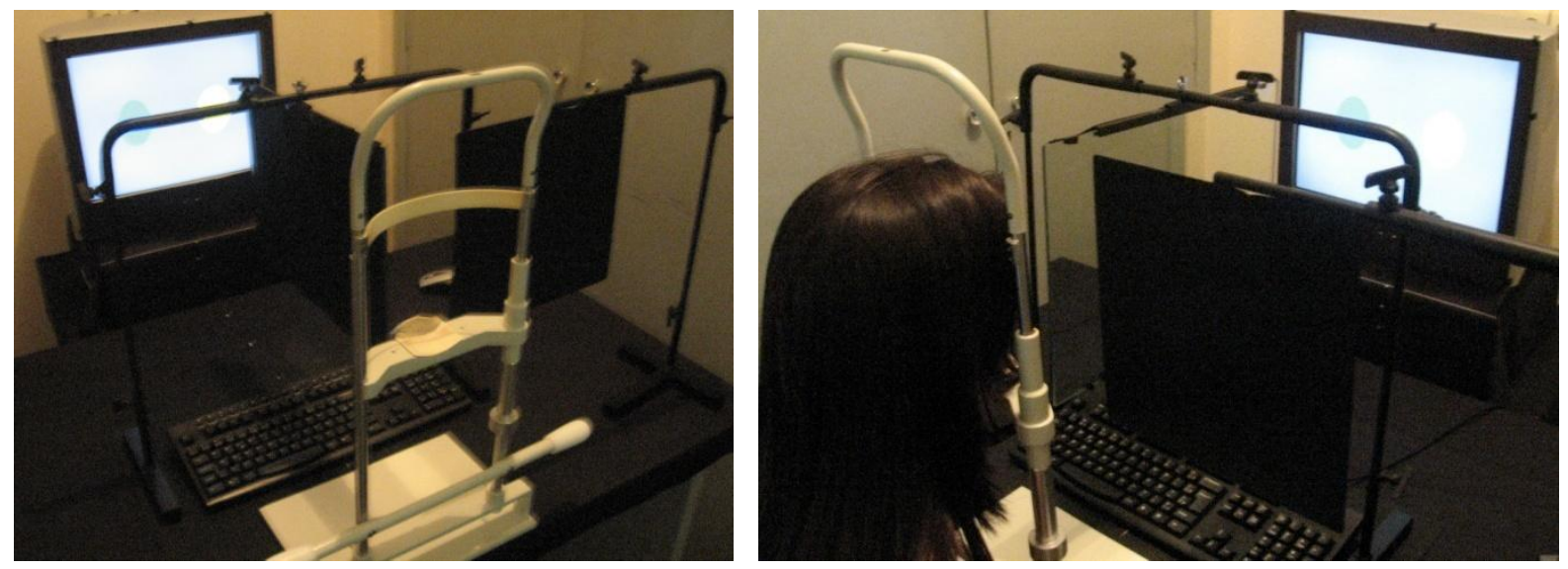

Figura 1: Equipamento utilizado para a apresentação dicótica dos estímulos.

Para utilizá-lo, o voluntário alinhava seu eixo de simetria facial à borda vertical do espelho, com a cabeça colocada sob o apoiador de queixo. O espelho foi fixado verticalmente, perpendicular à linha média do monitor, no plano septal do observador (Figuras 1 e 2). Ao testar-se o HE, um anteparo é colocado na metade esquerda do monitor, e a face refletora do espelho fica do lado esquerdo do participante. É deixada uma fenda entre o anteparo e o espelho, ajustada para cada observador, de modo que ele enxergasse os estímulos do hemicampo visual esquerdo apenas pelo reflexo do espelho. Sendo assim, a informação do lado do anteparo (esquerdo, no caso), é enviada para a hemiretina temporal do olho esquerdo, que possui conexões ipsilaterais, e o estímulo presente no lado livre (direito) é enviado para a 
hemiretina nasal, que cruza os hemisférios no quiasma óptico (Figura 2) (TRIPHATY et al., 1995). Isto resulta em uma única imagem percebida à direita do ponto de fixação, dado o efeito da fusão binocular pela incidência da imagem de cada olho em regiões correspondentes. Inverte-se o processo para se testar o hemisfério direito. $\mathrm{O}$ experimento foi realizado em uma sala adaptada e sem iluminação.

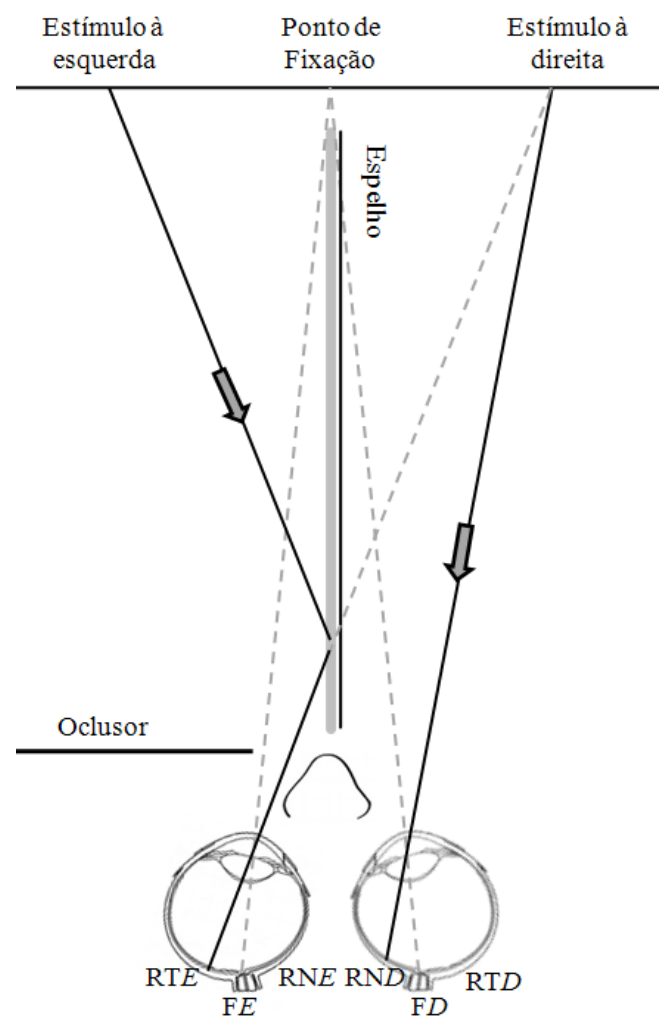

Figura 2: Esquema da apresentação dicótica dos estímulos. O estímulo à esquerda se reflete no espelho para a retina temporal do olho esquerdo e o estímulo à direita se projeta para a retina nasal do olho direito. O processo se inverte para testar o hemisfério oposto. Imagem inspirada no esquema de Triphaty et al. (1995). Legenda: F fóvea; $\mathrm{RN}$ - hemiretina nasal; RT - hemiretina temporal; $D$ - direita; $E$ - esquerda.

\subsubsection{Estímulos}

Foram utilizadas 115 fotos digitais coloridas frontais de faces caucasianas e pardas (57 femininas), com expressões de emoção neutra do Banco de Faces do Laboratório de Percepção e Psicofísica (MENDES; ARRAIS; FUKUSIMA, 2009). Por meio do programa Photoshop 7.0 (Adobe), as imagens foram colocadas em escala de cinza, características faciais marcantes (rugas, manchas, espinhas, barba) foram atenuadas, e as características externas (cabelo, orelhas, pescoço) foram removidas por meio de um enquadramento a uma janela oval. Externamente à janela oval, o quadrante em que o estímulo foi inserido ( 256 x 256 pixels) foi preenchido com cinza médio (128) uniforme. 
O processo de filtragem ${ }^{5}$ (ver APÊNDICE B) das fotos foi realizado por meio do programa MatLab 7.9 (Mathworks). As imagens foram normalizadas para obter luminância global com média zero e desvio padrão do $\mathrm{RMS}^{6}$ do contraste igual a um. Feito isso, as imagens passaram pela transformada rápida de Fourier e foram multiplicadas por filtros Gaussianos passa-faixa. Três filtros foram utilizados. Um deles preservou uma ampla faixa do espectro de FE, que vai de 2 a 128 ciclos por imagem (cpi). O outro preservou FEBs que vão de 2 a 8 cpi e o último apenas as FEAs, que vão de 32 a 128 cpi.

Depois de filtradas, as imagens passaram pela transformada inversa de Fourier, quando a média da luminância total e o desvio padrão do RMS do contraste total de cada imagem foram ajustados para atingir a taxa de luminância global e RMS do contraste do conjunto de imagens originais. Para uma descrição mais detalhada, consultar Goffaux et al. (2011). Abaixo (Figura 3), um exemplo dos estímulos utilizados no experimento.
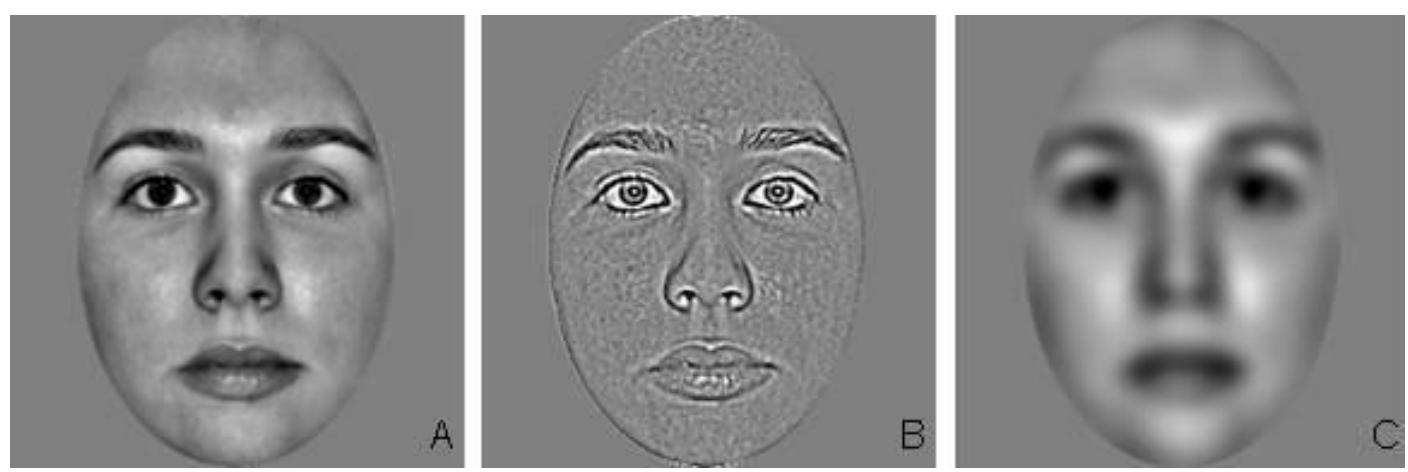

Figura 3: Estímulos utilizados no experimento. A, face com frequências espaciais que vão de 2-128 cpi; B, imagem em altas frequências espaciais (32-128 cpi); C, imagem em baixas frequências espaciais (2-8 cpi).

\subsubsection{Apresentação dos estímulos e delineamento experimental}

O experimento foi realizado em duas sessões. Cada uma utilizou 56 faces, e destas, 14 foram memorizadas para uma tarefa de reconhecimento. As 42 faces restantes foram utilizadas como distratores. As fotos masculinas e femininas foram divididas equitativamente tanto na memorização quanto no reconhecimento.

Os estímulos memorizados foram apresentados no centro da tela preenchida por cinza médio (128) uniforme (COLLIN; WANG; O’BYRNE, 2006), com resolução de 300 dpi, de 1024 x 768 pixels, a uma distância de $85 \mathrm{~cm}$ do participante. As faces medem

\footnotetext{
${ }^{5}$ Os códigos utilizados para processar as imagens no MatLab foram gentilmente cedidos pela pesquisadora Ph.D Valerie Goffaux, da University of Maastricht. E foram os mesmos utilizados em Goffaux et al. (2011).

${ }^{6}$ Do inglês, root mean square. Refere-se a media quadrática, uma medida de tendência central geralmente utilizada para análise de contraste.
} 
aproximadamente $6 \times 8,5 \mathrm{~cm}(180 \times 256$ pixels $)$, equivalente a $4 \times 5,8$ graus de ângulo visual, e têm luminância em torno de $30 \mathrm{~cd} / \mathrm{m}^{2}$, quando apresentadas no monitor utilizado.

$\mathrm{Na}$ etapa de reconhecimento, a tela também foi preenchida por cinza médio uniforme, de igual resolução, e os estímulos apresentavam as mesmas dimensões, com luminância em torno de $27 \mathrm{~cd} / \mathrm{m}^{2}$. Em adicional, as imagens se encontravam duplicadas para que fosse feita a apresentação dicótica exigida pelo método do campo visual dividido (APÊNDICE A). Uma das imagens era espelhada, já que um hemicampo visual foi percebido pelo reflexo do espelho (consultar Materiais e equipamentos). Um círculo verde (ponto de fixação) estava presente no centro da tela. A borda interna do estímulo facial se distanciava 4,45cm (134 pixels), equivalente a 3 graus de ângulo visual, tanto à direita quanto à esquerda do centro do ponto de fixação (BOURNE, 2006). Esta distância é de aproximadamente 10,45cm (314 pixels) ou 7 graus de ângulo visual da borda externa da face (Figura 4). As telas apresentadas no experimento, tanto das faces memorizadas quanto das faces distratoras, foram construídas por meio do programa CorelDraw X3 13.0 (Corel).

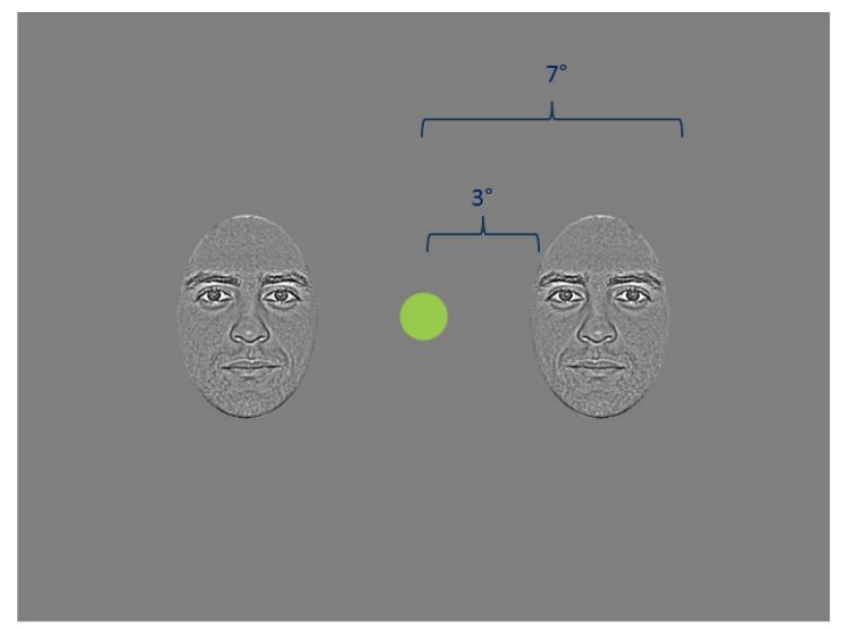

Figura 4: Exemplo de imagem apresentada na etapa de reconhecimento. As bordas internas e externas das faces possuíam aproximadamente 3 e 7 graus de ângulo visual, respectivamente.

$\mathrm{Na}$ etapa de reconhecimento foram apresentados tanto os estímulos memorizados quanto os distratores. Ao passo que na etapa de memorização foram apresentadas 14 imagens $\mathrm{SFE}^{7}$, na etapa de reconhecimento todas elas foram apresentadas SFE (0,34-22 ciclos por grau de ângulo visual, cpg), em FEBs (0,34-1,35 cpg) e em FEAs (5,4-22 cpg). Somado aos estímulos alvos foram apresentados os estímulos distratores: as 42 fotos não memorizadas.

\footnotetext{
7 As imagens sem filtragem espacial ou naturais, descritas no texto são relativas às imagens filtradas que preservam frequências espaciais entre 2 e 128 cpi.
} 
Destas, 14 foram apresentadas SFE, e o mesmo montante em FEA e em FEB. Ou seja, nenhuma das faces distratoras se repetiu.

O programa SuperLab Pro 4.5 (Cedrus) foi utilizado para controlar a apresentação das telas e coletar as respostas e tempos de resposta dos participantes. Cada tentativa se iniciava com um quadrado azul no centro da tela (tela de descanso). A próxima tela só era apresentada depois de pressionada a barra de espaço. Feito isso, um círculo amarelo (ponto de fixação) era apresentado no centro da tela por $350 \mathrm{~ms}$. Este círculo se tornava vermelho e era exposto por mais $150 \mathrm{~ms}$. Isto indicava que os estímulos estavam prestes a serem apresentados e auxiliava o participante não a desviar o olhar do ponto de fixação (JORDAN et al., 2009). Logo após, uma face duplicada era apresentada por $300 \mathrm{~ms}$. Por fim, uma tela de resposta de tempo livre era apresentada ao participante para que este indicasse seu grau de certeza no reconhecimento do estímulo apresentado. Para isso, ele pressionava uma das teclas de 1 a 6 no teclado numérico, que correspondiam do total não reconhecimento ao total reconhecimento. Dada a resposta, a tela de descanso novamente era apresentada, dando início a mais uma tentativa (Figura 5). Cada sessão contava com 90 tentativas, sendo seis tentativas-treino apresentadas no início do experimento, e 84 de reconhecimento apresentadas aleatoriamente.

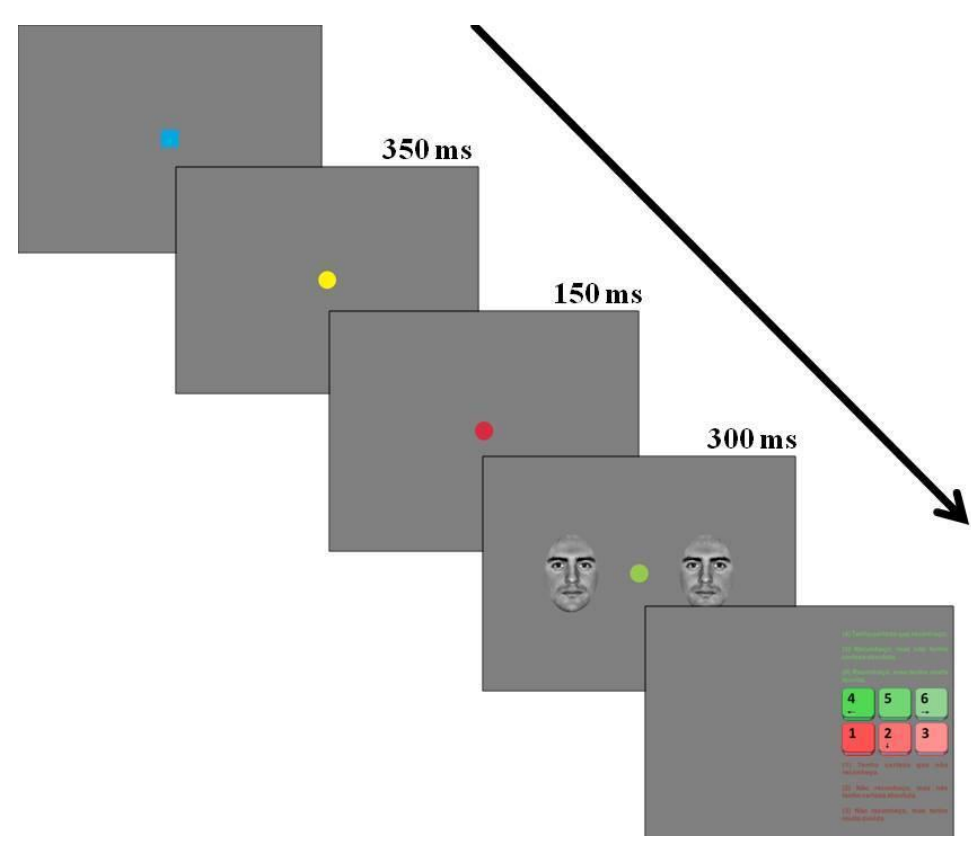

Figura 5: Sequência de apresentação dos estímulos em cada tentativa.

A segunda sessão experimental foi realizada nos mesmos moldes da primeira, com apenas duas exceções: 1) o participante tinha o hemicampo oposto testado; 2) foram utilizadas imagens faciais diferentes. 


\subsubsection{Procedimento}

Antes de iniciar o experimento, foram avaliados acuidade visual, dominância manual e histórico de doenças oculares e neurológicas. Os voluntários que não preencheram os critérios estabelecidos não foram incluídos na amostra. Todos os participantes leram e assinaram o Termo de Consentimento Livre e Esclarecido antes de iniciar o experimento. Cada indivíduo foi submetido às duas sessões do experimento num intervalo de tempo não superior a 10 dias. Em cada sessão foi testado um hemicampo. Houve contrabalancemanento em relação ao grupo de imagens apresentadas, sexo e hemicampo.

A primeira etapa do experimento foi a memorização dos estímulos alvos. O conjunto das 14 faces memorizadas foi apresentado quatro vezes, em tempo livre e aleatoriamente. Na última vez em que o conjunto de faces era apresentado, o participante devia dizer se se lembrava ou não de cada face vista na tela. Aqueles que não conseguiram memorizar as faces foram instruídos a fazer um novo treino até que todas as imagens fossem memorizadas. Somente depois de garantido isso o experimento continuava.

Depois de memorizado o conjunto de fotos, o suporte que produz o campo visual dividido era calibrado para que cada participante tivesse uma percepção binocular pela hemiretina temporal de um olho e pela hemiretina nasal do olho contrário. Feito isso, uma etapa de treinamento foi realizada. Neste momento, possíveis dúvidas ou dificuldades foram esclarecidas e solucionadas para que se desse início à sessão experimental em si. Os voluntários foram instruídos a não desviar o olhar do ponto de fixação durante a apresentação das fotos e responder o mais rápido possível. Na segunda sessão do experimento, o procedimento e as instruções (ANEXO D) se repetiam.

\subsubsection{Análise dos dados}

As frequências de respostas às categorias do grau de certeza da tarefa de discriminar faces conhecidas e desconhecidas foram utilizadas para o cálculo das curvas ROC (Receiver Operating Characteristic) e os parâmetros da e Az da TDS, segundo o método confidence rating (APÊNDICE C). Adotou-se um nível de significância de 5\%. O cálculo foi realizado com programa Excel 2007 (Microsoft).

Ainda, submeteram-se os tempos de respostas (TRs) a uma análise de variância (ANOVA) Mista: 2 sexos (homens e mulheres) x [2 hemisférios (direito e esquerdo) x 3 filtragem dos estímulos (SFE, FEA, FEB)]. Os TRs foram ajustados a uma distribuição normal por meio de uma transformação logarítmica (logaritmo natural, ln). A normalidade foi checada por meio do teste de Kolmogorov-Smirnov (com a correção de significância de 
Lilliefors). Adotou-se o teste post-hoc de Bonferroni e um nível de significância de 5\%. Para isso foi utilizado o programa SPSS 18 (IBM).

\subsection{Resultados}

\subsubsection{Análise das Curvas ROC e dos parâmetros Az e da}

A partir dos dados, foram obtidas curvas ROC e os parâmetros $\mathrm{A} z$ e da para o desempenho no reconhecimento de faces em FEAs, FEBs e SFE no HD e HE na amostra masculina , feminina e geral. Os gráficos e os valores dos parâmetros podem ser vistos na Figura 6.

No HD da amostra geral, as imagens SFE tiveram maior taxa de reconhecimento $\left(\mathrm{A}_{z}=0,77 ; \mathrm{d} a=1,04\right)$, seguidas pelas imagens em FEAs $\left(\mathrm{A}_{z}=0,67 ; \mathrm{d} a=0,63\right)$ e, com menor, taxa as imagens em FEBs $(\mathrm{A} z=0,63 ; \mathrm{d} a=0,46)$. Entre as mulheres, a diferença de reconhecimento entre faces em FEAs e FEBs foi maior $\left(\mathrm{A}_{z}=0,70 ; \mathrm{d} a=0,73\right.$ e $\mathrm{A} z=0,63 ; \mathrm{d} a=0,46$, respectivamente). Ainda, as imagens SFE foram reconhecidas mais facilmente no grupo feminino $\left(\mathrm{A}_{z}=0,79 ; \mathrm{d} a=1,12\right)$. Já na análise do HD dos homens, as faces SFE também foram reconhecidas mais facilmente $\left(\mathrm{A}_{z}=0,75 ; \mathrm{d} a=0,96\right)$. Porém, as retas de regressão das taxas de reconhecimento das imagens em FEAs e FEBs estão quase sobrepostas, mas com uma inversão de padrão em relação às mulheres. Ou seja, imagens em FEBs foram mais reconhecidas que imagens em FEAs $\left(\mathrm{A}_{z}=0,65 ; \mathrm{d} a=0,53\right.$ e $\mathrm{A}_{z}=0,64 ; \mathrm{d} a=0,52$, respectivamente).

No HE da amostra geral, do mesmo modo que o desempenho dos homens no HD, as retas de regressão relativas às imagens em FEAs e FEBs estão quase sobrepostas. A diferença também é de apenas 0,01 tanto no $\mathrm{A} z$ quanto no $\mathrm{d} a$, com vantagem das faces em FEAs (FEAs: $\mathrm{A}_{z}=0,66 ; \mathrm{d} a=0,57$ e FEBs: $\left.\mathrm{A}_{z}=0,65 ; \mathrm{d} a=0,56\right)$. As imagens SFE obtiveram as melhores taxas de reconhecimento para o HE na amostra geral $\left(\mathrm{A}_{z}=0,81 ; \mathrm{d} a=1,23\right)$. As mulheres também tiveram maior sensibilidade para reconhecer imagens SFE $\left(\mathrm{A}_{z}=0,84 ; \mathrm{d} a=1,42\right)$, seguidas das faces em FEAs e FEBs no $\mathrm{HE}\left(\mathrm{A}_{z}=0,68 ; \mathrm{d} a=0,65\right.$ e $\mathrm{A}_{z}=0,65 ; \mathrm{d} a=0,56$, respectivamente). $\mathrm{Ou}$ seja, o desempenho feminino no HE seguiu o mesmo padrão encontrado no HD. Os homens no HE também obtiveram o mesmo padrão de seu desempenho no $\mathrm{HD}$ : faces $\mathrm{SFE}\left(\mathrm{A}_{z}=0,77\right.$; $\mathrm{d} a=1,04)$, em FEBs $(\mathrm{A} z=0,66 ; \mathrm{d} a=0,57)$ e em FEAs $\left(\mathrm{A}_{z}=0,63 ; \mathrm{d} a=0,48\right)$, em ordem decrescente de desempenho. 


\section{HEMISFÉRIO ESQUERDO}
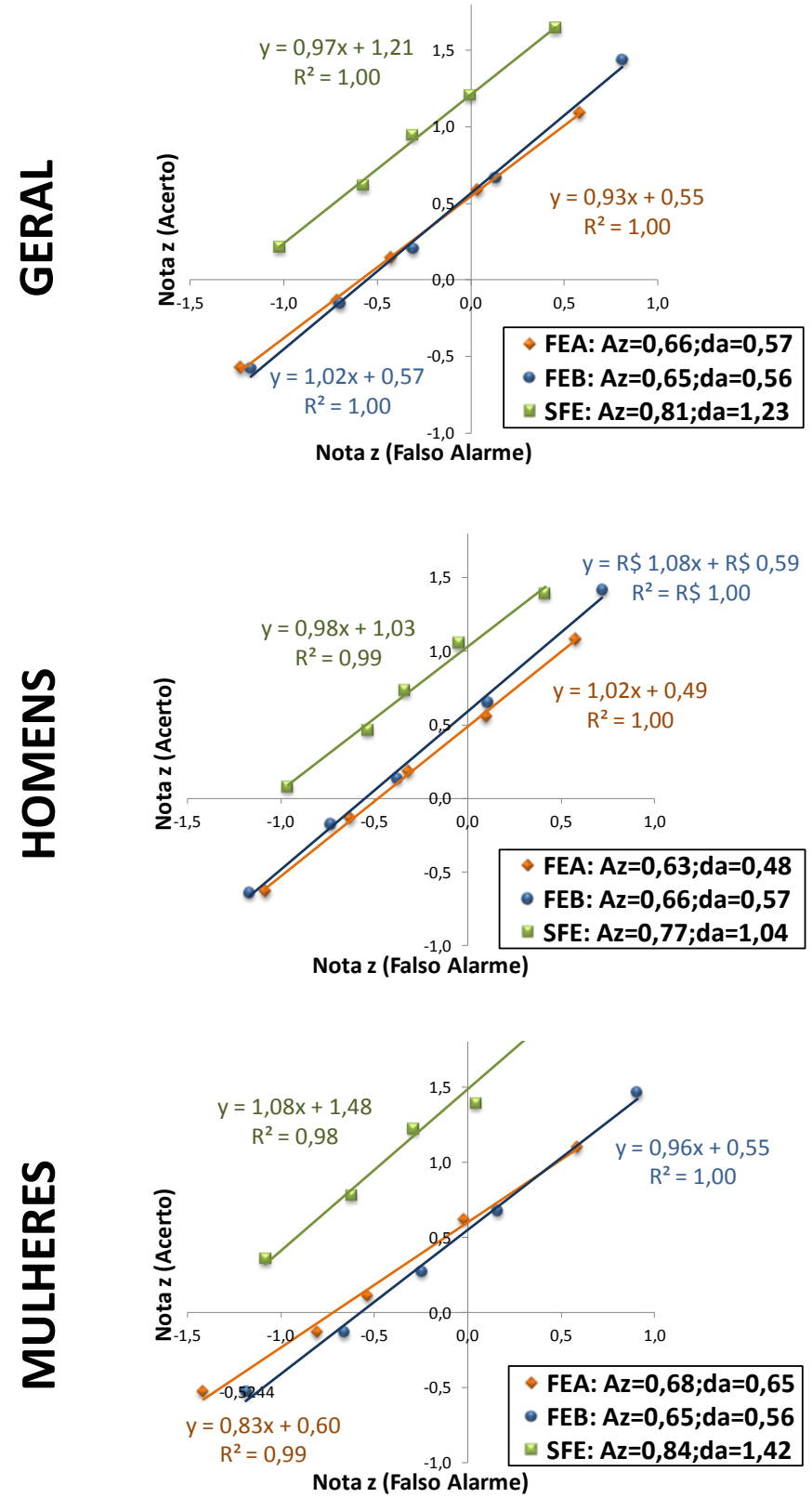

HEMISFÉRIO DIREITO
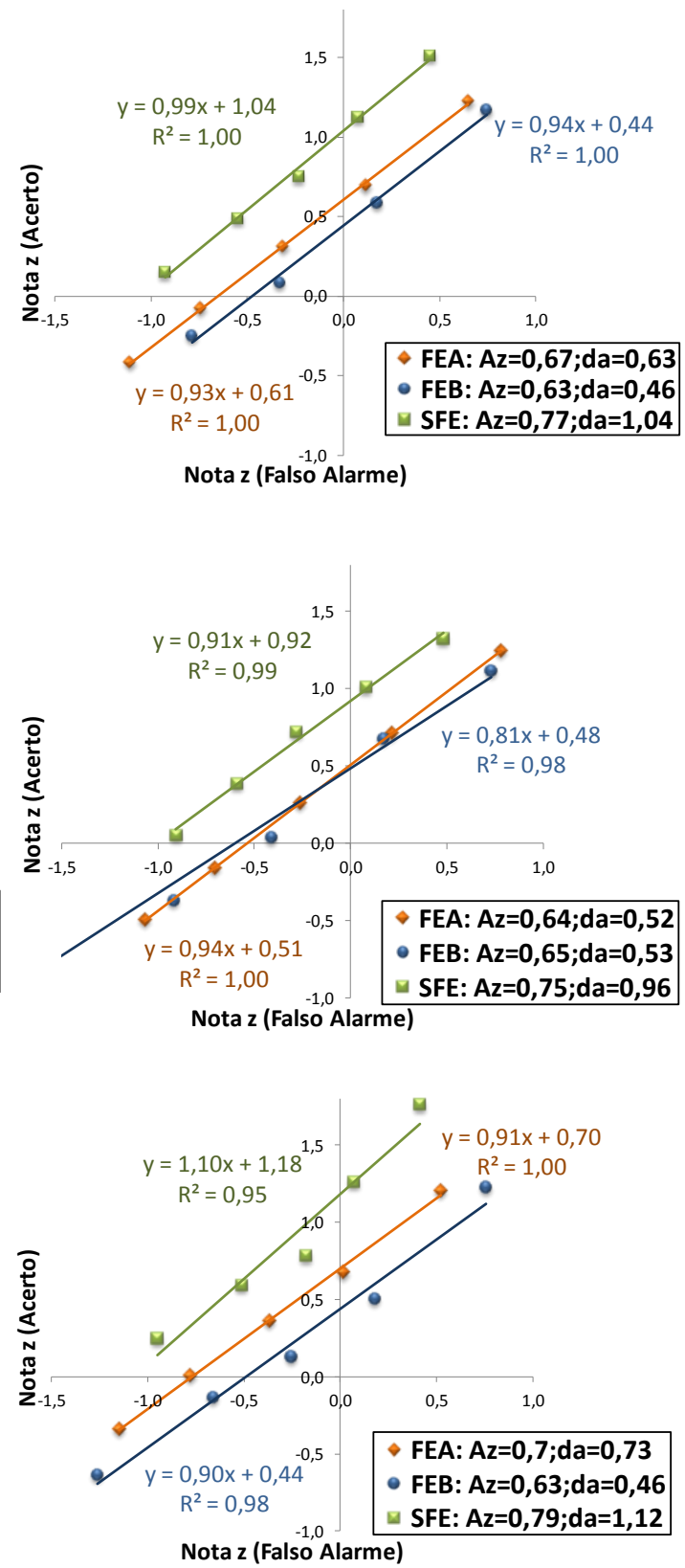

Figura 6: Curvas ROC e parâmetros $\mathrm{A} z$ e da do desempenho dos grupos amostrais no reconhecimento de faces em frequências espaciais altas (FEA), frequências espaciais baixas (FEB) e sem filtragem espacial (SFE) nos hemisférios direito e esquerdo em homens, mulheres e na amostra total.

O gráfico da Figura 7 resume os dados das duas condições (HD e HE) e dos subgrupos amostrais (homens, mulheres e amostra total) por meio do parâmetro da. 


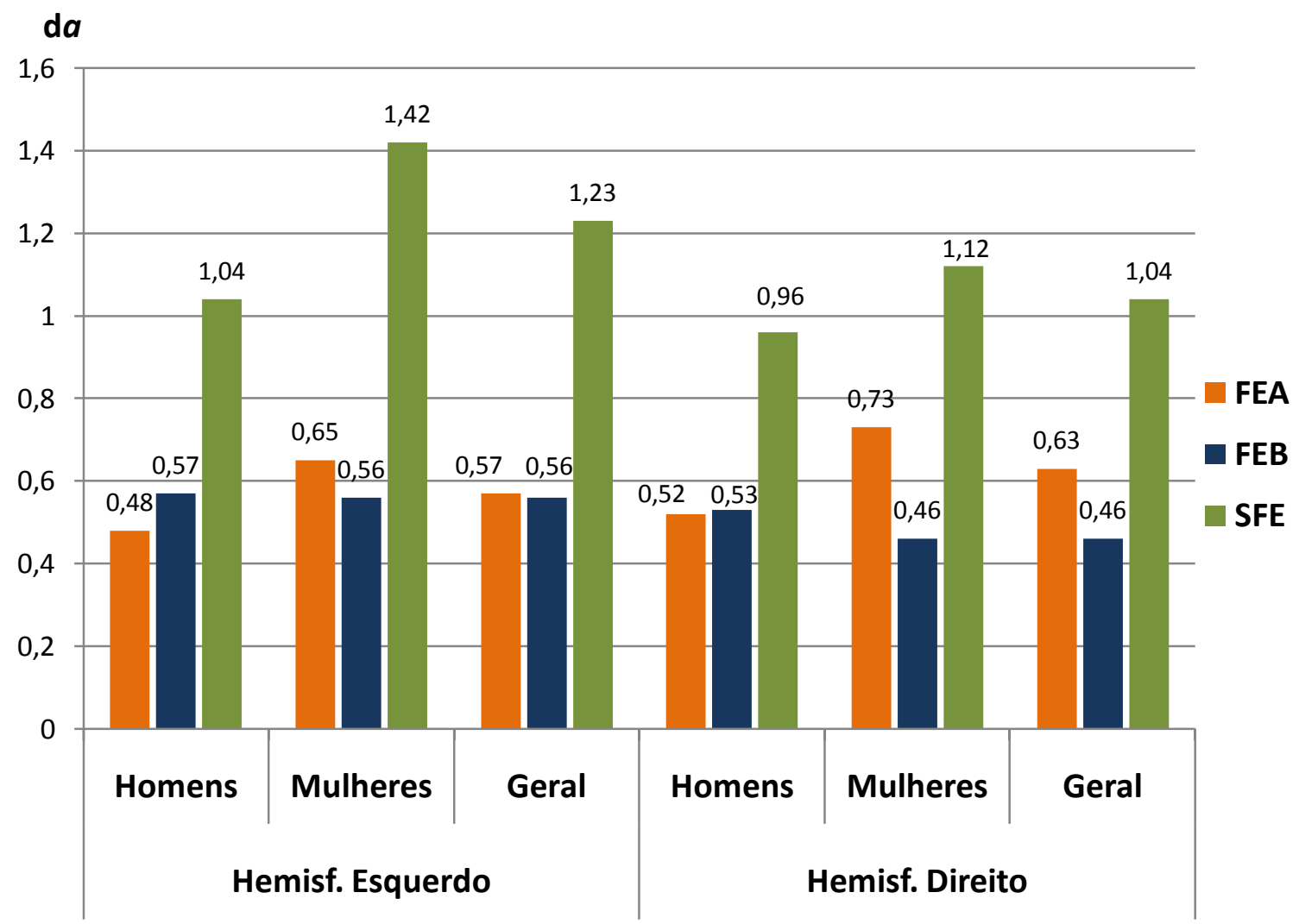

Figura 7: Parâmetro da obtido na tarefa de reconhecimento de faces apresentadas em frequências espaciais altas (FEA), baixas (FEB) e sem filtragem espacial (SFE) para os hemisférios direito e esquerdo, em homens, mulheres e em toda a amostra.

Observa-se que, em todas as condições e para todos os subgrupos, o desempenho no reconhecimento de faces SFE foi bem superior em relação aos estímulos com cortes no espectro de FE. Ainda, o desempenho do HE foi superior ao do HD. Por fim, o desempenho das mulheres foi superior ao dos homens.

O desempenho dos participantes para faces em FEAs e FEBs diferenciaram-se ligeiramente, com exceção para o HD feminino. Os dados não evidenciaram especialização hemisférica de FEs no reconhecimento de faces. No entanto, homens e mulheres apresentaram padrões de desempenho diferentes. Os homens, tanto no HD quanto no HE, reconheceram melhor as faces em FEBs em relação às faces em FEAs. O inverso aconteceu para as mulheres, melhores no reconhecimento de faces em FEAs em relação às em FEBs, em ambos os hemisférios cerebrais. Ainda, as mulheres foram melhores que os homens no desempenho de reconhecimento de faces em FEAs (diferença de 0,21 valor de da no HD e de 0,17 no HE). E os homens foram melhores que as mulheres em reconhecer faces em FEBs (diferença de 0,07 valor de d $a$ no HD e de apenas 0,01 no $\mathrm{HE}$ ). 


\subsubsection{Análise dos tempos de resposta}

$\mathrm{Na}$ amostra geral, HD e HE apresentam TRs semelhantes nas respostas às faces em FEAs [HD: 7,699 $\ln (\mathrm{ms})$ e HE: 7,703 $\ln (\mathrm{ms})]$ e FEBs [HD: 7,683 $\ln (\mathrm{ms})$ e HE: 7,682 $\ln (\mathrm{ms})$ ], e um melhor desempenho (menor TR) para faces SFE [HD: 7,593 $\ln (\mathrm{ms})$ e HE: 7,611 $\ln (\mathrm{ms})$ ] (Figura 8).

Quando a amostra foi dividida por sexo, o padrão dos TRs aos estímulos com diferentes filtragens espaciais foi o mesmo em homens e mulheres no HD. Ou seja, houve vantagem dos TRs para faces SFE em relação às faces em FEBs e em FEAs, que obtiveram TRs próximos. [Homens - SFE: 7,500, FEBs: 7599, FEAs: 7,617 $\ln (\mathrm{ms})$; Mulheres - SFE: 7,685, FEBs: 7,767, FEAs: 7,780 $\ln (\mathrm{ms})]$.

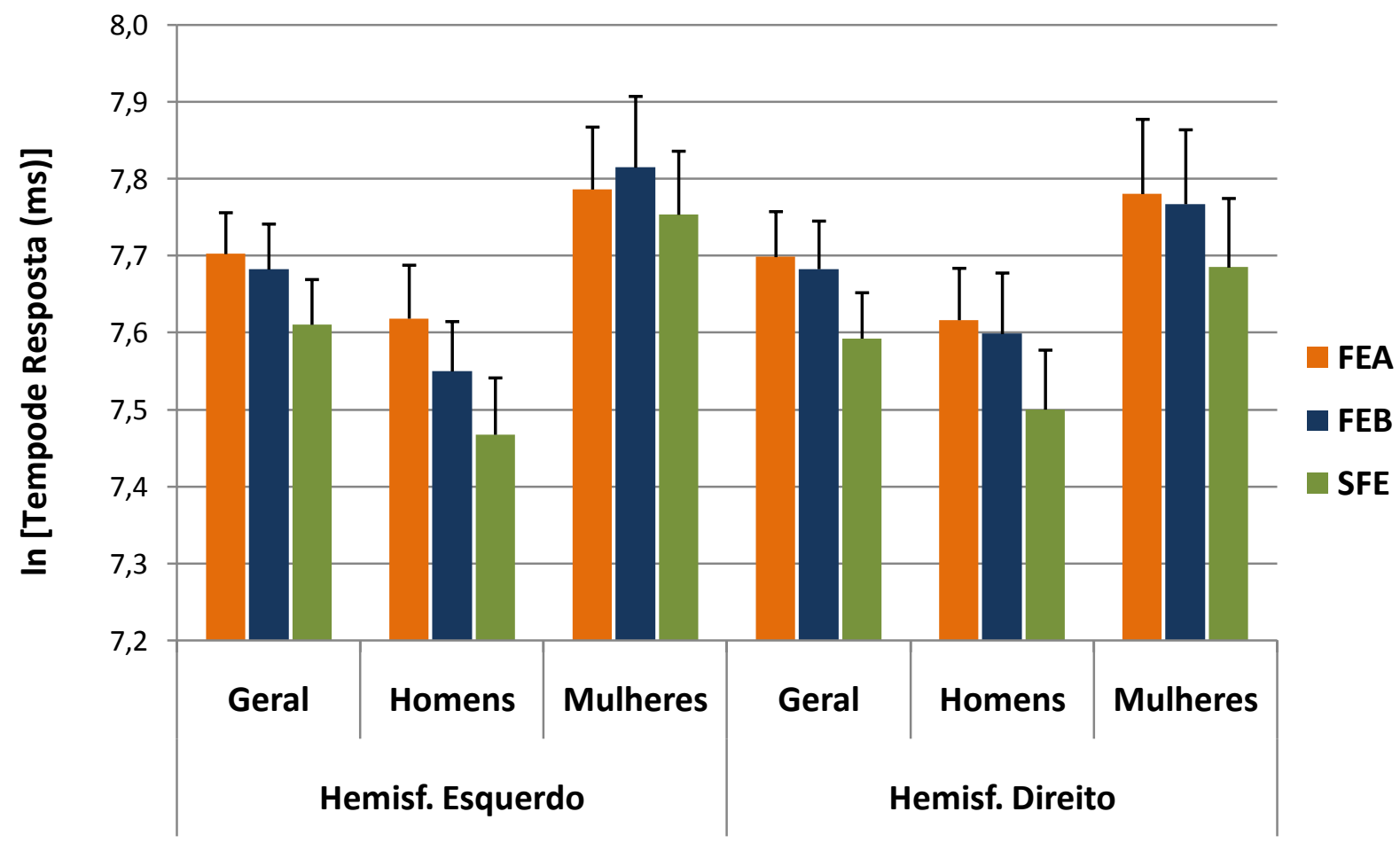

Figura 8: Logaritmo natural da média dos tempos de resposta $(\mathrm{ms})$ de homens, mulheres e de toda a amostra para estímulos faciais apresentados em frequências espaciais altas (FEA), baixas (FEB) e sem filtragem espacial (SFE) em campo visual lateralizado.

Já no HE, o padrão dos TRs de homens e mulheres foi diferente. As imagens SFE continuaram sendo as que possuíam menores TRs. Porém, ao passo que os homens foram mais rápidos para faces apresentadas em FEBs, o inverso acontece para as mulheres [Homens -SFE: 7,468, FEBs: 7,550, FEAs: 7,619 $\ln (\mathrm{ms})$; Mulheres - SFE: 7,754, FEAs: 7,786, FEBs: $7,815 \ln (\mathrm{ms})]$. 
Ainda, os TRs dos homens foram menores do que o das mulheres em todas as condições de filtragens e em ambos os hemisférios cerebrais. Por fim, com exceção dos resultados obtidos pela apresentação dos estímulos ao HE das mulheres, todas as outras condições e subgrupos amostrais tiveram menores médias de TRs para faces em FEBs em relação às faces em FEAs, mesmo que a vantagem tenha sido pequena.

Foi encontrado efeito estatisticamente significativo dentre participantes para as filtragens espaciais, independente do hemisfério e sexo. Sendo que $20 \%$ da variação dos TRs podem ser creditadas às diferentes filtragens $\left[\mathrm{F}(2,75)=9,52 ; p<0,001 ; \eta^{2}\right.$ parcial $\left.=0,20\right]$. $\mathrm{O}$ teste post-hoc verificou diferenças significativas dos TRs das imagens apresentadas SFE e FEA $(p<0,001)$, e entre as imagens SFE e FEB $(p=0,006)$. A análise entre os participantes revelou diferença estatisticamente significativa relativa ao sexo, sendo que este foi responsável por $10 \%$ da variação do $\operatorname{TR}\left[\mathrm{F}(1,38)=4,30 ; \mathrm{p}=0,045 ; \eta^{2}\right.$ parcial $\left.=0,10\right]$.

Em resumo, os participantes responderam mais rapidamente às faces em FEBs, em relação àquelas em FEAs (com exceção feita aos estímulos apresentados ao HE das mulheres). Não foi evidenciado efeito de especialização hemisférica de FEs. Em contrapartida, independente dos hemisférios cerebrais, homens reconheceram mais faces em FEBs e mulheres, faces em FEAs. Para verificar se a apresentação lateralizada não afetava esta diferença de sexo encontrada, realizou-se o Experimento II. 


\section{EXPERIMENTO II}

\subsection{Objetivo}

Verificar se as diferenças de sexo encontradas no Experimento I persistiam com apresentação central dos estímulos. A tarefa dos participantes se manteve a mesma.

\subsection{Método}

\subsubsection{Participantes}

Vinte voluntários ( $\bar{x}=24,25$ e s=3,26), alunos da Universidade de São Paulo (USP), campus de Ribeirão Preto, maiores de 18 anos, sendo 10 homens ( $\bar{x}=24,40$ e s=2,95) e 10 mulheres $(\bar{x}=24,10$ e $s=3,70)$, participaram deste estudo. Foram escolhidos apenas participantes com acuidade visual normal ou corrigida, sem histórico de doença neurológica e livres de doenças oculares identificáveis. Foram cumpridas todas as orientações éticas descritas no Experimento I.

\subsubsection{Materiais e equipamentos}

Foram utilizados os mesmos materiais do Experimento I, com exceção do Inventário de Dominância Manual de Edimburgo (OLDFIELD, 1971) e do aparato utilizado para a apresentação dicótica dos estímulos.

\subsubsection{Estímulos, delineamento experimental, procedimento}

O Experimento II foi delineado analogamente a uma sessão experimental do Experimento I, e seguiu o mesmo procedimento. As únicas diferenças se referem à posição e ao tamanho dos estímulos apresentados: cada face era apresentada num quadrante cinza médio de 6,3 x 6,3 cm (190 x 190 pixels) no centro da tela e media aproximadamente 4,4 x 6,3 cm (134 x 190 pixels), equivalente a 3 x 4,2 graus de ângulo visual. Sendo assim, as imagens apresentadas SFE contêm FEs entre 0,48-30,6 cpg, e as imagens em FEBs e FEAs entre $0,48-1,9$ cpg e 5,24-30,6 cpg, respectivamente. 


\subsubsection{Análise dos dados}

Idem Experimento I.

\subsection{Resultados}

\subsubsection{Análise das Curvas ROC e dos parâmetros Az e da}

As curvas ROC e os parâmetros $\mathrm{A} z$ e da do desempenho de homens e mulheres no reconhecimento de faces SFE, em FEAs e em FEBs podem ser vistos na Figura 9.

Ao analisar os dados de todos os participantes, observou-se uma superioridade pronunciada (mais de 0,90 valor de $\mathrm{d} a$ ) do desempenho de reconhecimento das imagens SFE $\left(\mathrm{A}_{z}=0,93 ; \mathrm{d} a=2,08\right)$ em relação às imagens com corte de FE. Já as retas de regressão das imagens em FEAs e em FEBs estão quase sobrepostas com diferença de apenas 0,04 valor de $\mathrm{d} a$ a favor do reconhecimento das faces em FEAs (FEAs: $\mathrm{A} z=0,79 ; \mathrm{d} a=1,16$ e FEBs: $\mathrm{A} z=0,78$ ; $\mathrm{d} a=1,11)$.

Porém, ao se realizar uma análise por sexo, resultados divergentes são evidenciados. Ainda assim, as faces SFE foram as que tiveram maiores taxas de reconhecimento (homens: $\mathrm{A} z=0,94 ; \mathrm{d} a=2,24$ e mulheres: $\left.\mathrm{A}_{z}=0,91 ; \mathrm{d} a=1,93\right)$, sendo que os homens obtiveram melhor desempenho. Os homens reconheceram melhor as faces em FEBs $(\mathrm{A} z=0,78 ; \mathrm{d} a=1,11)$, em relação as em FEAs $\left(\mathrm{A}_{z}=0,75 ; 0,95\right)$. O inverso aconteceu com as mulheres (FEAs: $\mathrm{A}_{z}=0,84$; $\mathrm{d} a=1,39$ e FEBs: $\left.\mathrm{A}_{z}=0,78 ; \mathrm{da}=1,1\right)$. O padrão foi o mesmo encontrado no Experimento I. Ainda, as mulheres foram melhores que os homens no desempenho de reconhecimento de faces em FEAs (diferença de 0,44 valor de $\mathrm{d} a$ ). E os homens foram melhores que as mulheres ao reconhecer faces em FEBs (diferença de apenas 0,01 valor de $\mathrm{d} a$ ). 

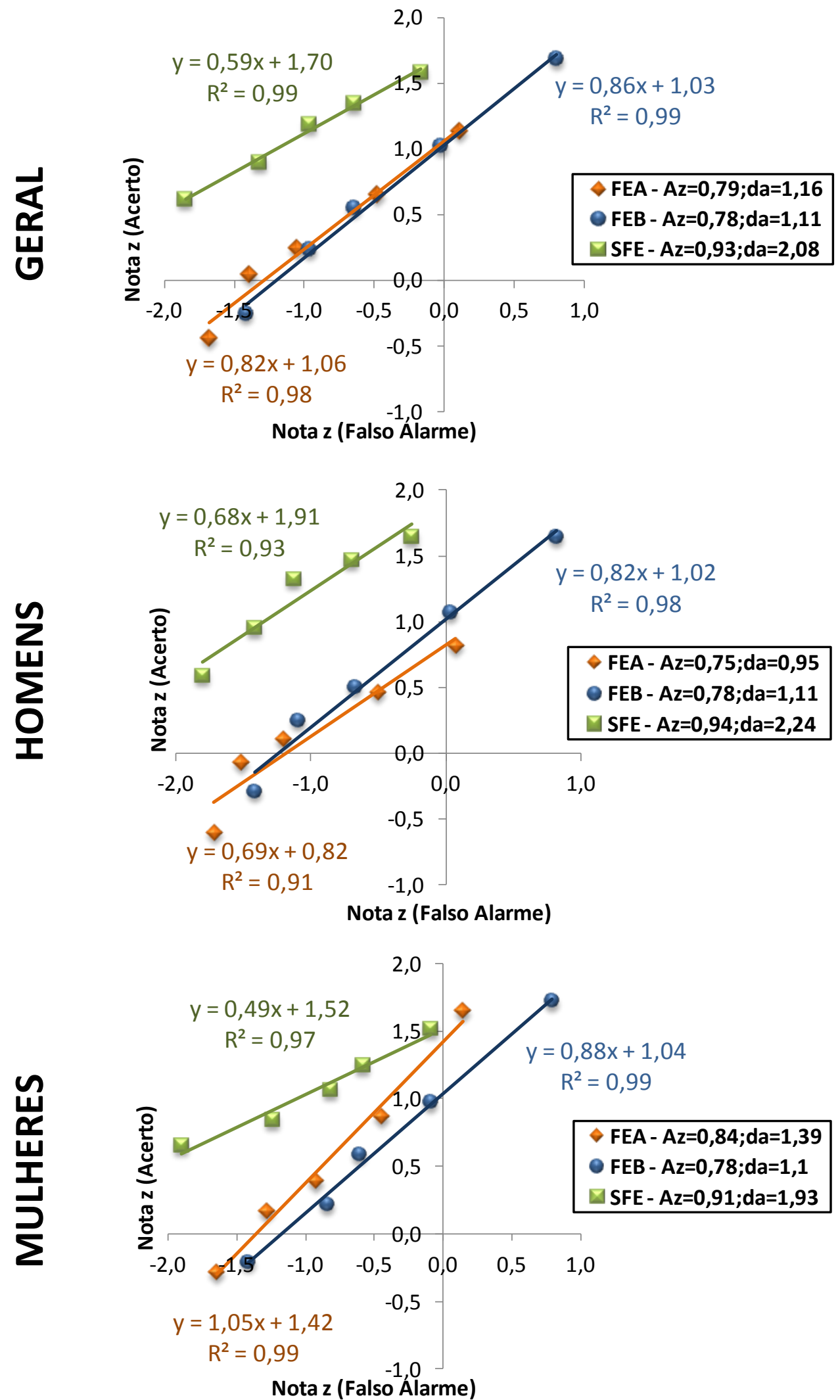

Figura 9: Curvas ROC e parâmetros $\mathrm{A} z$ e d $a$ para o reconhecimento de faces em altas (FEA) e baixas (FEB) frequências espaciais e sem filtragem espacial (SFE) em homens, mulheres e em toda a amostra. 
O gráfico da Figura 10 resume os dados dos subgrupos amostrais (homens, mulheres e amostra total) por meio do parâmetro da.

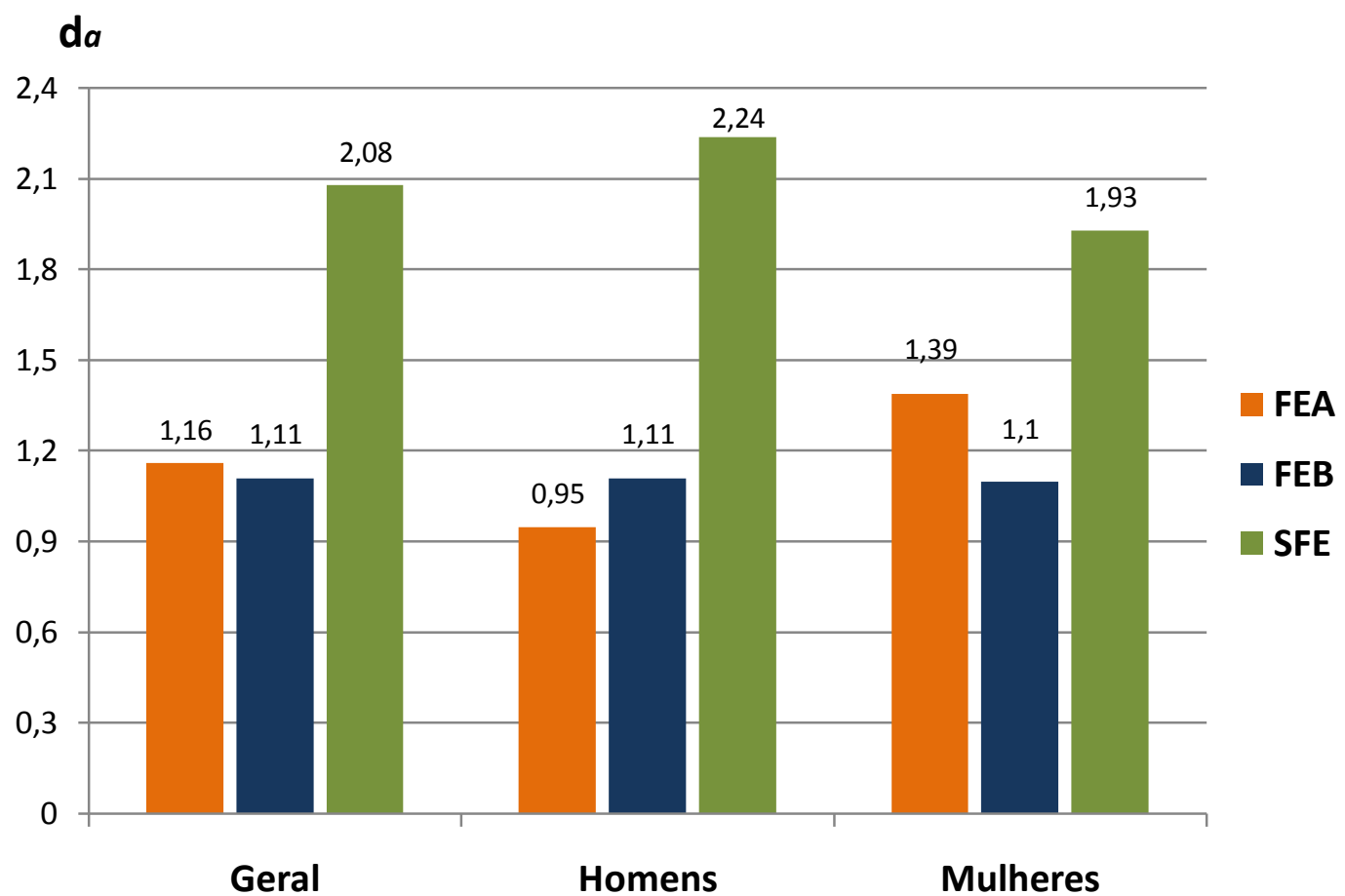

Figura 10: Parâmetro da obtido em tarefa de reconhecimento de faces em altas (FEA) e baixas (FEB) frequências espaciais e sem filtragem espacial (SFE) em homens, mulheres e em todo o grupo amostral.

\subsubsection{Análise dos tempos de resposta}

A Figura 11 mostra os TRs dos subgrupos amostrais aos estímulos em diferentes faixas de FE. O padrão do TR entre as filtragens espaciais dos homens, mulheres e para a amostra total é semelhante. A diferença encontrada foi na latência dos TRs, menores nos homens. Para todos os subgrupos, o desempenho foi melhor para faces apresentadas SFE, seguidas das faces em FEAs e FEBs, em ordem decrescente [Homens - SFE $^{8}:$ 7,104, FEAs: 7,199, FEBs: 7,243 $\ln (\mathrm{ms})$; Mulheres: - SFE: 7,550, FEAs: 7,693, FEBs: 7,717 $\ln (\mathrm{ms})$; Geral - SFE: 7,327, FEAs: 7,446, FEBs: 7,480 $\ln (\mathrm{ms})]$.

Foi encontrado efeito estatisticamente significativo dentre participantes entre as filtragens espaciais, independente do sexo. Sendo que $26 \%$ da variação dos TRs podem ser

\footnotetext{
${ }^{8}$ Os TRs das imagens apresentadas SFE aos homens não foram considerados normalmente distribuídos no teste Kolmogorov-Smirnov. Porém, como a amostra é pequena $(n=10)$ e as exigências de homogeneidade da variância (teste de Levene) e de esfericidade (ajuste de Green-House) foram atendidas, optou-se por aplicar uma ferramenta paramétrica.
} 
creditadas às diferentes filtragens $\left[\mathrm{F}(2,32)=6,23 ; p=0,006 ; \eta^{2}\right.$ parcial $\left.=0,26\right]$. O teste post-hoc verificou diferenças significativas dos TRs das imagens apresentadas SFE e FEA $(p=0,003)$ e entre as imagens SFE e FEB $(p=0,028)$. A análise entre os participantes revelou diferença estatisticamente significativa relativa ao sexo, sendo que este foi responsável por $32 \%$ da variação do TR $\left[\mathrm{F}(1,18)=8,39 ; p=0,01 ; \eta^{2}\right.$ parcial $\left.=0,32\right]$.

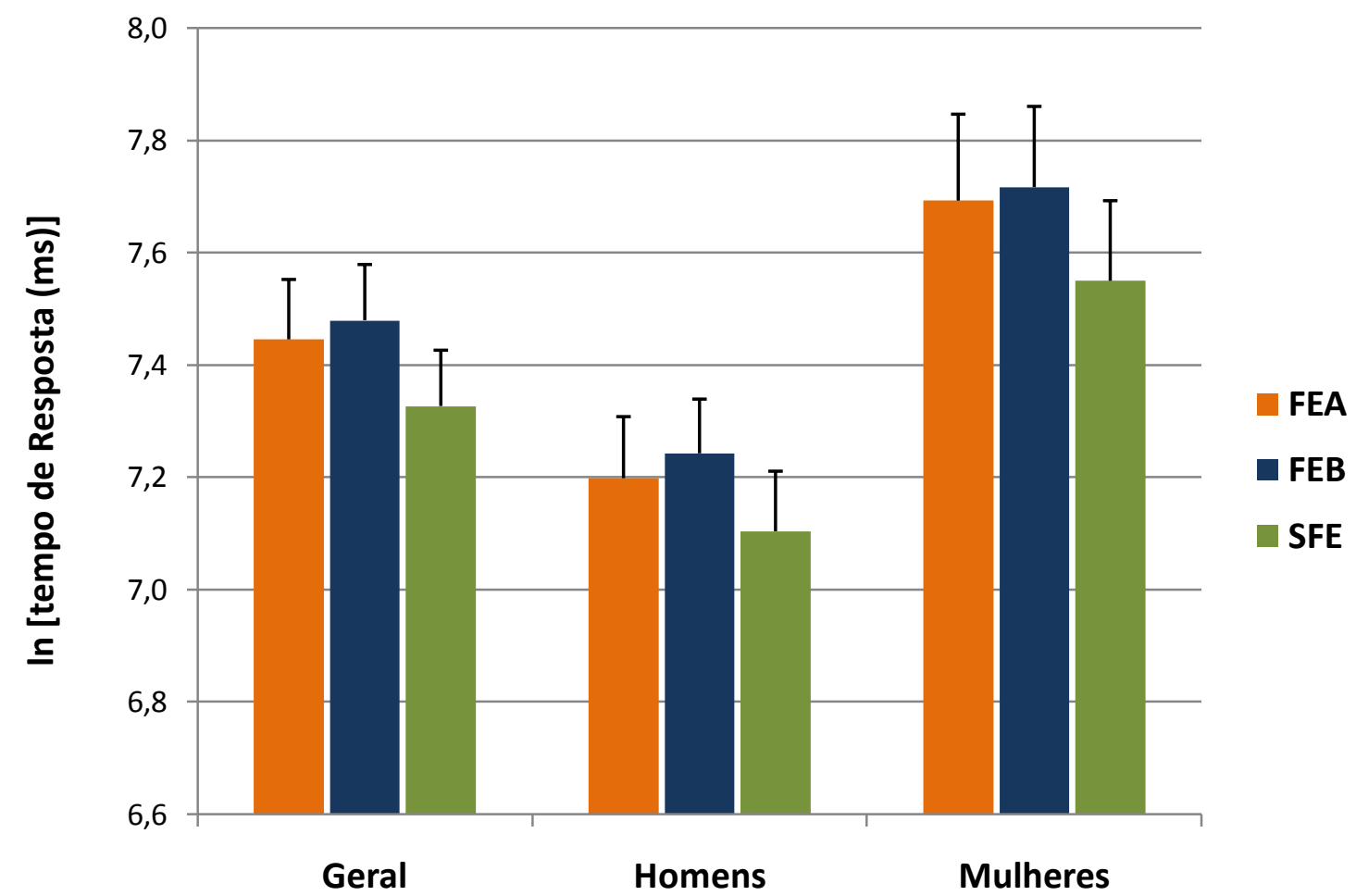

Figura 11: Logaritmo natural da média dos tempos de resposta (ms) de homens, mulheres e de toda a amostra para estímulos faciais apresentados em frequências espaciais altas (FEA), baixas (FEB) e sem filtragem espacial (SFE) no centro da tela.

Em resumo, os resultados referentes à diferença de sexo encontrados no Experimento I foram intensificados no Experimento II: homens e mulheres reconheceram mais faces em FEBs e FEAs, respectivamente. Com relação ao tempo de resposta, diferentemente do Experimento I, os participantes foram mais rápidos quando foram apresentadas faces em FEAs, em relação às em FEBs. 


\section{DISCUSSÃO}

O Experimento I investigou o desempenho dos participantes em uma tarefa de reconhecimento de faces em FEAs, FEBs e SFE em campo visual lateralizado por meio dos parâmetros $\mathrm{A} z$ e da da TDS. O desempenho no reconhecimento de faces SFE foi superior em relação aos estímulos com cortes no espectro de $\mathrm{FE}$, sendo que o $\mathrm{HE}$ obteve melhor desempenho. Este resultado vai de encontro à literatura que afirma que o reconhecimento de faces é mais sensível ao espectro de FE, e que em tempos de apresentação mais longos o HE é superior na discriminação de faces (CURYTO, 2000; GOFFAUX et al., 2011).

Ainda com relação às imagens apresentadas SFE, o desempenho das mulheres foi superior ao dos homens. Este resultado também é confirmado pela literatura (SHAPIRO; PENROD, 1986; BIGUN; CHOY; OLSSON, 2001; MCBAIN; NORTON; CHEN, 2009). É apontado que esta vantagem feminina no reconhecimento facial se dá pela habilidade em reconhecer rostos do mesmo sexo (REHNMAN; HERLITZ, 2006; WEIRCH et al.; 2011).

Não foi evidenciado efeito de assimetria cerebral HD/FEBs vs. HE/FEAs. No entanto, homens reconheceram mais faces em FEBs, e mulheres faces em FEAs, em ambos os hemisférios. De modo a verificar se este efeito entre os sexos é replicável e não ocorre em função da apresentação lateralizada dos estímulos, realizou-se um experimento semelhante com apresentação central. O mesmo padrão de desempenho de homens e mulheres no Experimento I foi observado no Experimento II. Mas, contrário à literatura, as imagens SFE foram mais reconhecidas pelos homens. Assimetria cerebral e diferenças de sexo em relação à FE serão discutidas de maneira mais aprofundada em tópicos à parte.

Também foram analisados os TRs. Em geral, os TRs dos homens foram menores que o das mulheres. Resultados que apontam uma vantagem masculina nos tempos de reação são evidenciados na literatura, e atribuídos a diferenças neurofisiológicas na velocidade de processamento da informação. Outros estudos, no entanto, apontam que a diferença da velocidade da resposta entre os sexos se dá em função do tipo de estímulo apresentado. Estímulos verbais ou auditivos com conteúdo semântico são mais rapidamente processados por mulheres, ao passo que estímulos de natureza espacial ou visual o são pelos homens (LAHTELA; NIEMI; KUUSELA, 1985; SPIERER et al, 2010).

No Experimento I faces SFE obtiveram menores TRs, seguidos de faces em FEBs e, com maiores latências, faces em FEAs, o que sugere um processamento sequencial corse-tofine (ver adiante no texto). À exceção, estão os resultados obtidos da amostra feminina no HE, 
que obtiveram melhor desempenho para as faces em FEAs, em relação àquelas em FEBs. Esse resultado se deve em função de dois fatores. Primeiro, tarefas que exigem operações analíticas ou processamento de FEAs são melhor desempenhadas pelo HE (SPRINGER; DEUTSCH, 1993). Segundo, os resultados de Perilla-Rodríguez (2008) e os Experimentos I e II da presente pesquisa mostraram que as mulheres têm melhor desempenho no reconhecimento de faces em FEAs em comparação àquelas em FEBs.

No Experimento II, faces SFE também obtiveram menores TRs. Porém, as faces apresentadas em FEAs apresentaram menor TR em relação às faces em FEBs. A localização espacial dos estímulos pode explicar esta diferença. No Experimento I, as faces são apresentadas no campo visual periférico, no qual a incidência retiniana recai sobre os bastonetes. Os bastonetes se ligam às células ganglionares $\mathrm{M}$, sensíveis a FEBs. Já no Experimento II, os estímulos foram apresentados na região foveal do campo visual. A fóvea é a região de maior acurácia da retina devido à alta concentração de cones. Os cones fazem conexões com células ganglionares P, que processam FEAs (LIVINGSTONE; HUBEL, 1988) (vide APÊNDICE B). Em resumo, a interação entre conteúdo de FE e a localização espacial dos estímulos afetam a velocidade de processamento do sistema visual. Estes resultados dão margem a uma interpretação da não ocorrência de assimetria: a de que a sensibilidade a diferentes faixas de FEs no córtex visual segue um mapa retinotópico. Esta hipótese será discutida nas linhas seguintes.

\subsection{Especialização hemisférica}

No Experimento I, a sensibilidade dos participantes às faixas de FEAs e FEBs foi semelhante no HD e HE. Este resultado não corrobora a hipótese de especialização hemisférica no processamento de FEs, proposta por Sergent (1982). De fato, alguns estudos não apoiam esta hipótese (GRABOWSKA; NOWICKA, 1996; REBAÏ et al., 1998; KENEMANS et al., 2000, BOESCHOTEN et al., 2005).

Boeschoten et al. (2005), em um estudo de potenciais relacionados ao evento (ERPs) e Kenemans et al. (2000), por meio de potenciais visuais evocados (VEPs) chegaram aos mesmos resultados. Eles concluíram que o processamento de FEs é mapeado retinotopicamente no córtex visual: medialmente para informações locais/FEAs e lateralmente para informações globais/FEBs. O córtex visual primário segue a mesma estruturação da 
retina, que em seu campo central, a fóvea, é especializada nos detalhes de escala fina. Ao contrário do campo periférico, que se desenvolveu para perceber movimento e grandes variações de luminosidade.

Em um estudo semelhante, Sasaki et al. (2001) mapearam as áreas de sensibilidade à atenção a características locais e globais e à FE no córtex occipital por meio de ressonância magnética funcional $(f \mathrm{MRI})$. A atenção às características locais ativou a representação foveal no córtex, onde a sensibilidade à FEAs foi mais alta. Quando se exige atenção global, ocorre um aumento da sensibilidade à FEBs em áreas mais periféricas. Os mapas de atenção e FE encontrados foram simétricos e bilaterais, retinotopicamente marcados.

Os dados dos TRs dos Experimentos I e II corroboram a hipótese de que o processamento de FEs segue o mapa retinotópico da visão. No Experimento I, os estímulos foram apresentados no campo de visão periférico, e os TRs das imagens em FEBs (com exceção da amostra feminina do HE) foram menores do que o das imagens em FEAs. O contrário aconteceu no Experimento II, onde os estímulos foram apresentados na visão foveal: os TRs das imagens em FEAs foram menores do que o das imagens em FEBs.

Os argumentos apresentados a favor de um mapa retinotópico no córtex visual trabalham com a hipótese de que não há especialização hemisférica para processamento de FEs. Isto nos ajuda a compreender porque não foi encontrada diferença de desempenho entre os hemisférios no Experimento I. Mas, por outro lado, pode ser que haja especialização hemisférica, que é alcançada por meio de variações metodológicas.

O método do campo visual dividido, apesar de clássico na literatura, pode ter ajudado a mascarar algum efeito de assimetria cerebral. Han et al. (2002) e Lux et al. (2004) realizaram pesquisas por meio de $f \mathrm{MRI}$, nas quais apresentavam estímulos hierárquicos (letras navon) na periferia e no centro do campo visual. Em ambos os estudos, os resultados foram os mesmos. Quando a apresentação foi central, aspectos globais e locais do estímulo ativaram o córtex occipital direito e esquerdo, respectivamente, caracterizando um efeito de assimetria cerebral. Quando a apresentação se deu na periferia dos hemicampos visuais, o efeito foi notavelmente atenuado.

Han et al. (2002) sugerem que, quando a apresentação é central, e o input sensorial chega aos dois hemisférios, há uma "competição" no processamento da informação. Isto dá origem a ativações occipitais lateralizadas: maior ativação no HD quando a atenção está voltada a características globais, e maior ativação do HE quando a atenção está voltada para aspectos locais do estímulo. Outra hipótese é dada por Lux et al. (2004). Segundo estes autores, independentemente de onde o estímulo é projetado, no hemicampo direito ou 
esquerdo, a informação local é extraída pelo HE e a informação global pelo HD. Logo, se informações locais são apresentadas no lado esquerdo (se projetando no HD), a ativação do HE seria atenuada pelo resultado da transferência da informação por meio do corpo caloso, que se projetaria de áreas occipitais do HD ao HE. O inverso aconteceria para dados globais apresentados no hemicampo direito (projeção no HE).

Um mascaramento de efeitos de assimetria no Experimento I também pode ter acontecido devido à adaptação feita ao método do campo visual dividido (vide Método, no Experimento I). Esta foi feita com a finalidade de apresentar as faces em uma baixa restrição temporal para garantir que, mesmo na ocorrência de sacadas, apenas o hemicampo de interesse seja percebido. Independentemente da adaptação utilizada, o córtex visual direito e esquerdo ainda se comunicam via corpo caloso. O método do campo visual dividido assume esta comunicação, mas como a informação do hemisfério contralateral que atravessa o corpo caloso chega atrasada e degradada, o método é válido. Porém, quanto maior o tempo de processamento da informação, maior a comunicação inter-hemisférica, o que diminui diferenças de especialização hemisférica (PEYRIN et al., 2006b).

A partir disso, podemos levantar outra hipótese. É possível que encontremos uma assimetria cerebral de FEs no reconhecimento de faces, mas em uma maior restrição temporal. De acordo com Peyrin et al. (2006b), quanto maior a restrição temporal, mais os hemisférios são especializados no processamento de FEs.

Segundo a hipótese coarse-to-fine, a contribuição de diferentes faixas do espectro de FE para o sistema visual é dinâmica e dependente do tempo. FEBs, que carregam informações globais e grosseiras, são extraídas nos estágios iniciais do processamento visual, e iniciam a análise da cena visual antes de FEAs. Mas esta resposta decai progressivamente ao longo do tempo, dando lugar aos recursos especializados no processamento de informações locais e detalhadas por meio de FEAs (GOFFAUX et al., 2011, PEYRIN et al., 2010). Não só a extração de FEs pelo sistema visual para formações de representações perceptuais segue uma ordem coarse-to-fine. A transferência da informação de FE para a memória visual de curto prazo é mais rápida para FEBs do que para FEAs. Esta transferência se inicia antes de a integração perceptiva estar completa. Já o decaimento da retenção da memória visual de curto prazo é similar entre as faixas de FEs (GAO; BENTIN, 2011).

Goffaux et al. (2011) investigaram medidas comportamentais (julgamento em tarefa de reconhecimento e tempo de respostas corretas) e de neuroimagem ( $f \mathrm{MRI}$ ) numa tarefa de reconhecimento de faces filtradas. Foi encontrado um processamento coarse-to-fine de FEs em regiões altamente sensíveis ao padrão facial no córtex cerebral. Na Área Fusiforme Facial 
do HD, a mais sensível na percepção facial, faces em FEBs provocaram uma alta ativação em 75 ms e baixa em 150 ms. Já faces em FEAs, ao contrário, apresentaram baixa ativação em 75 ms e alta em 150. Ambas as faces, em FEAs e em FEBs, não apresentaram diferença em magnitude de ativação neural aos 300 ms. O mesmo padrão de ativação coarse-to-fine foi encontrado na Área Fusiforme Facial do hemisfério esquerdo e na Área Occipital Facial do hemisfério direito ${ }^{9}$. Porém, a ativação se tornou mais robusta no intervalo entre 150 e 300 ms, e não entre 75 e 150, como aconteceu na Área Fusiforme Facial do HD. De modo geral, o decaimento do processamento de FEBs acontece até os $150 \mathrm{~ms}$, e o processamento de FEA é intensificado em intervalos temporais diferentes, dependendo da região.

No mesmo estudo, o Complexo Occipital Lateral, área de codificação de estímulos visuais complexos não categorizados, não apresentou a sequência de processamento coarseto-fine. Não foi observada diferença de resposta entre estímulos de faces e de carros. Faixas de FEs intermediárias e altas foram mais ativadas, independente do tempo de exposição. Isto nos dá evidências de que regiões corticais que não estão relacionadas a estímulos categorizados, como faces por exemplo, não respondem numa sequência coarse-to-fine.

Peyrin et al. (2006b) realizaram um estudo psicofísico que corrobora esta hipótese. Este grupo de pesquisadores investigou o processamento de FEs de cenas naturais entre os hemisférios. Foram utilizados dois tempos de exposição, 30 e $150 \mathrm{~ms}$ em uma tarefa matchto-task. Somente na condição de $30 \mathrm{~ms}$ foi observado o efeito de especialização hemisférica proposto por Sergent (1982). As variações do tempo de exposição afetaram a extração da informação visual, mas não num modelo coarse-to-fine de processamento.

Por fim, as condições de maior tempo de exposição em Peyrin et al. (2006b), 150 ms, que utilizou paisagens, assim como a de Gouffaux, et al. (2011), $300 \mathrm{~ms}$, que utilizou faces, não apresentaram a clássica assimetria HD/FEBs vs. HE/FEAs. Do mesmo modo, o estudo comportamental de Blanca et al. (1994), ao investigar diferenças hemisféricas de elementos globais e locais em estímulos navon, obteve esta assimetria apenas em um tempo de exposição de 50 ms; não foi encontrado assimetria em 100 e 200 ms. Os dados do Experimento I do presente trabalho estão de acordo com estes achados, visto que em um tempo de exposição lateralizada de $300 \mathrm{~ms}$ não foi observado efeito de especialização hemisférica das faces com filtragem de FEs. Os TRs do experimento I também seguem um processamento coarse-to-fine.

\footnotetext{
${ }^{9}$ A Área Occipital Facial do hemisfério esquerdo foi descartada da análise, visto que as faces não mostraram uma diferença significativamente maior em relação às faces que tiveram a fase mexida no domínio de Fourier (escrambled faces, estímulos controles para comparação do nível de ativação com as faces teste, filtradas com a fase intacta).
} 


\subsection{Diferenças de sexo}

Apesar de não ter sido evidenciado efeito de assimetria cerebral no Experimento I, homens e mulheres obtiveram um padrão diferente: ao passo que os homens foram mais sensíveis para faces em FEBs, as mulheres o foram para faces em FEAs. Para verificar se o efeito não ocorreu em função da apresentação lateralizada, foi elaborado o Experimento II com mesmo delineamento, mas com apresentação central dos estímulos, na área de convergência binocular. As diferenças entre os sexos, embora sutis, não foram somente replicadas, como também intensificadas. Os resultados de Perilla-Rodríguez (2008) apoiam parcialmente estes achados. Neste, para a amostra feminina, apenas no HE as mulheres foram mais sensíveis às faces em FEAs em relação às em FEBs. Mas os resultados do HD das mulheres e de ambos os hemisférios na amostra masculina apoiam nossos resultados: as mulheres obtiveram melhor desempenho no reconhecimento de faces em FEAs em relação às em FEBs, e os homens reconheceram mais faces em FEBs, em comparação às em FEAs.

A preferência do sistema visual das mulheres no processamento de FEAs, e dos homens no de FEBs observado em Perilla-Rodríguez (2008), e nos experimentos deste estudo, é robusta a diferentes amostras e condições de apresentação do estímulo (grau de ângulo visual, excentricidade, frequência de corte dos filtros espaciais, luminância, contraste). Ainda não foi divulgado na literatura científica uma faixa preferencial de FEs para homens e mulheres no processamento de faces.

Solberg e Brown (2002) não encontraram diferenças na percepção de FE de homens e mulheres em estudo com sensibilidade ao contraste e tempo de reação utilizando como estímulos manchas Gabor. Ainda, eles relatam que pesquisas que investigaram diferenças de sexo na resposta à FE mostram resultados conflitantes e que não se replicam. Foi encontrado na literatura apenas um estudo sobre diferenças de sexo na percepção de FE utilizando estímulos complexos. Esta pesquisa (Peyrin et al., 2006a) também estudou efeito de assimetria cerebral, que foi encontrado somente nos homens, ao passo que as mulheres mostraram resultados controversos

Além disso, a diferença de sexo encontrada no presente trabalho pode ser interpretada em função da predominância hemisférica. Homens utilizam mais o HD, e tem um processamento da informação mais holístico. Por outro lado, as mulheres utilizam mais o HE, e tem um processamento marcadamente mais analítico (SPRINGER; DEUTSCH, 1993). Corroborando isto, Roalf, Lowery e Turetsky (2006) investigaram a ativação provocada por 
estímulos navon por meio de ERP. Neste trabalho os homens mostraram resultados similares entre as condições do estímulo (local e global) e de hemisfério, sendo que obtiveram menor TR para estímulos globais. As mulheres foram mais lateralizadas com dominância do HE, especialmente a estímulos locais, e obtiveram um atraso nas respostas aos estímulos globais. Outro estudo com uma amostra pediátrica (KRAMER et al., 1996) também dá apoio a uma distinção entre sexos. Neste, os garotos obtiveram melhor desempenho em tarefas que envolviam processamento global, e as meninas naquelas em que se exigiam mais recursos analíticos.

\subsection{Limitações e sugestões para estudos posteriores}

A maioria dos experimentos de reconhecimento faz uso de delineamentos livres de etapas de memorização. Isso é feito para minimizar o efeito da aprendizagem e de processos mnemônicos em relação aos processos de codificação visual. Senso assim, desenhos experimentais como (ou similares a) matching tasks são amplamente utilizados. Porém, este tipo de experimento apresenta algumas desvantagens ao se utilizar faces com filtragem de FEs como estímulos. Primeiro, a face é um estímulo de fácil discriminação, e matching tasks facilitam o reconhecimento. Segundo, o curto tempo de duração de cada tentativa pode prejudicar a transferência da informação de faixas de FEs para a memória visual de curto prazo; por exemplo, em 800 ms FEAs ainda estão sendo transferidas para a memória visual de curto prazo (GAO; BENTIN, 2011). Por último, desenhos em matching tasks são mais afetados pelo overlap de FEs entre a face original e a face teste (LIU et al., 2000). Por essas razões optou-se por uma fase de memorização nos experimentos do trabalho aqui apresentado. Os resultados são interpretados em função de processos perceptuais de processamento e codificação facial, visto que o decaimento da retenção da memória visual de curto prazo não é influenciado pelo espectro de FE (GAO; BENTIN, 2011).

Ainda assim, nos experimentos I e II, de mesmo delineamento, a fase de memorização foi a que contou com mais baixo controle experimental. O número de faces memorizadas (14) excede a capacidade da memória de curto prazo. Também não se utilizou medida objetiva para medir a taxa de memorização. Apesar destas limitações, a taxa de reconhecimento das faces SFE foi utilizada como condição controle para a memorização, e se observou elevado índice de julgamentos corretos para esta classe de estímulos. Mas para garantir maior controle 
experimental, algumas melhoras podem ser efetuadas durante a memorização: 1) diminuir o número de estímulos a serem memorizados; 2) obter um índice objetivo de memorização (taxa de acertos em um experimento prévio, por exemplo). Pode-se ainda utilizar um delineamento experimental em que não se faça necessário uma fase de memorização: forced-choice e matching task, por exemplo (desde que levando-se em consideração as desvantagem citadas no parágrafo anterior).

Também há de se ter um controle adicional com a amostra feminina. Já foram observadas diferenças dos resultados em medidas repetidas de experimentos com campo visual lateralizado apenas nas mulheres (HAUSMANN; GUNTURKUN, 1999). Hormônios sexuais afetam habilidades espaciais (HAUSMANN et al., 2000) e assimetrias funcionais (HAUSMANN et al., 2002) ao longo do ciclo menstrual. Grande parte dos estudos comportamentais não toma este cuidado, e alguns pesquisadores preferem utilizar apenas voluntários homens. Testar mulheres que fazem uso de anticoncepcional é uma alternativa segura e não onerosa para o pesquisador.

Com relação aos TRs, a complexidade da tarefa (perceber o estímulo, recuperar informação da memória, realizar um julgamento com seis opções de resposta, e efetuar um comportamento motor) foi um fator que impediu que a latência da resposta refletisse de maneira mais precisa a velocidade de processamento dos estímulos pelo sistema visual. Isto explica em parte porque os TRs entre as faixas de FE selecionadas foram discretos. Em estudos posteriores, quando esta medida se mostrar de maior importância, é sugerido que menos opções de resposta estejam disponíveis ao participante (delineamentos sim/não e go/no-go, por exemplo). Quanto mais simples a resposta, mais o TR poderá dizer acerca de processos sensoriais, em oposição a processos de decisão e respostas motoras.

Outra sugestão, com relação aos estímulos: optou-se trabalhar com estímulos com filtragem de FE, pois a literatura evidencia que um pré-processamento retinal botton-up de FE precede operações top-down do tipo local/global no córtex visual. Mas outras modalidades de estímulo devem ser testadas: faces quiméricas (LEVY; TRVARTHEN; SPERRY, 1972), faces invertidas (FLEVARIS; ROBERTSON; BENTIN, 2008), faces configuracionais (MAURER et al., 2007), faces combinadas (CHEUNG et al., 2008), partes das faces (GOFFAUX; ROSSION, 2006) e faces embaralhadas (CASEY; NEWELL, 2007). Estes exemplos recaem diretamente em operações cognitivas complexas, e não dependem, de maneira direta, do processamento de FEs para inferir processos locais ou globais. 
Com relação ao tempo de apresentação, são interessantes estudos que utilizam mais de uma condição de tempo de exposição. O estudo do continuum temporal se justifica pelo fato de a codificação de FE ser dinâmica ao longo do tempo.

Por fim, é de grande utilidade, em estudos que utilizam o campo visual dividido, a utilização de um equipamento eyetracker, utilizado para o rastreamento ocular. O eyetracker pode determinar se o participante fixa seu olhar no ponto de fixação apresentado antes dos estímulos. Isso garante que a informação sensorial será enviada ao hemisfério desejado. Equipamentos de eletrofisiologia (ERP e VEP, por exemplo) e neuroimagem (PET e $f$ MRI, por exemplo) também garantem informações adicionais sobre o padrão de ativação e as áreas cerebrais específicas mais envolvidas durante experimentos psicofísicos.

\subsection{Importância do estudo}

O efeito de especialização hemisférica de FE é influenciado por muitos fatores: atributos físicos dos estímulos, foco atentivo, tempo de exposição, excentricidade, sexo etc. Em virtude disto, resultados diferentes e mesmo contraditórios são comuns na literatura. Ainda assim, os resultados do presente trabalho se mostram robustos, e trazem dois tipos de contribuição à literatura: uma no campo metodológico e outra no campo experimental.

No campo metodológico, podemos ressaltar duas contribuições. Primeiro, foi utilizado e relatado pela segunda vez na literatura uma variação do método do campo visual dividido por meio de um aparato composto por um espelho e um oclusor. Esta técnica foi inicialmente utilizada para se estudar o preenchimento da mancha cega (TRIPHATY et al., 1995) e adaptada para investigar assimetria cerebral por Perilla-Rodrígues (2008). O relato desta variação do método na literatura científica permite que pesquisadores realizem apresentações com baixa restrição temporal (acima de $180 \mathrm{~ms}$ ). Ela garante que, mesmo na ocorrência de sacadas, não haverá varredura visual fora do hemicampo de interesse. Esta adaptação é de baixo custo e favorece a pesquisa em laboratórios que não contam com equipamento de rastreamento ocular (eyetracker). Segundo, outra contribuição é relativa ao controle amostral. Em estudos de FE, os resultados de homens e mulheres devem ser analisados em separado. Trabalhos anteriores comumente não realizaram isto, mas nossos resultados apontam para um processamento diferencial de FEs entre os sexos no reconhecimento facial. Este fato já se mostra como uma contribuição experimental, visto que ainda não foi relatado na literatura. A 
outra contribuição experimental é relativa à especialização hemisférica. Neste trabalho apontamos evidências de ausência de assimetria cerebral no reconhecimento de faces em bandas de FEAs e FEBs em longos tempos de exposição (acima de 300 ms) em campo visual dividido. 


\section{CONCLUSÃO}

A partir da revisão de literatura e da análise dos resultados obtidos, concluímos que:

- Em longos tempos de exposição, a partir de 300 ms, não foram encontradas evidências de especialização hemisférica de FEs no reconhecimento de faces.

- Homens têm melhor desempenho para faces apresentadas em FEBs, o que dá base para operações holísticas de processamento; as mulheres têm melhor desempenho no reconhecimento de faces que preservam FEAs, o que dá base para operações analíticas de processamento. 


\section{REFERÊNCIAS ${ }^{10}$}

BARBEAU, E. J.; TAYLOR, M. J.; REGIS, J.; MARQUIS, P.; CHAUVEL, P.; LIÉGEOISCHAUVEL, C. Spatial temporal dynamics of face recognition. Cerebral Cortex, v. 18, n. 5, p. 997-1009, 2008.

BICAS, H. E. A. O idiotismo 20/20. Arquivos Brasileiros de Oftalmologia, v. 66, p. 259, 2003.

BIGUN, J.; CHOY, K.; OLSSON, H. Evidence on skill differences of women and men concerning face recognition. In: BIGUN, J.; SMERALDI, F (Eds.). Audio and Video Based Biometric Person Authentication - AVBPA 2001, Springer: Heidelberg, 2001, p. 44-51.

BLANCA, M. J.; ZALABARDO, C.; GARI-CRIADO, F.; SILES, R. Hemispheric differences in global and local processing dependent on exposure duration. Neuropsychologia, v. 32, p. 1343-1351, 1994.

BOESCHOTEN, M. A.; KEMNER, C.; KENEMANS, J. L.; VAN ENGELAND, H. The relationship between local and global processing of high and low spatial frequencies studied by event-related potentials and source modeling. Cognitive Brain Research, v. 24, p. 224236, 2005.

BOURNE, V. The divided visual field paradigm: Methodological considerations. Laterality: Asymmetries of Body, Brain, and Cognition, v. 11, n. 4, p. 373-393, 2006.

BRUCE, V.; YOUNG, A. In the eye of the beholder: The science of face perception. New York: Oxford University Press Inc, 1998.

CAMPBELL, F. W.; ROBSON, F. G. Application of the Fourier analysis to the visibility of gratings. Journal of Phisiology,v. 19, p. 551-556, 1968.

CARBON, C. C. Face processing: Early processing in the recognition of faces. 2002. 300 p. Ph. D. Thesis (Psychology), Freie Universität Berlin, Berlin, 2003.

CARMEL, D.; BENTIN, S. Domain specificity versus expertise: factors influencing distinct processing of faces. Cognition, v. 83, p. 1-29, 2002.

\footnotetext{
${ }^{10}$ De acordo com a Associação Brasileira de Normas Técnicas. NBR 6023.
} 
CASEY, S.; NEWELL, F. Are representations of unfamiliar faces independent of encoding modality? Neuropsychologia, v. 45, p. 506-513, 2007.

CHELLAPA, R.; WILSON, C.; SIROHEY, S. Human and machine recognition of faces: a survey. Proceedings of the IEEE, v. 83, n. 5, p. 705-740, 1995.

CHEUNG, O. S.; J. RICHLER, J. J.; PALMERI, T. J.; GAUTHIER. Revisiting the role of spatial frequencies in the holistic processing of faces. Journal of Experimental Psychology: Human, Perception and Performance, v.34, n. 6, p. 1327-1336, 2008.

COLlin, C. A.; LIU, C. H.; TROJE, N. F.; MCMULLEN, P. A.; CHAUDHURI, A. Face recognition is affected by similarity in spatial frequency range to a greater degree than withincategory object recognition. Journal of Experimental Psychology: Human, Perception and Performance, v. 30, p. 975-987, 2004.

COLLIN, C. A.; WANG, L.; O'BYRNE, B. Effects of image background on spatial frequency thresholds for face recognition. Perception, v. 35, p. 1459-1472, 2006.

CURYTO, K. A model of hemispheric asymmetry: The effects of spatial frequency and processing duration. 2000. 116 p. Ph. D. Thesis (Psychology), Wayne State University, Detroit, 2000.

FRISHMAN, L. J. Basic visual processes. In: GOLDSTEIN, E. B (Ed.). Blackwell handbook of sensation and perception. Oxford: Blackwell Publishing, 2001. cap. 3, p. 5591.

GAO, Z.; BENTIN, S. Coarse-to-fine encoding of spatial frequency information into shortterm memory for faces but impartial decay. Journal of Experimental Psychology: Human Perception and performance, v. 37, n. 4, p. 1051-1064, 2011.

GAUTHIER, I.; TARR, J. M. Becoming a "Greeble" expert: exploring mechanisms for a face recognition. Vision Research, v. 37, n. 12, p. 1673-1682, 1997.

GAZZANIGA, M. S. Cerebral specialization and interhemispheric communication: Does the corpus callosum enable the human condition. Brain, v. 123, p. 1293-1326, 2000.

GOFFAUX, V.; HAULT, B.; MICHEL, C.; VUONGÔ, Q. C.; ROSSION, B. The respective role of low and high spatial frequencies in supporting configural and featural processing of faces. Perception, v. 34, p. 77-86, 2005. 
GOFFAUX, V.; PETERS, J.; HAUBRECHTS, J.; SCHILTZ, C.; JANSMA, B.; GOEBEL, R. From coarse to fine? Spatial and temporal dynamics of cortical face processing. Cerebral Cortex, v. 21, p. 467-476, 2011.

GOFFAUX, V.; ROSSION, B. Faces are "spatial": Holistic face perception is supported by low spatial frequencies. Journal of Experimental Psychology: Human perception and Performance, v. 32, n. 4, p. 1023-1039, 2006.

GRABOWSKA, A.; NOWICKA, A. Visuo-spatial-frequency model of cerebral asymmetry: a critical survey of behavioral and electrophysiological studies. Psychological Bulletin, v. 120, p. 434-449, 1996.

HAN, S.; WEAVER, J. A.; MURRAY, S. O.; KANG, X.; YUND, E. W.; WOODS, D. L. Hemispheric asymmetry in global/local: effects of stimulus position and spatial frequency. NeuroImage, v. 17, p. 1290-1299, 2002.

HAUSMANN, M.; BECKER, C.; GATHER, U.; GÜNTÜRKÜN, O. Funcional cerebral asymmetries during the menstrual cycle: a cross-sectional and longitudinal analysis. Neuropsychologia, v. 40, p. 808-816, 2002.

HAUSMANN, M.; GÜNTÜRKÜN, O. Sex differences in functional cerebral asymmetries in a repeated measures design. Brain and Cognition, v. 41, p. 263-275, 1999.

HAUSMANN, M.; SLABBEKOORN, D.; VAN GOOZEN, S. H. M.; COHEN-KETTENIS, P. T.; GÜNTÜRKÜN, O. Sex hormones affect spatial abilities during the menstrual cycle. Behavioral Neuroscience, v. 114, n. 6, p. 1245-1250, 2000.

HAXBY, J. V.; UNGERLEIDER, L. G.; CLARK, V. P.; SCHOUTEN, J. L.; HOFFMAN, E. A.; MARTIN A. The effect of face inversion on activity in human neural systems for face and object perception. Neuron, v. 22, p. 189-199, 1999.

HECKER, R.; MAPPERSON, B. Dissociation of visual and spatial processing in working memory. Neuropsychologia, v. 35, n. 5, p. 599-603, 1997

HILLS, P. J.; LEWIS, M. B. A spatial frequency account of the detriment that local processing of navon letters has on face recognition. Journal of experimental Psychology, v. 35, n. 5, p. 1427-1442, 2009. 
HILLGER, L. A.; KOENIG, O. Separable mechanisms in face processing: Evidence from hemispheric specialization. Journal of Cognitive Neuroscience, v. 3, n. 1, p. 42-58, 1991.

JORDAN, T. R.; PATERSON, K. B.; KURTEV, S.; XU, M. Do fixation cues ensure fixation accuracy in split-fovea studies of word recognition? Neuropsychologia, v. 47, p. 2004-2007, 2009.

KEENAN, P. A.; WHITMAN, R. D.; PEPE J. Hemispheric asymmetry in the processing of high and low spatial frequancies: a facial recognition task. Brain and Cognition, v. 11, n. 2, p. 229-237, 1989.

KENEMANS, J. L.; BAAS, J. M. P.; MANGUN, J. R.; LIJFFIJT, M.; VERBATEN, M. N. On the processing of spatial frequencies as revealed by evoked potential source modeling. Clinical Neurophysiology, v. 111, p. 1113-1123, 2000.

KESSELS, R. P. C.; POSTMA A.; DE HAAN, E. H. F. P and M channel-specific interference in the what and where pathway. Neuroreport, v. 10, p. 3765-3767, 1999.

KRAMER, J. H.; ELLENBERG, L.; LEONARD, J.; SHARE, L. J. Developmental sex differences in global-local perceptual bias. Neuropsychology, v. 10, n. 3, p. 402-407, 1996.

LAHTELA, K.; NIEMI, P.; KUUSELA, V. Adult visual choice-reaction time, age, sex and preparedness: a test of Welford's problem in a large population sample. Scandinavian Journal of Psychology, v. 26, p. 357-362, 1985.

LEVY, J.; TREVARTHEN, C.; SPERRY, R. W. Perception of bilateral chimeric figures following hemispheric deconnexion. Brain, v. 95, p. 61-78, 1972.

LIU, C. H.; COLlin, C. A.; RAINVILLE, S. J.; CHAUDHURI, A. The effects of spatial frequency overlap on face recognition. Journal of experimental psychology: Human, perception and Performance, v. 26, p. 956-979, 2000.

LIVINGTONE, M.; HUBEL, D. Segregation of form, color, movement, and depth: anatomy, physiology, and perception. Science, v. 240, p. 740-749, 1988.

LUX, S.; MARSHALL, J. C.; RITZL, A.; WEISS, P. H.; PIETRZYK, U.; SHAH, N. J.;

ZILLESA K.; FINK, G. R. A functional magnetic resonance imaging study of local/global processing with stimulus presentation in the peripheral visual hemifields. Neuroscience, $\mathrm{v}$. 124, p. 113-120, 2004. 
MACBAIN, R.; NORTON, D.; CHEN, Y. Females excel at basic face perception. Acta Psychologica, v. 130, p. 168-173, 2009.

MAURER, D.; LE GRAND, R.; MONDLOCHD, C. J. The many faces of configural processing. Trends in Cognitive Sciences, v. 6, n. 6, p. 255-260, 2002

MAURER, D.; O'CRAVEN, K. M.; LE GRAND, R.; MONDLOCHD, C. J.; SPRINGER, M. V.; LEWIS, T. L.; GRADY, C. L. Neural correlates of processing facial identity based on features versus their spacing. Neuropsychologia, v. 45, p. 1438-1451, 2007.

MEADOWS, J. C. The anatomical basis of prosopagnosia. Journal of Neurology, Neurosurgery, and Psychiatry, v. 37, 489-501, 1974.

MENDES, A. I. F.; ARRAIS, K. C.; FUKUSIMA, S. S. Faces prototípicas provenientes de amostras populacionais de uma região brasileira. Psicologia: Reflexão e Crítica, v. 22, n.2, 261-268, 2009.

MÜNTE, T. F.; BRACK, M.; GROOTHER, O.; WIERINGA, B. M.; MATZKE, M.; JOHANNES, S. Brain potentials reveal the timing of face identity and expression judgments. Neuroscience Research, v. 30, n.1, 25-34, 1998.

OLDFIELD, R.C. The assessment and analysis of handedness: The Edinburgh inventory. Neuropsychologia, v. 9, p. 97-113, 1971.

PALLER, K. A.; GONSALVES, B.; GRABOWECKY, M.; BOZIC, V. S.; YAMADA, S. Electrophysiological correlates of recollecting faces of known and unknown individuals. NeuroImage, v. 11, n. 2, p. 98-110, 2000.

PALLER, K. A.; RANGANATH, C.; GONSALVES, B.; LABAR, K. S.; PARRISH, T. B.; GITELMAN, D. R.; MESULAM, M. M.; REBER, P. J. Neural correlates of person recognition. Learning and Memory, v. 10, n. 4, p. 253-260, 2003.

PERILLA-RODRÍGUEZ, L. M. Efeitos de bandas de freqüência espacial alta e baixa no reconhecimento de faces em campo visual lateralizado. 2008. 65p. Dissertação (Mestrado em Ciências) - Faculdade de Filosofia, Ciências e Letras de Ribeirão Preto, Universidade de São Paulo, Ribeirão Preto, 2008. 
PEYRIN, C.; CHOKRON, S.; GUYADER, N.; GOUT, O.; MORET, J.; MARANDAZ, C. Neural correlates of spatial frequency processing: a neuropsychological approach. Brain Research, 1073-1074, p. 1-10, 2006 .

PEYRIN, C.; MERMILLOD, M.; CHOKRON, S.; MARANDAZ, C. Effect of temporal constraints on hemispheric asymmetries during spatial frequency processing. Brain and Cognition, v. 62, p. 214-220, 2006 b.

PEYRIN, C.; MICHEL, C. M.; SCHWARTZ, S.; THUT, G.; SEGUIER, M.; LANDIS, T.; MARANDAZ, C.; VUILLEUMIER, P. The neural substrates and timing of top-down processes during coarse-to-fine categorization of visual scenes: a combined fMRI and ERP study. Journal of Cognitive Neuroscience, v. 22:12, p. 2768-2780, 2010.

REBAÏ, M.; BERNARD, C.; LANNOU, J.; JOUEN, F. Spatial frequency and right hemisphere: an electrophysiological investigation. Brain and Cognition, v. 36, p. 21-29, 1998.

REHMAN, J.; HERLITZ, A. Higher face recognition ability in girls: magnified by own-sex and own-ethnicity bias. Memory, v. 14, p. 289-296, 2006.

RHODES, G. Configural, expertise and the right hemisphere advantage for face recognition. Brain and Cognition, v. 22, p. 19-41, 1993.

ROALF, D.; LOWERY, N.; TURETSKY, B. I. Behavioral and psychological findings of gender differences in global-local visual processing. Brain and Cognition, v. 60, n. 1, p. 3241, 2006.

ROBBINS, R.; MCKONE, E. No face-like processing for objects-of-expertise in three behavioural tasks. Cognition, v. 103, p. 34-74, 2007.

ROSSION, B.; CALDARA, R.; SEGHIER, M.; SCHULLER, A-M.; LAZEYRAS, F.; MAYER, E. A network of occipito-temporal face-sensitive areas besides the right middle fusiform gyrus is necessary for normal face processing. Brain, v. 126, p. 2381-2395, 2003.

ROSSION, B.; DRICOT, L.; DEVOLVER, A.; BODART, J.; GELDER, B.; ZOONTJES, R. Hemispheric asymmetries for whole-based and part-based face processing in the human fusiform gyrus. Journal of Cognitive Neuroscience, v. 12, n. 5, p. 793-802, 2000. 
SANDERS, G.; SINCLAIR, K.; WALSH, T. Testing predictions from the hunter-gatherer hypothesis-2: sex differences in the visual processing of near and far space. Evolutionary Psychology, v. 5, p. 666-679, 2007.

SANTOS, N. A.; SIMAS, M. L. B. Percepção e processamento visual da forma: discutindo modelos teóricos atuais. Psicologia: Reflexão e Crítica, v. 14, p. 157-166, 2001.

SASAKI, Y.; HADJIKHANI, N.; FISCHL, B.; LIU, A. K.; MARRET, S. DALE, A. M.; TOTELL, R. B. H. Local and global attention are mapped retinotopically in human occipital cortex. PNAS, v. 98, n. 4, p. 2077-2082, 2001.

SERGENT, J. The cerebral balance of power: confrontation or cooperation? Journal of Experimental Psychology: Human Perception and Performance, v. 8, p. 174-179, 1982.

SHAPIRO, P. N.; PENROD, S. Meta-analysis of facial identification studies. Psychological Bulletin, v. 100, p. 139-156, 1986.

SOLBERG, J. L.; BROWN, J. M. No sex differences in spatial contrast sensitivity and reaction time to spatial frequency. Perceptual and Motor Skills, v. 94, p. 1053-1055, 2002.

SPIERER, D. K.; PETERSEN, R. A.; DUFFY, K.; CORCORAN, B. M.; RAWLS-MARTIN. Gender influence on response time to sensory stimuli. Journal of Strength and Conditioning Research, v. 24, n. 4, p. 957-963, 2010.

SPRINGER, S.; DEUTSCH, G. Cérebro Esquerdo, Cérebro Direito. São Paulo: Summus. 1993.

STANCEY, H.; TURNER, M. Close women, distant men: line bisection reveals sexdimorphic patterns of visuomotor performance in near and far space. British Journal of Psychology, v. 101, p. 293-309, 2010.

STERNBERG, R. Psicologia cognitiva. 5. ed. São Paulo: Cengage Learning, 2010.

TRIPATHY, S.; LEVI, D.; OGMEN, H.; HARDEN, C. Perceived Length across the physiological blind spot. Visual Neuroscience, v. 12, p. 385-402, 1995.

WEIRICH, S.; HOFFMANN, F.; MEIßENER, L.; BENGNER, A. H. T. Sex influence on face recognition memory moderated by presentation duration and reencoding. Neuropsychology, v. 25, n. 6, p. 806-813, 2011. 
WHITMAN, R. D.; KEEGAN, J. J. Lateralization of facial processing: a spatial frequency model. International Journal of Neuroscience. v. 60, p. 177-185, 1991.

YAMAGUCHI, S.; YAMAGATA, S.; KOBAYASHI, S. Cerebral asymmetry of the "topdown" allocation of attention to global and local features. The Journal of Neuroscience, v. 20 , p. $1-5,2000$.

YOVEL, G.; KANWISHER, N. Face perception: Domain specific, not process specific. Neuron, v. 44, p. 889-898, 2004.

YOVEL, G.; LEVY, J.; GRABOWECKY, M.; PALLER, K. A. Neural correlates of the leftvisual-field superiority in face perception appear at multiple stages of face processing. Journal of Cognitive Neuroscience, v. 15, n. 3, 462-474, 2003

YUE, X.; TJAN, B. S.; BIEDERMAN, I. What makes face special? Vision Research, v. 46, p. 3802-3811, 2006. 
APÊNDICES 


\section{APÊNDICE A - Método do campo visual dividido}

O método do campo visual dividido (divided visual field method) é uma ferramenta clássica para se estudarem dominância e assimetria hemisférica de funções perceptuais e cognitivas do sistema visual em estudos comportamentais. Ele consiste na apresentação lateralizada dos estímulos no campo visual do observador e se valida em função da arquitetura do sistema visual humano. Um estímulo apresentado em um hemicampo visual é projetado na hemiretina nasal de um olho e na hemiretina temporal do outro olho. Apenas a hemiretina nasal cruza a informação por entre os hemisférios no quiasma óptico. Sendo assim, toda informação visual apresentada em um hemicampo visual será inicialmente processada pelo hemisfério contralateral (Figura A). Mas, para que isso ocorra de fato, a apresentação lateralizada do estímulo deve estar presente no campo visual periférico, a partir de $2^{\circ}$ excentricidade, para que ela não incida na região de convergência binocular. Além disso, a estimulação sensorial ocorre em restrição temporal de no máximo $180 \mathrm{~ms}$. Isso garante que não ocorram movimentos sacádicos em uma probabilidade aceitável (SERGENT, 1995; BOURNE, 2006).

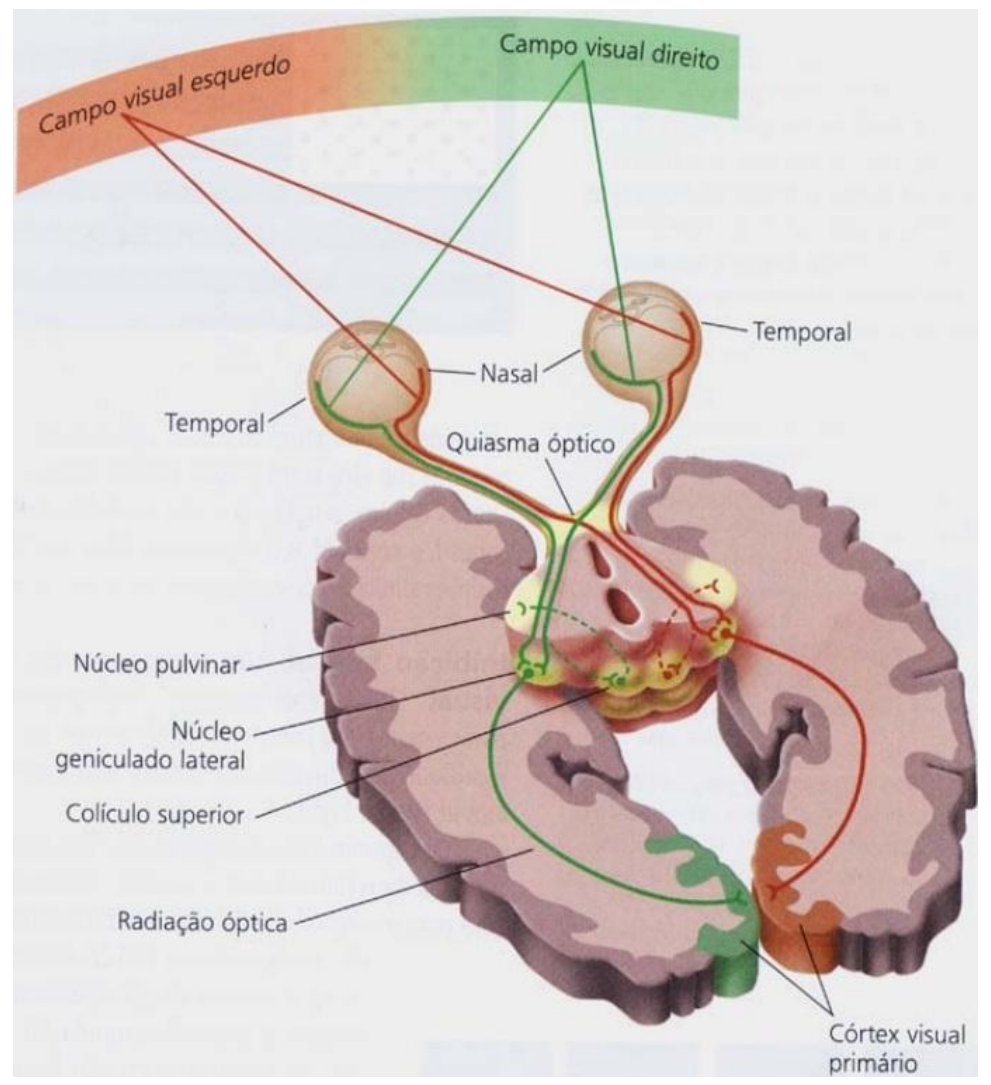

Figura A: Representação do sistema visual. A hemiretina temporal projeta a imagem para o hemisfério ipsilateral, enquanto a hemiretina nasal projeta no hemisfério contralateral. Deste modo, o que é apresentado em um hemicampo visual, é processado inicialmente no córtex visual contralateral. Imagem extraída de Lent (2004). 
As inferências relativas ao desempenho de um hemisfério são possíveis por meio de medidas como o tempo de reação/resposta e acurácia de julgamentos de estímulos apresentados no hemicampo visual contralateral.

Esta técnica não apresenta capacidade de localização cerebral de funções, mas permite flexibilidade na manipulação de estímulos e tarefas experimentais (SERGENT, 1983). Ela é da fácil execução e amplamente utilizada na literatura. Ainda, não apresenta os problemas das modernas técnicas de neuroimagem: incerteza de valores limiares ou de base e ausência de padronização nos protocolos experimentais (JANSEN et al., 2006).

O presente trabalho realizou uma variação no método do campo visual dividido que permite a exposição do estímulo em tempos de exposições superiores a $180 \mathrm{~ms}$. O aparato usado e sua utilização são explicados na seção Materiais e equipamentos e Procedimento, no Experimento I.

\section{Referências}

BOURNE, V. The divided visual field paradigm: Methodological considerations. Laterality: Asymmetries of Body, Brain, and Cognition, v. 11, n. 4, p. 373-393, 2006.

JANSEN, A.; MENKE, R.; SOMMER, J.; FÖRSTER, A. F.; BRUCHMANN, S.; HEMPLEMAN, J.; WEBER, B.; KNECHT, S. The assessment of hemispheric lateralization in functional MRI - robustness and reproducibility. Neuroimage, v. 33, p. 204-217, 2006.

LENT, R. Cem Bilhões de Neurônios. São Paulo: Atheneu, 2004.

SERGENT, J. Hemispheric contribution to face processing: patterns of convergence and divergence. In: DAVIDSON, R, J.; HUGHDAHL, K. Brain asymmetry. Cambridge: MIT Press, p. 157-181, 1995.

SERGENT, J. Role of the input in visual hemispheric asymmetries. Psychological Bulletin, v. 93, n. 3, p. 481-512, 1983. 


\section{APÊNDICE B - Processamento computacional e biológico de frequências espaciais}

\section{Frequências espaciais}

Toda energia eletromagnética que chega à retina carrega uma série de informações que podem ser estudadas de diferentes maneiras. Entre elas está a análise das frequências espaciais (FEs), ou seja, o número de variações de luminância em determinado espaço.

Um cenário visual normal contém um padrão complexo de intensidades de luz, ou altas variações das FEs, contendo frequências muito baixas a altas. A FE é medida em função do número de ciclos de alternância entre regiões claras e regiões escuras por unidade de área (SCHIFFMAN, 2005). Um ciclo é definido por uma região clara e uma escura, adjacentes no campo visual (Figura B1). É o que define o comprimento de onda (BICAS, 2002). Sendo assim, padrões de frequências espaciais altas (FEAs) consistem em elementos finos e detalhes. Já os padrões de frequências espaciais baixas (FEBs) compõem elementos largos e grosseiros. Facilita-se o entendimento desta modalidade de análise se, ao prestarmos atenção em uma imagem, desconsiderarmos sua cor e observar que ela se compõe de padrões alternados de regiões claras e escuras (SCHIFFMAN, 2005).

A unidade adotada pelo Sistema Internacional de Unidades para indicar frequência é Hertz. Essa medida indica o número de ocorrências de um evento em determinado tempo. Mas, quando falamos em FE, não estamos interessados no tempo em que ocorre o evento, e sim na longitude em uma dada direção. Para isso o Sistema internacional utiliza a unidade ciclos por metro (BICAS, 2002). Como na área de percepção visual trabalhamos com estímulos muito menores que $1 \mathrm{~m}$, adota-se a notação ciclos/centímetro ou ciclo/imagem. Mas o que realmente importa quando se trata de percepção visual é o tamanho da imagem formada na retina. Logo, a medida fundamental é ciclos/grau de ângulo visual (cpg), uma medida relativa que leva em consideração a distância da pessoa em relação ao objeto percebido. Por exemplo, um cpg teria um par de barras, uma barra clara e outra escura, adjacentes por grau de ângulo visual (SIMAS; SANTOS, 2001), como mostra a figura a seguir (Figura B1). 


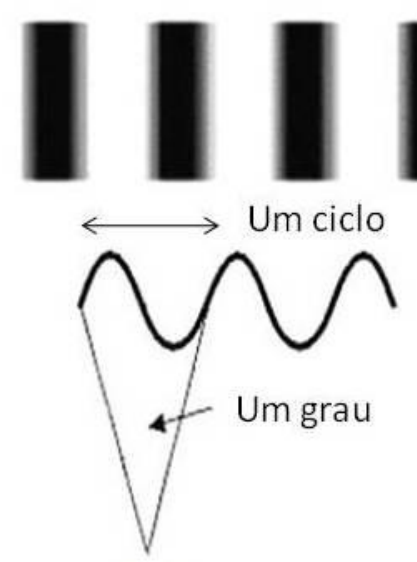

(a)

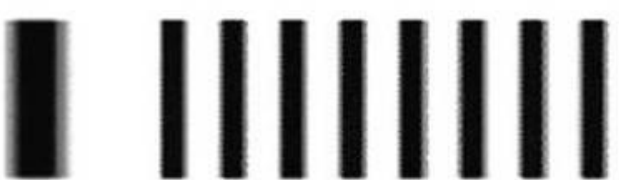

$\longleftrightarrow$ Dois ciclos

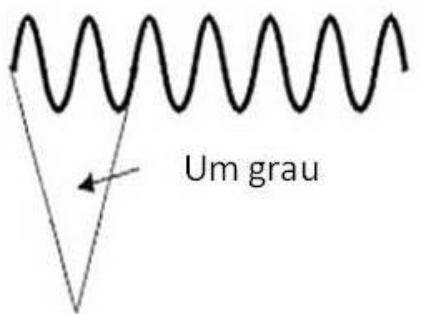

(b)

Figura B1: Ilustração didática do conceito de frequência espacial. Em (a) temos um padrão em baixas frequências, com $1 \mathrm{cpg}$ e em (b) um padrão em altas frequências, com $2 \mathrm{cpg}$. Imagem modificada do site: http://webvision.med.utah.edu/ .

Em resumo, a FE, tecnicamente, se refere ao "número de ciclos de alterações luminosas por grau de ângulo visual” (SCHIFFMAN, 2005, p. 109).

\section{Tranformada de Fourier}

A luz se propaga pelo espaço em um comportamento ondulatório, e a distribuição de suas intensidades exibe a forma de ondas senoidais. Uma cena visual cotidiana qualquer apresenta uma distribuição complexa de muitos padrões de luz, sendo uma série de componentes senoidais simples (SCHIFFMAN, 2005). Isso pode dar a ideia de que o estudo do espectro de FE é confuso e intrincado.

Mas no início do século XIX, o físico e matemático Jean-Baptiste Fourier (1768-1830) formulou um teorema que propõe que a distribuição complexa da luz que abrange uma imagem pode ser analisada em componentes senoidais simples. A análise de Fourier é a decomposição de ondas complexas senoidais e/ou cossenoidais, enquanto que a síntese ou transformada de Fourier realiza um somatório das ondas senoidais e/ou cossenoidais componentes de uma imagem para produzir o padrão complexo (SCHIFFMAN, 2005; SANTOS; SIMAS, 2001) (Figura B2). 


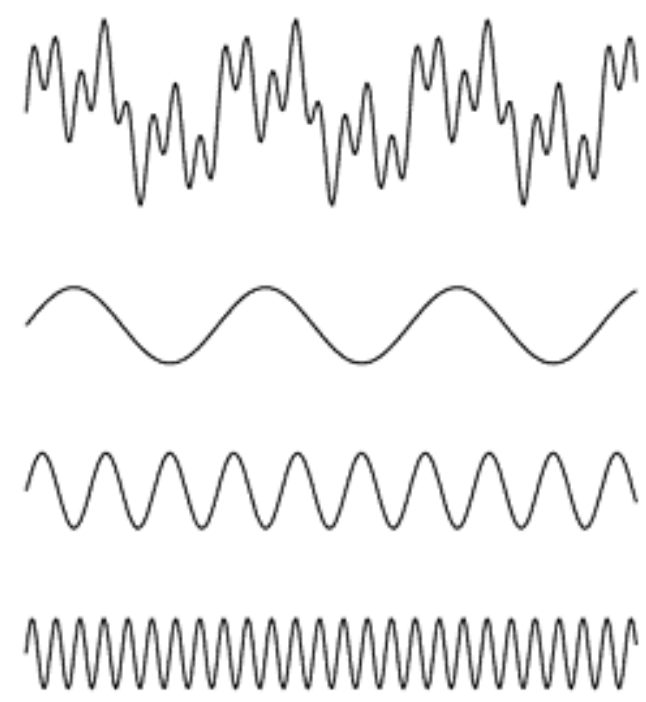

Figura B2: A onda complexa do topo pode ser decomposta pela soma das três ondas simples abaixo dela. Imagem retirada do site http://www.science.org.au/nova/029/029box02.htm

Este somatório, de maneira mais específica, é expresso pela soma de senos e cossenos de diferentes frequências, multiplicada, cada uma, por um coeficiente diferente. Pode ser realizado em toda função que se repete periodicamente, e mesmo daquelas que não são, mas a área abaixo da curva é finita. $\mathrm{O}$ que é de grande utilidade para grande parte dos fenômenos físicos e, consequentemente, dos problemas práticos. Sua aplicabilidade foi potencializada com o advento da computação digital e do desenvolvimento do algoritmo da transformada rápida de Fourier, no final da década de 50 (GONZALEZ; WOODS, 2001).

A resultante da transformada de Fourier é uma representação no domínio de frequência, ou domínio de Fourier, na qual é trabalhada com maior facilidade e funcionalidade. Uma imagem volta ao domínio de imagem por meio da transformada inversa sem que haja perda de informação, o que pode ser visto como a maior vantagem desta técnica e do processamento digital no domínio de frequência (GONZALEZ; WOODS, 2001).

Por isso, ao utilizar um estímulo visual, a face, que é finita no espaço e se compõe de um padrão complexo de componentes senoidais simples, foi realizada a análise de Fourier. Esta decompôs o sinal da imagem nas suas componentes em frequência, o que permitiu que a imagem pudesse ser tratada por meio da utilização de filtros (explicação adiante no texto). Em uma analogia, pode-se dizer que a análise de Fourier é um prisma matemático, que separa a luz em componentes de acordo com sua faixa de FE.

Como as imagens são representadas computacionalmente por arranjos $\mathrm{M} \times \mathrm{N}$ pixels, mais especificamente 256 × 256 pixels no caso das faces apresentadas, é utilizada a transformada bi-dimensional de Fourier. 


\section{Processamento computacional - filtragem no domínio de Fourier}

O processamento digital de imagens tem como intuito o melhoramento da imagem para interpretação e extração de características importantes para interpretação humana ou computacional. Para isso, é comum a retirada de faixas de FEs da imagem, ou seja, a utilização de filtros. Estes são utilizados comumente para salientar determinados aspectos de uma imagem, ou reduzir ruídos.

O uso de imagens no domínio de frequência propicia um tratamento digital mais prático e seguro. Isso acontece porque a resultante de Fourier ganha certa organização física quanto à disposição das FEs. Quanto mais baixas as frequências, mais centralizadas elas ficam no domínio de frequência (isso quando a origem da transformada é deslocada para o centro da imagem, o que é muito comum). À medida que as frequências aumentam o número de ciclos ou ondas por unidade de medida, se afastam uniformemente por todos os eixos com origem no centro da imagem. Por esta razão, os filtros geralmente são sobrepostos de maneira central e circularmente simétricos.

Para ser filtrada, uma imagem deve passar pela transformada de Fourier para que, no domínio de frequência, seja multiplicada pela função de transferência de um filtro. No entanto, muitas vezes é mais fácil "zerar" os coeficientes das faixas que queremos excluir. Zerar uma determinada banda de FE significa excluir da imagem toda a informação desta faixa.

Vemos o resultado da filtragem espacial numa imagem quando fazemos a transformada inversa desta. Um melhoramento adicional da imagem ainda pode ser obtido por pós-processamento, executado já no domínio da imagem, ou seja, alterações feitas diretamente nos pixels da matriz da imagem (GONZALEZ; WOODS, 2001).

Há basicamente três tipos de filtros definidos com relação à anulação de determinadas bandas ao longo do espectro de luz: passa-baixa, passa-alta e passa-banda (ou passa-faixa). Um filtro passa-baixa atenua as FEAs e preserva as FEBs. Isso causa um efeito de suavização de contornos e bordas, e a imagem aparenta um borramento, já que as transições mais abruptas de luminância foram eliminadas. Um filtro passa-alta desempenha o papel oposto; ele elimina as FEBs e mantém as FEAs. As imagens apresentam mais bordas e contornos detalhados e aparecem mais nítidas. Já um filtro passa-banda preserva faixas intermediárias de FE e elimina faixas extremas; seu efeito visual depende da faixa preservada (GONZALEZ; 
WOODS, 2001). O esquema abaixo (Figura B3) resume, de maneira didática, como foi feito o processo de filtragem espacial realizado nos estímulos do trabalho em questão.

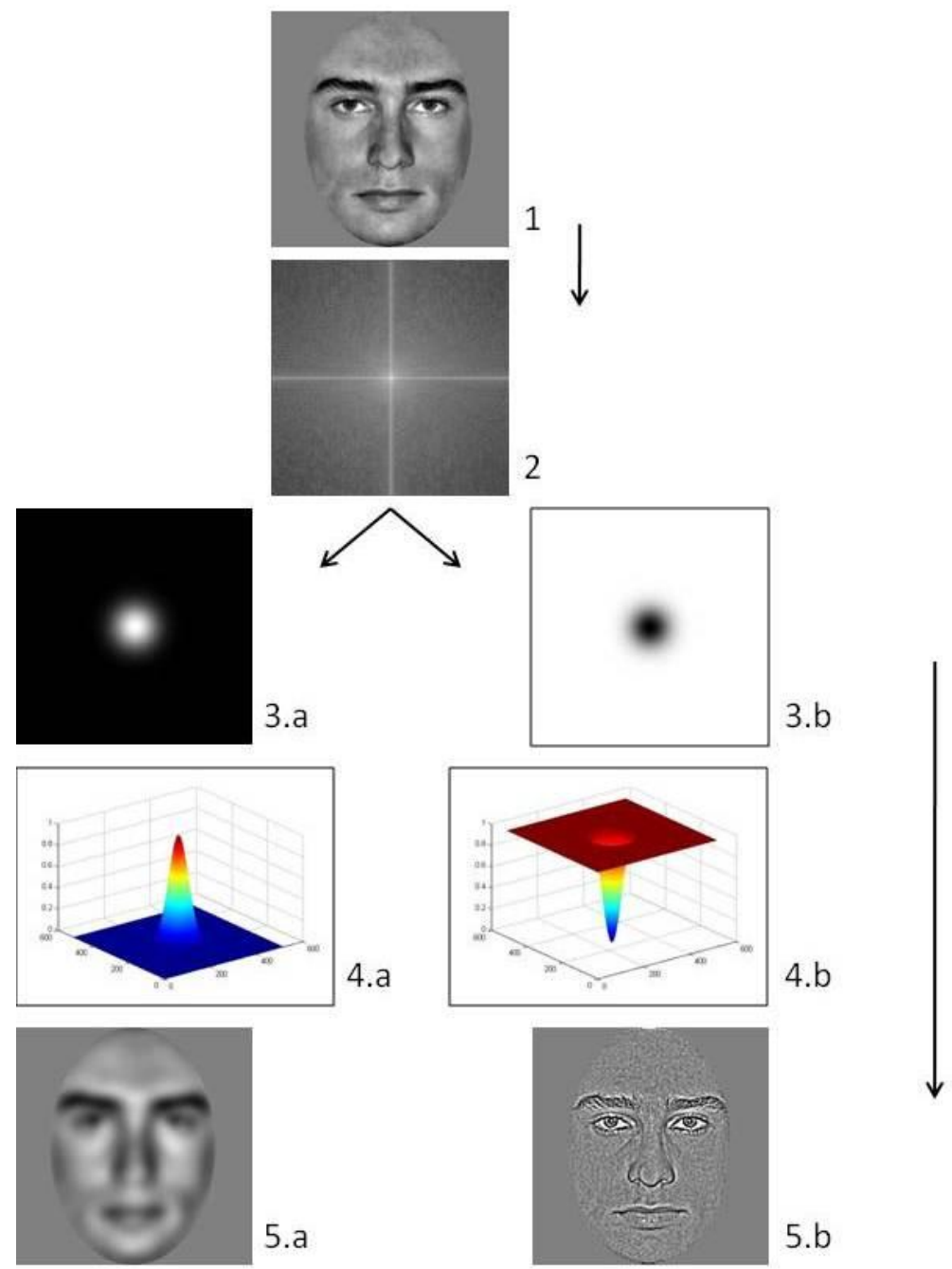

Figura B3: Esquema do processo de filtragem dos estímulos. Em (1) está presente a imagem a ser tratada. Esta, por meio da transformada de Fourier, é representada em seu domínio de frequência espacial (2) e multiplicada por filtros passa-baixa (3.a) e passa-alta (3.b). Os cortes Gaussianos realizados pelos filtros estão representados em (4.a) e (4.b). A trasformada inversa apresenta as imagens em baixas frequências (5.a) e em altas frequências espaciais (5.b). Imagens apenas ilustrativas.

Os filtros podem ser mais seletivos, ou permissíveis, ou seja, eles podem ter bandas de FEs mais estreitas ou mais largas, respectivamente, dependendo da freqüência de corte. Para um filtro passa-baixa, quanto maior a frequência de corte, maior a faixa selecionada. $\mathrm{O}$ inverso acontece com um filtro passa-alta. Já um filtro passa-banda necessita de dois pontos de corte. Estes vão dizer o quanto a banda preservada é larga ou estreita.

No estudo em questão, no processamento digital das faces, foram utilizados filtros passa-banda tanto na seleção das baixas quanto das altas freqüências (p. 24, Estímulos). Estes 
filtros cumprem a função de filtros passa-baixa e passa-alta, já que preservam FEs muito baixas (2-8 cpi) ou muito altas (32-128 cpi), respectivamente.

Os filtros passa-banda utilizados são Gaussianos. Estes filtros são circularmente simétricos (isotrópicos) e utilizam uma função Gaussiana para obter uma máscara digital (núcleo de convolução). Um filtro Gaussiano tem a vantagem de apresentar uma resultante da transformada inversa de Fourier também Gaussiana (GONZALEZ; WOODS, 2001). Isto, de um ponto de vista prático, elimina o ringing. Este efeito é caracterizado por linhas radiais concêntricas na imagem que é resultante de uma transformada inversa depois de multiplicada por um filtro de corte abrupto. Nos filtros Gaussianos os cortes de frequência são suaves e a transição entre altas e baixas frequências são graduais (modulado pelo desvio padrão estipulado na função de cada filtro Gaussiano). Mas o que se mostra de maior importância para a presente pesquisa é o fato de que algumas células retinianas têm a resposta aproximadamente Gaussiana ao processar diferencialmente faixas do espectro espacial.

\section{Processamento biológico}

O sistema visual humano realiza, de certa forma, uma transformada de Fourier. A imagem que recebemos por nossos olhos é decomposta na retina por canais de frequências espaciais seletivos a diferentes faixas do espectro. Somente em áreas corticais a informação é reconstruída.

Este fenômeno é efetuado principalmente pela atividade das células ganglionares da retina. Estas células apresentam ligações com os fotorreceptores (cones e bastonetes) que formam seu campo receptivo. Este campo representa a área da retina sobre a qual o estímulo luminoso é capaz de alterar a atividade da célula ganglionar.

Ademais, os campos receptivos das células ganglionares são do tipo centro-periferia. A magnitude da resposta destes campos (frequência de disparos) depende da região em que ele for estimulado. Os centros podem ser on ou off. Se uma célula ganglionar com campo receptivo de centro on, por exemplo, recebe mais luz que a periferia, ela responde com maior intensidade. Se, ao contrário, a periferia recebe luz e o centro não, quase não acontecem disparos de potenciais de ação. $\mathrm{O}$ efeito se inverte para células com campos com centro off. Tanto células on quanto as off, respondem de maneira intermediária quando centro e periferia são estimulados uniformemente (Figura B4). O efeito antagônico das células ganglionares 
permite que as células respondam ao contraste, o que permite que o sistema visual refine a resposta a margens e bordas (SCHIFFMAN, 2005).

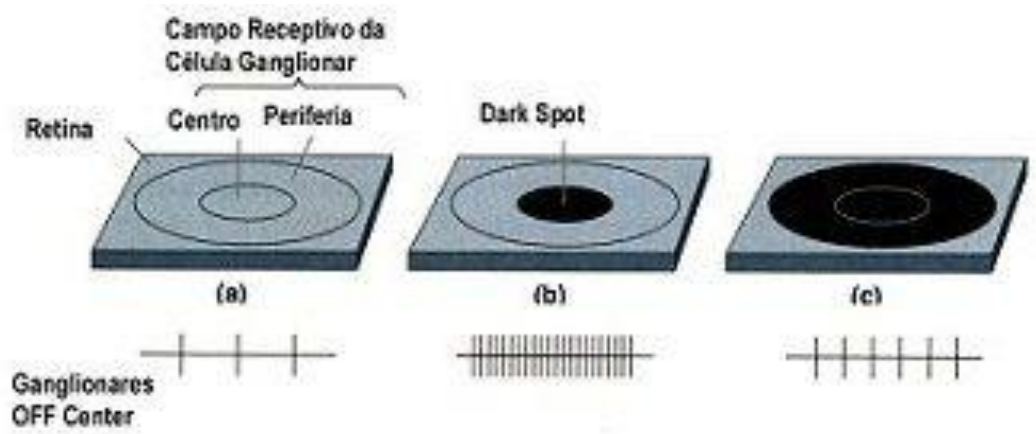

Figura B4: Modelo de um campo receptivo de uma célula ganglionar de centro off. Se todo o campo receptivo for estimulado, a frequência dos potenciais de ação (PA) é muito baixa (a); se somente a periferia for iluminada (b), a frequência dos PA é alta; a resposta celular é intermediária se tanto centro quanto periferia não forem iluminados (c). Imagem modificada do site: www.opticanet.com.br

Há dois tipos de células ganglionares: $\mathrm{P}$ e $\mathrm{M}$. As células $\mathrm{P}$ (do latim parvum, pequeno) integram informação de uma pequena área da retina, visto que estabelecem conexões com poucos fotorreceptores, o que faz com que tenham campos receptivos pequenos. São encontradas com frequência muito maior na fóvea, ligadas a cones. A baixa convergência de sinais devido à integração de dados de poucos fotorreceptores faz com que as células retinianas ganglionares $\mathrm{P}$ tenham alta acuidade visual e reajam a detalhes minuciosos da cena visual principalmente quando os estímulos são estacionários. Além disso, elas apresentam baixa velocidade de condução, e reagem de maneira estável e sustentada ao serem estimuladas. As células M (do latim magnum, grande), por sua vez, são encontradas externamente à região foveal, fazendo conexões com muitos bastonetes. Elas integram informações de uma grande área retinal devido a convergência de sinais de muitos fotorreceptores. Isto faz com que as células $\mathrm{M}$ sofram uma perda significativa da acuidade visual. Sendo assim, elas somente reagem a baixas variações de luminância, o que as tornam praticamente incapazes de fazer discriminações finas. As células $M$ têm uma maior velocidade de condução em relação às células $P$, com reações abruptas e transitórias, o que as capacitam a responderem melhor ao movimento. Sendo assim, células P e M são responsáveis pelo processamento inicial de FEAs e FEBs, respectivamente (LIVINGSTONE; HUBEL, 1988; SCHIFFMAN, 2005).

As células $\mathrm{P}$ e $\mathrm{M}$ originam duas vias neurais distintas que se projetam ao núcleo geniculado lateral: a via parvocelular (ou via P)e a via magnocelular (ou via $\mathrm{M}$ ), visto que as 
diferenças anatômicas e funcionais celulares são mantidas. A via parvocelular é uma via lenta que se projeta principalmente para áreas ventrais do córtex, como, por exemplo, o giro fusiforme. A via magnocelular, por sua vez, é uma via rápida, que envia sinais à amígdala por meio da via tecto-pulvinar. As divisões parvo e magno celular colaboram de maneira funcionalmente diferentes para a visão. As células da divisão parvocelular do núcleo geniculado lateral são responsáveis pela percepção de cor, forma e detalhes. Já as células da divisão magnocelular são muito mais sensíveis ao movimento, e melhores na busca por varredura do estímulo visual (LIVINGSTONE; HUBEL, 1988; SCHIFFMAN, 2005; OBAYASHI et al., 2009; GARDELLE; KOIUDER, 2010).

As células do núcleo geniculado lateral possuem uma ordenação representativa da topografia celular da retina, os chamados mapas retinotópicos. O córtex visual também mantém essa organização presente na retina. Ou seja, a disposição estrutural e funcional das células ganglionares $\mathrm{P}$ e M se mantém nas células do núcleo geniculado lateral nas divisões parvo e magno celular, e se perpetuam em mapas retinotópicos corticais. Estes criam representações do input visual inicial específicas e distintas. Cada área cortical pode processar diferencialmente ou prioritariamente algumas propriedades do estímulo físico (SCHIFFMAN, 2005).

O estágio inicial de filtragem espacial do sistema visual humano provê uma base perceptual para todo o subsequente processamento local/global de operações de alto nível cognitivo, como reconhecimento de padrões (HEERING et al., 2008) e, consequentemente, o reconhecimento facial.

As descobertas acerca da especialização do sistema visual para perceber contraste e forma instigaram pesquisadores a formular contructos teóricos acerca do funcionamento da visão humana. Dentre os modelos criados, o de canais múltiplos é o que reúne maior número de evidências empíricas. Mas para ter conhecimento de outros modelos, o trabalho teórico de Santos e Simas (2001) faz uma abrangente busca bibliográfica.

O modelo de canais múltiplos foi criado por Campbell e Robson em 1968, ao utilizarem a grade senoidal como estímulo em experimentos comportamentais. Os autores afirmam que o sistema visual realiza um tipo de análise de Fourier, visto que fragmenta a cena visual complexa em componentes elementares (ondas senoidais e cossenoidais). Cada canal seria um filtro sensível a uma faixa estreita do espectro de FE, sob um ponto de vista psicofísico. Estes filtros, num aporte fisiológico, seriam populações de neurônios sintonizados a estreitas bandas de FEs (SANTOS; SIMAS, 2001). Há diversas hipóteses testadas quanto ao número destes canais referenciados na literatura. 
Independente do modelo adotado, o acúmulo de evidências e descobertas neurofisiológicas e comportamentais corroboram um processamento de baixo para cima ou bottom-up para percepção de formas. Ou seja, um pré-processamento retinal precede operações de síntese no córtex visual, como, por exemplo, funções analítico/locais e configuracionais/globais.

\section{Referências}

BICAS, H. E. A. Acuidade visual: medidas e notações. Arquivos Brasileiros de Oftalmologia, v. 65, p. 375-384, 2002.

GARDELLE, V.; KOUIDER, S. How spatial frequency and visual awareness interact during face processing. Psychological Science, v. 21, n. 1, p. 58-66, 2010.

GONZALEZ, R. C.; WOODS, R. E. Digital image processing. Reading, MA: AddisonWesley, 1992.

HEERING, A.; TURATI, C.; ROSSION, B.; BULF, H.; GOFFAUX, V.; SIMION, F. Newborn's face recognition is based on spatial frequencies below 0.5 cycles per degree. Cognition, v. 106, p. 444-454, 2008.

LIVINGSTONE, M. HUBEL. Segregation of form, color, movement, and depth: anatomy, physiology, and perception. Science, v. 240, p. 740-749, 1988.

OBAYASHI, C.; NAKASHIMA, T.; ONITSUKA, T. MAEKAWA, T.; HIRANO, Y.; HIRANO, S.; ORIBE, N.; KANEKO, K.; KANBA, S.; TOBIMATSU, S. Decreased spatial frequency sensitivities for processing faces in male patients with chronic schizophrenia. Clinical Neurophysiology, v. 120, p. 1525-1533, 2009.

SANTOS, N. A.; SIMAS, M. L. B. Percepção e processamento visual da forma: discutindo modelos teóricos atuais. Psicologia: reflexão e crítica, v. 14, p. 157-166, 2001.

SCHIFFMAN, H. R. Sensação e percepção. Rio de janeiro: LTC, 2005. 


\section{APÊNDICE C - Confidence rating method}

O método confidence rating tem como base a Teoria de Detecção do Sinal (TDS). A TDS é uma teoria estatística de aproximação psicofísica originada da Teoria Estatística de Decisão. Como grande diferencial em relação aos métodos psicofísicos clássicos, a TDS leva em consideração não somente a sensibilidade, mas também o processo de decisão. Ela assume que fatores não-sensoriais (atenção, motivação, expectativa) afetam o critério de decisão do observador $(\beta)$, e conferem um grau de incerteza ao processo de decisão, comumente chamado de ruído (noise). A TDS pode ser usada sempre que a distribuição do ruído se sobrepuser à distribuição da detectabilidade do sinal + ruído (signal + noise) sobre um eixo de decisão (Figura C).

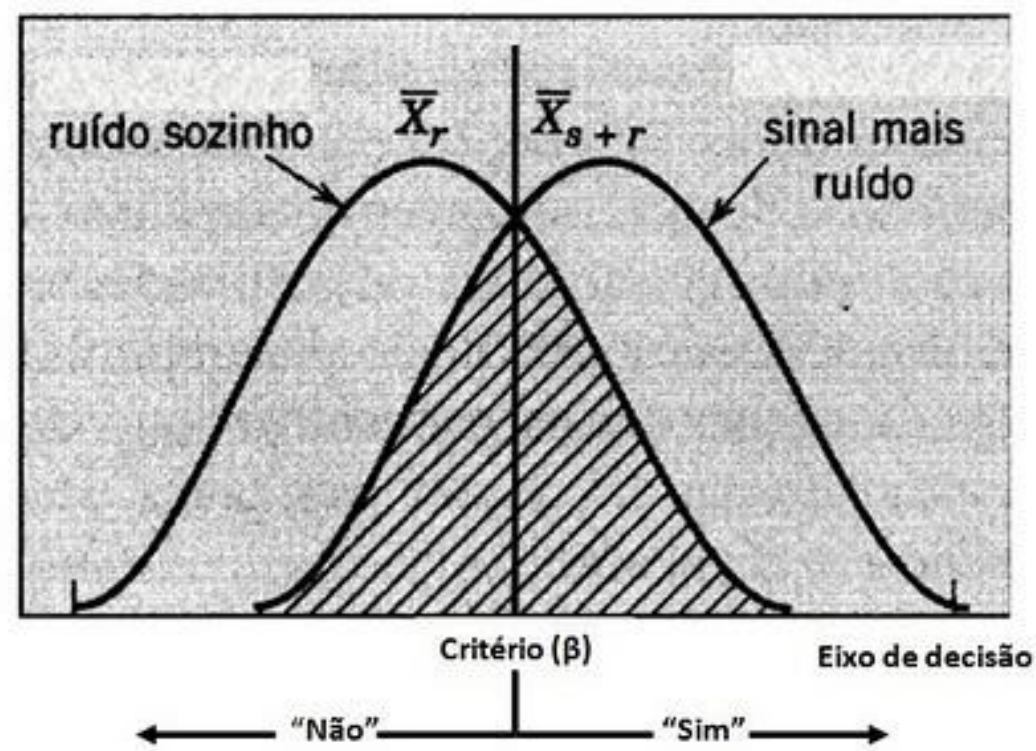

Figura C: Distribuição do "ruído" e do "sinal + ruído" sobre o eixo de decisão. A valência da resposta é dada em função do critério de resposta $(\beta)$. Quanto maior a distância entre as distribuições, maior sensibilidade sensorial. Imagem extraída de http://www.blogpercepto.com/2011/10/psicofisica-moderna-ii-teoria-de.html .

Quanto maior a distância entre as médias das duas distribuições $\left(d^{\prime}\right)$, maior a força da evidência associada a uma alternativa (presença ou ausência do estímulo, por exemplo) e discrepância entre a estimulação física e fatores não-sensoriais. Ou seja, maior sensibilidade do participante. Para maior detalhamento, consultar Macmillian e Creelman (2005).

No presente estudo foi utilizado um procedimento de classificação, confidence rating, em oposição ao procedimento sim-não, mais tradicional na literatura. A sequência da ocorrência dos eventos é a mesma nos dois procedimentos, mas a natureza da resposta 
compreende mais de duas respostas de graus de certeza no modo confidence rating. Em vantagem, ele estabelece o $\mathrm{d} a$ (equivalente ao $d^{\prime}$ do procedimento binário sim-não) em um único procedimento experimental.

$\mathrm{O}$ d $a$ é calculado com base nas frequências de respostas aos eventos em função da presença ou não de um estímulo pelo grau de certeza das respostas, em matrizes como a que está representada abaixo:

Tabela: Modelo de matriz utilizada em procedimentos confidence rating.

\begin{tabular}{|l|l|l|l|l|l|l|}
\hline Magnitude da resposta & $\mathbf{6}$ & $\mathbf{5}$ & $\mathbf{4}$ & $\mathbf{3}$ & $\mathbf{2}$ & $\mathbf{1}$ \\
\hline Freq. respostas de eventos com estímulo presente/memorizado (hit rate) & & & & & & \\
\hline Freq. respostas de eventos com estímulo ausente/distrator (false alarm rate) & & & & & & \\
\hline
\end{tabular}

Em seguida, é calculada a frequência relativa acumulada das respostas (que corresponde à probabilidade condicional) para o cálculo das curvas ROC (Receiver Operating Characteristic). Para isto, são plotados os valores dos acertos (hit rate) no eixo das ordenadas (y) e os valores dos falsos alarmes (false alarm rate) no eixo das abscissas (x). A curva, em geral, apresenta a forma de um arco posicionado na diagonal do gráfico com a concavidade para baixo. Por uma questão de facilidade de implementação e de visualização, as curvas ROC deste estudo foram representadas por retas, por meio de uma regressão linear. Para isso, a frequência acumulada das respostas foi transformada em nota $z$. Os coeficientes da equação da reta são utilizados, então, para o cálculo do parâmetro de sensibilidade da, mediante a seguinte fórmula:

$$
d_{a}=\sqrt{\frac{2}{1+b^{2}}} a
$$

Onde d $a$ é o parâmetro de sensibilidade da TDS, e $a$ e $b$ são os coeficientes angular e linear, respectivamente, da reta de regressão.

Por meio do da é possível calcular outra medida comumente encontrada na literatura e utilizada neste estudo: o $\mathrm{A} z$. Este parâmetro representa a área abaixo da reta de regressão correspondente à taxa de acertos. Embora não leve em consideração o critério de decisão, é de fácil interpretação. $\mathrm{O} \mathrm{Az}$ é calculado mediante a seguinte fórmula:

$$
A_{z}=\sqrt{\frac{d_{a}}{2}}
$$


O Az foi utilizado como medida de desempenho complementar no estudo atual.

Tanto o parâmetro da como $\mathrm{A} z$ foram extraídos dos grupos amostrais e não de cada participante. Tal prática é aceita pela TDS. As retas de regressão individuais não proviam um coeficiente de determinação $\left(\mathrm{R}^{2}\right)$ satisfatório $(\geq 0,8)$.

\section{Referências}

HARVEY JUNIOR, L. O. Detection sensitivity and response bias. Manuscrito Departament of Psychology, University of Colorado, Bolder, 2003.

MACMILlan, N. A.; CREELMAN, C. D. Detection theory: A user's guide.2. ed. New Jersey: Lawrence Erlbaum Associates, 2005.

STANISLAW, H.; TODOROV, N. Calculation of signal detection theory measures. Behavior Research Methods, Instruments and Computers, v. 31, n. 1, p. 137-149, 1999. 
ANEXOS 


\section{ANEXO A - Termo de Consentimento Livre e Esclarecido}

Gostaria de convidá-lo a participar de uma pesquisa para o desenvolvimento de meu mestrado no programa de Psicobiologia da FFCLRP-USP. Ela tem por objetivo investigar como se dá a percepção e o processamento visual de faces humanas.

Os requisitos para que você participe desta pesquisa são: (1) ter boa acuidade visual e (2) ser destro. Por isso você já foi submetido a um teste de acuidade visual e respondeu um questionário de destreza manual que indicaram que sua visão é normal e que é destro.

Caso você queira se voluntariar para participar desta pesquisa, sua tarefa consistirá em:

(1) memorizar um conjunto de fotografias apresentadas naturalmente na tela do computador e, posteriormente,

(2) realizar uma tarefa de reconhecimento das faces memorizadas em que estas são agora apresentadas junto a outras faces e em um estado natural, borrado/embaçado ou delimitado pelos contornos faciais para indicar o grau de certeza da face apresentada, se ela pertencia ou não ao grupo de faces que você memorizou anteriormente.

O experimento consiste em duas sessões realizadas em dias diferentes, num intervalo de tempo, arbitrariamente estipulado pelo pesquisador, não superior a 10 dias. As tarefas a serem executadas não apresentam riscos à integridade de sua saúde física ou mental.

Cada sessão é realizada num tempo médio de 25 minutos. O procedimento experimental será feito em sessão individual, no Laboratório de Percepção e Psicofísica (Bloco 6) da FFCLRP/USP, em uma sala escura, de $2 \mathrm{~m} x$ $2,5 \mathrm{~m}$ x $3 \mathrm{~m}$, em frente ao computador, sob as orientações do pesquisador e as descritas na tela com a utilização de um apoiador de queixo.

É importante que você finalize o experimento; porém, se desejar interrompê-lo ou encerrá-lo, você assim poderá proceder a qualquer momento, sem qualquer prejuízo ou ônus.

Os dados desta pesquisa serão divulgados em reuniões e publicações científicas, e as identidades dos participantes serão mantidas em absoluto sigilo.

Caso ainda tenha quaisquer dúvidas sobre esta pesquisa, por favor, sinta-se a vontade para solicitar esclarecimentos.

Este termo foi elaborado em duas vias, uma delas será fornecida a você e a outra será mantida com o pesquisador.

Local e data:

Nome do participante:

Endereço:

Assinatura do participante:

Nome do Pesquisador: Rui de Moraes Júnior

Assinatura do pesquisador:

Orientador: Prof. Dr. Sérgio Sheiji Fukusima

Assinatura do orientador:

Endereço: Av. Bandeirantes, 3900. Bairro: Monte Alegre. CEP: 14.040-901. Ribeirão Preto-SP

Universidade de São Paulo - Faculdade de Filosofia, Ciências e Letras.

Departamento de Psicologia. Telefone: (16) 3602-3729/3602-3873 
ANEXO B - Parecer do Comitê de Ética em Pesquisa da FFCLRP

UNIVERSIDADE DE SÃO PAULO

FACULDADE DE FILOSOFIA, CIÊNCIAS E LETRAS DE RIBEIRÃO PRETO

COMITÊ DE ÉTICA EM PESQUISA - CEP

Of.CEtP/FFCLRP-USP.042/2010- 08/07/2010

Senhor(a) Pesquisador(a):

Comunicamos a V. Sa. que o trabalho intitulado "RECONHECIMENTO DE FACES COM FILTRAGENS DE FREQÜÊNCIAS ESPACIAIS ALTAS E BAIXAS NOS HEMICAMPOS VISUAIS DIREITO E ESQUERDO", foi analisado pelo Comitê de Ética em Pesquisa da FFCLRP-USP, e enquadrado na categoria: APROVADO, de acordo com o Processo CEP-FFCLRP n 505/2010 - 2010.1.1042.59.0

Atenciosamente,

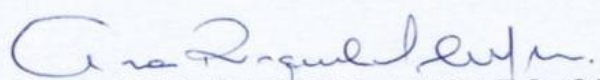

Profa. Dra. ANA RAQUEL LUCATO CIANFLONE Coordenadora do Comitê de Ética em Pesquisa - FFCLRP-USP

llustríssimo Senhor

Rui de Moraes Junior - aluno do Programa de PG em Psicobiologia

c.c.:

Prof. Dr. Sergio Sheiji Fukusima

Docente do Departamento de Psicologia e Educação

Desta FFCLRP-USP

CEP-FFCLRP-USP - coetp@ffclrp.usp.br Fone: (016) 3602-3653 - Fax: (016) 3633-5015 Avenida Bandeirantes, 3900 - Bloco A - 14040-901 - Ribeirão Preto - SP - Brasil 


\section{ANEXO C - Inventário de Dominância Manual de Edimburgo (OLDFIELD, 1971)}

Nome:

Data de Nascimento:

Sexo:

Por favor, indique sua preferência no uso das mãos nas seguintes atividades colocando o sinal + na coluna apropriada. Onde a preferência é tão forte que você nunca usaria a outra mão a menos que fosse forçado a usá-la, coloque ++ . Se em algum caso a mão utilizada é realmente indiferente, coloque $+\mathrm{em}$ ambas as colunas.

Algumas das atividades requerem as duas mãos. Nestes casos a parte da tarefa, ou objeto, para a qual a preferência manual é solicitada é indicada entre parênteses.

Por favor, tente responder todas as questões, e somente deixe em branco se você não tiver qualquer experiência com o objeto ou tarefa.

Você já teve alguma tendência a ser canhoto? Sim Não

\begin{tabular}{|l|l|l|l|}
\hline \multicolumn{2}{|l|}{} & Esquerda & Direita \\
\hline $\mathbf{1}$ & Escrever & & \\
\hline $\mathbf{2}$ & Desenhar & & \\
\hline $\mathbf{3}$ & Arremessar & & \\
\hline $\mathbf{4}$ & Uso de tesouras & & \\
\hline $\mathbf{5}$ & Escovar os dentes & & \\
\hline $\mathbf{6}$ & Uso de faca (sem garfo) & & \\
\hline $\mathbf{7}$ & Uso de colher & & \\
\hline $\mathbf{8}$ & Uso de vassoura (mão superior) & & \\
\hline $\mathbf{9}$ & Acender um fósforo (mão do fósforo) & & \\
\hline $\mathbf{1 0}$ & Abrir uma caixa (mão da tampa) & & \\
\hline $\mathbf{1 1}$ & Uso de pente & & \\
\hline $\mathbf{1 2}$ & Uso de martelo & & \\
\hline $\mathbf{1 3}$ & Uso de chave de fenda & & \\
\hline $\mathbf{1 4}$ & Distribuir cartas (carta sendo distribuída) & & \\
\hline $\mathbf{1 5}$ & Colocar linha no buraco da agulha (linha ou agulha de & & \\
\hline & acordo com qual delas é movimentada) & & \\
\hline $\mathbf{1 6}$ & Qual olho você usa quando está usando apenas um? & & \\
\hline
\end{tabular}




\section{ANEXO D - Instruções dadas durante os experimentos}

\section{Instruções dadas durante cada sessão do Experimento I}

Esta pesquisa tem por objetivo investigar como cada hemisfério cerebral reconhece faces.

A sessão levará cerca de 30 minutos. Procure responder da maneira mais acurada possível.

É importante que você finalize o experimento; porém, caso venha a desejar interrompê-lo, você poderá fazê-lo sem qualquer penalidade a você.

\section{$* * *$}

Nesta primeira parte do experimento aparecerão várias fotografias no centro da tela, e você deverá observá-las até que consiga memorizá-las. Para isso, pressione barra de espaço. Não haverá um limite de tempo para isso.

Quando você considerar que já conseguiu memorizá-las e reconhecê-las, então continuaremos com o experimento.

$$
* * *
$$

Nesta parte do experimento você deverá manter o olhar fixo no círculo amarelo que aparece no centro da tela. Este círculo se tornará vermelho, o que indica que as fotografias de faces serão apresentadas logo em seguida, e que você deve manter o olhar fixo no centro da tela.

Então, duas fotografias idênticas serão apresentadas simultaneamente por um intervalo curto de tempo. Uma será vista diretamente pela tela, e a outra pelo reflexo do espelho. Mas você terá a percepção de apenas uma imagem.

$$
* * *
$$

Sua tarefa é responder o mais rápido possível se cada face apresentada pertence ou não ao grupo de faces apresentadas na fase de memorização, mesmo que tenha sido utilizado um filtro sobre elas (detalhamento ou borramento). Para isso, pressione no teclado numérico o respectivo número da alternativa escolhida, segundo as seguintes opções de resposta:

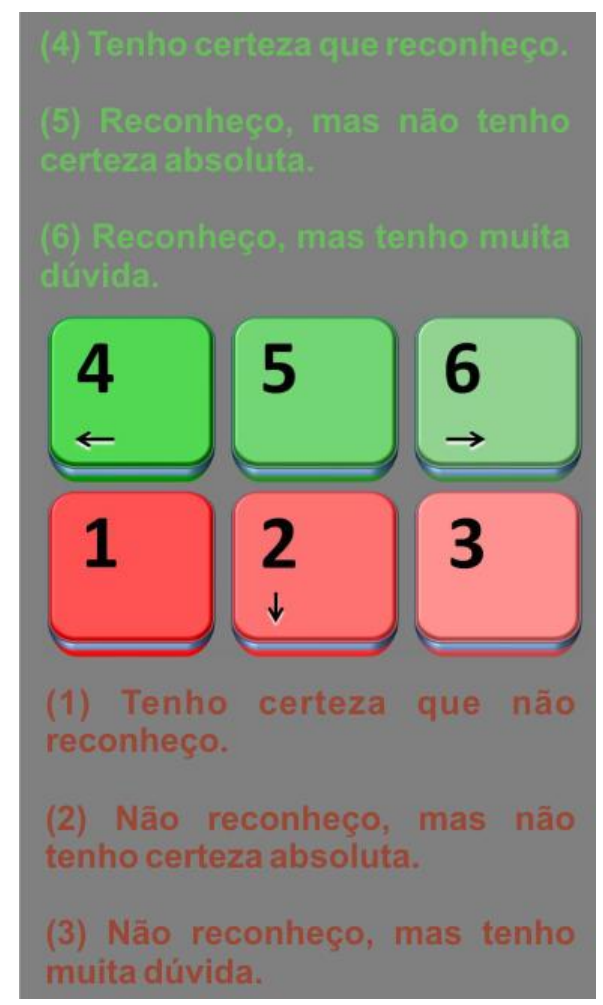


Após pressionar a tecla numérica da resposta, um quadrado azul será apresentado no centro da tela. Pressione a barra de espaços quando estiver pronto para a próxima apresentação, e volte a manter o olhar no ponto de fixação sem desviá-lo.

$$
* * *
$$

A seguir, será realizada uma etapa de treinamento na qual você poderá se acostumar com as opções de resposta no teclado numérico, o tempo de exposição e a filtragem dos estímulos.

$* * *$

Fim do treino. Aperte a barra de espaço para iniciar o experimento.

\section{Instruções dadas durante o Experimento II}

Esta pesquisa tem por objetivo investigar como homens e mulheres reconhecem faces.

O experimento tem duração total de aproximadamente 15 minutos. Procure responder de maneira mais acurada possível.

É importante que você finalize o experimento; porém, caso venha a desejar interrompê-lo, você poderá fazê-lo sem qualquer penalidade a você.

Nesta primeira parte do experimento aparecerão várias imagens de faces no centro da tela, e você deverá observá-las até que consiga memorizá-las. Para isso, pressione barra de espaço para mudar de imagem. Não haverá um limite de tempo para isso. experimento.

Quando você considerar que já conseguiu memorizá-las e reconhecê-las, então continuaremos com o

$$
* * *
$$

Agora o grupo de imagens de faces irá ser apresentado pela última vez.

A cada face apresentada, diga ao pesquisador se você consegue reconhecê-la com facilidade ou não. Isto certificará de que você memorizou ou não os estímulos.

Caso não se lembre de alguma das faces apresentadas, preste atenção nela até que consiga memorizá-la, para, então, passar para a próxima face.

Nesta parte do experimento você deverá manter o olhar fixo no círculo amarelo que aparece no centro da tela. Este círculo se tornará vermelho, o que indica que uma face será apresentadas logo em seguida, e que você deve manter o olhar fixo no centro da tela.

Sua tarefa é responder o mais rápido possível se cada face apresentada pertence ou não ao grupo de faces apresentadas na fase de memorização, mesmo que tenha sido utilizado um filtro sobre elas (detalhamento ou borramento).

$$
* * *
$$

Para isso pressione no teclado numérico o respectivo número da alternativa escolhida, segundo as seguintes opções de resposta: 


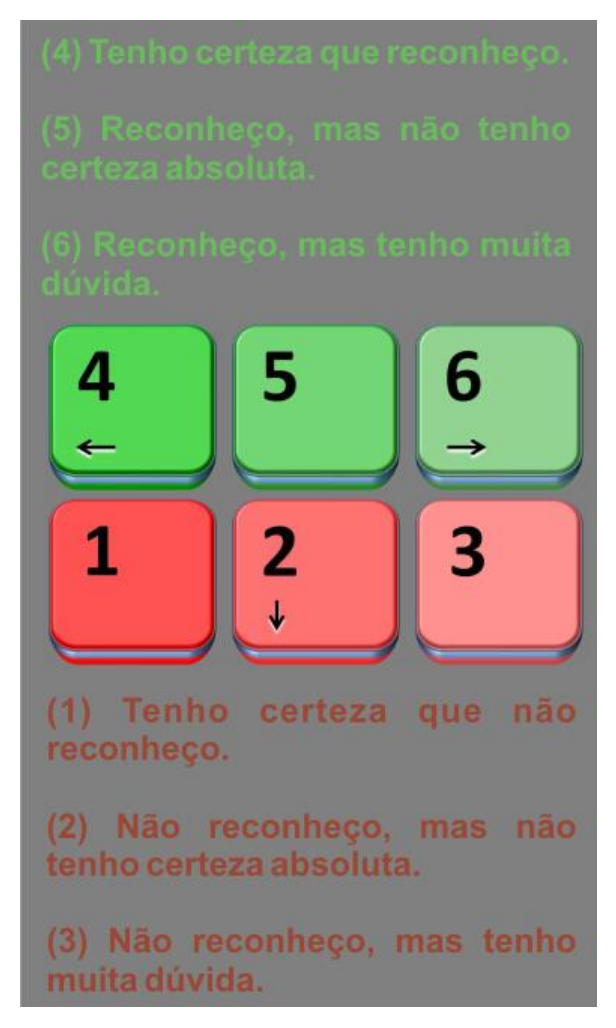

$* * *$

Após pressionar a tecla numérica da resposta, um quadrado azul será apresentado no centro da tela. Pressione a barra de espaços quando estiver pronto para a próxima apresentação, e volte a manter o olhar no ponto de fixação sem desviá-lo.

A seguir, será realizada uma etapa de treinamento na qual você poderá se acostumar com as opções de resposta no teclado numérico, o tempo de exposição e a filtragem dos estímulos.

$* * *$

Fim do treino. Aperte a barra de espaço para iniciar o experimento 


\title{
ANEXO E - Ata de defesa de Mestrado
}

\section{Sanus}

\author{
Universidade de São Paulo
}

\section{RELATÓRIO DE DEFESA}

Aluno: 59134 - 6950602 - 1/ Página 1 de 1

Relatório de defesa pública de Dissertação do(a) Senhor(a) Rui de Moraes Júnior no Programa: Psicobiologia, do(a) Faculdade de Filosofia, Ciências e Letras de Ribeirão Preto da Universidade de São Paulo.

Aos 06 dias do mês de março de 2012, no(a) Anfiteatro André Jacquemin realizou-se a Defesa da Dissertação do(a) Senhor(a) Rui de Moraes Júnior, apresentada para a obtenção do título de Mestre intitulada:

"Reconhecimento de faces com filtragens de frequências espaciais altas e baixas nos hemicampos visuais direito e esquerdo"

Após declarada aberta a sessão, o(a) Sr(a) Presidente passa a palavra ao candidato para exposição e a seguir aos examinadores para as devidas arguições que se desenvolvem nos termos regimentais. Em seguida, a Comissão Julgadora proclama o resultado: Sergio Sheiji Fukusima
Maria Lúcia Bustamante Simas
Nome dos Participantes da Banca
Cesar Alexis Galera
Função Sigla da CPG Presidente FFCLRP - USP
UFPE - Externo
FFCLRP - USP
Titular
Suplente

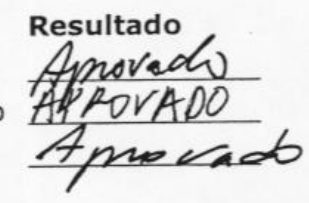

Resultado Final: Appovado

\section{Parecer da Comissão Julgadora *}

Eu, Cesar Pereira Brites Pesár Prites, lavrei a presente ata, que assino juntamente com os(as) Senhores(as). Ribeirão Preto, aos 06 dias do mês de março de 2012.
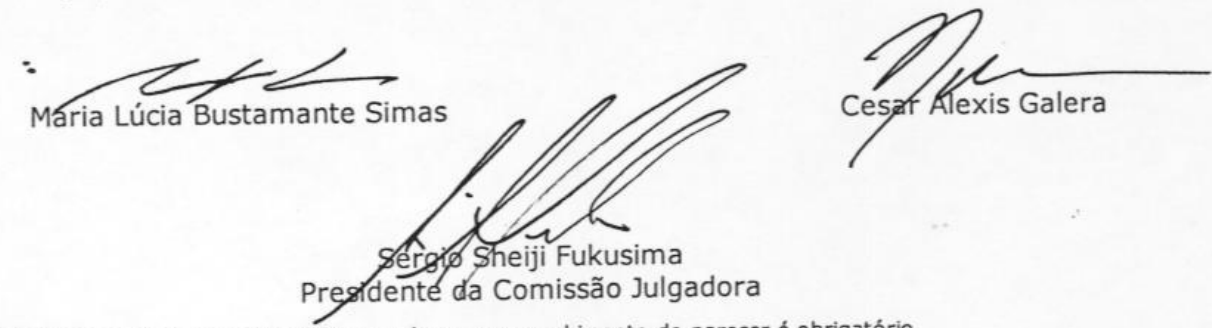

* Obs: Se o candidato for reprovado por algum dos membros, o preenchimento do parecer é obrigatório.

A defesa foi homologada pela Comissão de Pós-Graduação em $09103 / 2012$ e, portanto, o(a) aluno(a) faz jus ao título de Mestre em Ciências obtido no Programa Psicobiologia.

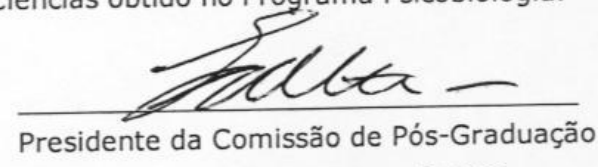

rrofa. Dra. Eucia Beatriz Lopes Petean 